\title{
Estimation of the helical twisting power of chiral inducers by time-dependent density functional theory (TD-DFT) for electrochemical polymerization in cholesteric liquid crystals
}

\author{
Haoyue Shen and Hiromasa Goto* \\ Department of materials Science, Faculty of Pure and Applied Sciences, University of \\ Tsukuba, Tsukuba, Ibaraki 305-8573, Japan. \\ *Corresponding author. E-mail: gotoh@ims.tsukuba.ac.jp
}

\begin{abstract}
Five chiral compounds were designed and synthesized using the Mitsunobu reaction to act as chiral inducers (i.e., chiral dopants) for the transformation of a nematic liquid crystal (LC) (4-n-octoxy-4'-cyanobiphenyl) into a cholesteric LC. These chiral inducers contain two types of chiral alkyl chains with different kinds of achiral mesogenic cores (biphenylcarboxylate, biphenoxy, and cyanobiphenoxy. We observed that the achiral mesogenic cores affected the helical twisting power in terms of both induction strength and helicity (left-/right-hand introduction). All the ester type inducers exhibited a positive Cotton effect and right-hand helical twisting power (HTP). However, ethers exhibited a negative Cotton effect and left-hand HTP. The microscopic HTPs $\left(\beta_{M}\right)$ of these inducers demonstrate a linear relation with their optical activities (ellipticity near the absorption maximum). Further, the time-dependent density functional theory (TD-DFT) calculation using the B3LYP/6-311++G (d, p) method has been used to predict the circular dichroism spectra of these inducers. The predicted optical activity was observed to be in accordance with that observed in the experimental result. This study proposes a method for predicting the HTP of chiral inducers that can be applied to achieve polymerization in the reaction fields of cholesteric LCs.
\end{abstract}

\section{INTRODUCTION}

The processing techniques that are used to control polymer aggregation have recently attracted considerable attention. Polymers having highly ordered structures exhibit various macroscopic properties, including ionic conduction [1-3], mechanical properties [4,5], and characteristic morphologies [6,7]. Conjugated polymers, a type of emerging functional materials with excellent semiconductive properties for applications in photovoltaics $[8,9]$ as well as electroluminescent $[8,10,11]$ and electrochromic $[12,13]$ materials, have also been extensively reported during the previous two decades. The usage of various processing techniques for controlling the macroscopic order of conjugated polymers is considered to be both attractive and valuable. The stacking direction of the conjugated polymers can be used to tune the efficiency of electric devices [15]. Further, conjugated polymers with left-/right-handed helical aggregations that are useful in optical activities can be produced $[16,18]$. This function is applicable in a circular polarized light transmitter $[17,19]$.

Electrochemical polymerization of the cholesteric liquid crystal (LC) has been reported as an effective method to directly synthesize conjugated polymers with left-/right-handed helical aggregations in the film state [18]. Further, the cholesteric LC acts as a solvent and a template for achieving an asymmetric chiral environment. 
The main chain grows regularly because of the interaction between the LC molecules in a matrix and the polymerized segment during the polymerization process. The main chains of the polymer are stacked, resulting in the formation of the left-/right-handed helix. The LC solvent is washed using organic solvents during the final stage of polymer preparation. Further, a beautiful polymer film can be observed after the washing is completed. The film as a product is insoluble and infusible. The resulting polymers exhibit optical activity, which can be further controlled by an external electric field [19]. Therefore, such conjugated polymers with electro-chiroptical activity that are synthesized in LCs can be applied to the polarize electrochromic devices.

The helical axis of the polymer that is prepared in a cholesteric LC is oriented in a parallel direction against the substrate. Further, the polymer film surface exhibits an oscillating wave shape owing to the rotation of the polymer segment around the helical axis. This periodically uneven surface exhibits structural color such as diffraction gratings [20, 21].

Controlling the twisting level of the LC molecule provides control of its helical pitch. Further, the cholesteric LC can be induced from a nematic LC by adding a small amount of the so-called chiral molecular inducer (i.e., chiral dopant). The structural design of inducers allows the helicity of the polymer film that is prepared I $\mathrm{n}$ cholesteric LCs to be tuned. [22] Further, the helical twisting power (HTP) is defined for estimating the performance of the induction function of chiral inducers and can be given as follows:

$$
\mathrm{HTP}=\left(p \times c_{\mathrm{w}}\right)^{-1}
$$

Here, $p$ denotes the length of the helical pitch and $c_{\mathrm{w}}$ denotes the weight concentration of the inducer in the LC.

Several researchers have modified the chemical structure of inducers to increase the HTP. Three-rings-type [23], chiral alkyl [24], and double-stereogenic-center-type [25] chiral inducers are effective for increasing the HTP. Our group has previously investigated the geometry of the chiral inducer [26]. This study established several guidelines for designing inducers based on experience without using a mathematical model. However, a systematic method for predicting HTP by computation has not yet been formulated.

Furthermore, our previous study implies a linear relation between the ellipticity maximum (optical activity) observed near the absorption maximum of the synthesized polymers and the HTP of inducers [26]. However, the relation between the HTP and ellipticity maximum of the inducer has not been discussed because it is difficult to measure the optical activity in dilute solutions in the circular dichroism (CD) measurements. Regardless, this discussion is considered to be valuable because the ellipticity maximum of the inducer can be predicted using a quantum chemical calculation and because the prediction of HTP can be realized using this relation.

Currently, electronic circular dichroism (ECD) can be predicted using quantum chemical calculations, such as the calculations of the density functional theory (DFT) method and the Hartree-Fock (HF) method, using the time-dependent self-consistent field (TD-SCF) treatment [27]. The aforementioned methods have been applied to predict the Cotton effect and to confirm the chirality of products in asymmetric synthesis [28]. Employing quantum chemical calculations for predicting the optical activity and HTP of the inducer is considered to be a crucial step in the synthesis of optically active polymers.

In this study, a family of five inducers with relative chemical structures is 
synthesized from two kinds of chiral sources, $(R)$-octan-2-ol and (S)-3,7-dimethyloctan-1-ol, using the Mitsunobu reaction. Five kinds of LC electrolyte solutions were prepared, containing 4-octoxy-4'-cyanobiphenyl (8OCB) as the host LC, 2,2'-bi(3,4-ethylenedioxythiophene) (bisEDOT) as the monomer, and tetrabutylammonium perchlorate (TBAP) as the supporting salt. Further, the polymer films were obtained using the electrochemical method in the LC electrolyte solution. Subsequently, the CD absorption spectroscopy measurements of these polymer films and inducers were conducted. The average helical pitch length of the polymer films was obtained by direct observation using a polarizing optical microscopy (POM). Finally, the conformation with the minimum energy, ultraviolet-visible (UV-vis), and ECD spectra among a set of inducers was obtained using the time-dependent density functional theory (TD-DFT) calculation in Gaussian 09 software. The macroscopic HTP $\left(\beta_{M}\right)$ is calculated using the helical pitch length $(p)$ and molar concentration of the inducer in an electrolyte. The ellipticity maximum $\left(\theta_{\max }\right)$ is defined by the peak or trough value of the $\mathrm{CD}$ spectrum near the absorption maximum. Further, four linear fittings were obtained as follows: $1 / \mathrm{p}$ vs. $\theta_{\max }$ (polymer); $\theta_{\max }$ (inducer) vs. $\beta_{\mathrm{M}} ; \Delta \varepsilon_{\max }$ (inducer, calculated) vs. $\theta_{\max }$ (inducer, experimental) and $\Delta \varepsilon_{\max }$ (inducer, calculated) vs. $\beta_{\mathrm{M}}$. All the linear fittings yield a high correlation coefficient, implying that TD-DFT is useful for predicting the HTP of inducers for the electrochemical polymerization of the LC.

\section{EXPERIMENT}

8OCB is considered to be a good choice for being employed as the host LC in this research because of the wide LC range observed during the cooling process. Further, the differential scanning calorimeter (DSC) data of 8OCB are presented in the supplementary data, Figure S3.1 [29]. The temperature range of the nematic phase of $8 \mathrm{OCB}$ is from $80.43{ }^{\circ} \mathrm{C}$ to $67.84{ }^{\circ} \mathrm{C}$ in the cooling process, as presented in Table S3.1. In this study, a temperature control stage (TM-600PM, Linkam Co.) was used to set appropriate temperatures for the samples that were used in the experiments.

The inducers should comprise a biphenyl core and long flexible alkyl chains to obtain good affinity with the host LC. The chemical structure of these inducers is presented in Figure 1. Different achiral mesogenic core types, including biphenyloxy (abbreviated as S-M7OB), cyanobiphenyl (S-M7OCB, S-DM8OCB), and biphenylcarboxylate (S-M7BCE, S-DM8BCE), were prepared. Further, the molecular form of the inducers was designed by considering the traditional form of LC molecules with a linear structure [23-25,29]. (R)-octan-2-ol and (S)-3,7-dimethyloctan-1-ol were selected as the two initial chiral sources. $(R)$-octan-2-ol has the same carbon number as that of the alkyl chain of 8OCB. (S)-3,7-dimethyloctan-1-ol was produced by a reduction reaction from the natural product (-)- $\beta$-citronellol by palladium-/carbon-catalyzed hydrogenation in accordance with the previously reported method [30]. This product represents a typical chiral monoterpenoid that is present in several kinds of flowers and that is used in perfumes [31].

These two chiral sources are linked to biphenyl using the Mitsunobu reaction (Figures S1.1 and S1.2, Supplementary Information, SI). Here, the Mitsunobu reaction is considered to be highly efficient for the nucleophilic substitution $\left(\mathrm{S}_{\mathrm{N}} 2\right)$ reaction to form a phenolic ester or ether. Because the Mitsunobu reaction often provides a high enantiomeric excess yield, the absolute configuration at the stereogenic center is inverted ( $100 \%$, Walden inversion) for forming a purely asymmetric chiral product 
[32]. The difficulty that is associated with this reaction is the subsequent purification process. The dehydrogenation reagent diisopropyl azodicarboxylate (DIAD) or diethyl azodicarboxylate (DEAD) may remain after the completion of the reaction. In this study, medium-pressure liquid chromatography (AI-580 from Yamazen) is used to separate the products. Further, the ${ }^{1} \mathrm{H}$ and ${ }^{13} \mathrm{C}$ nuclear magnetic resonance (NMR) spectra of each compound are presented in Figures S1.3-1.17, thereby confirming the high purity of the final products.

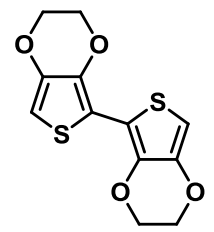

bisEDOT

(Mononer)<smiles>CCCCCC[C@H](C)O</smiles>

(R)-octan-2-ol

(Chiral source 1)

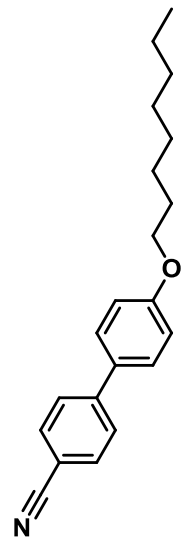

80CB

(Main liquid crystal)
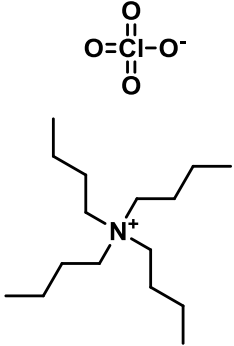

TBAP

(Supporting salt)

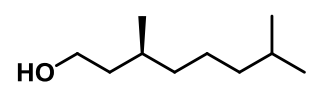

(S)-3,7-dimethyloctan-1-ol (Chiral source 2)

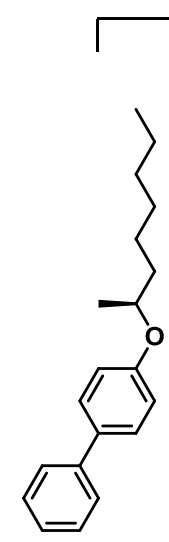

S-M7OB (Inducer 1)

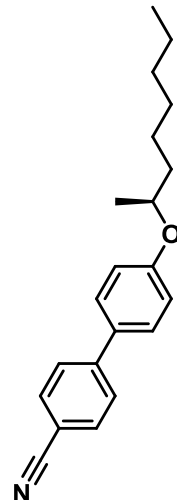

S-M7OCB (Inducer 2)

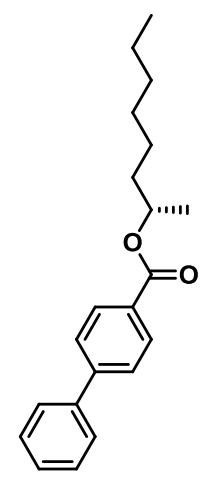

S-M7BCE (Inducer 3)
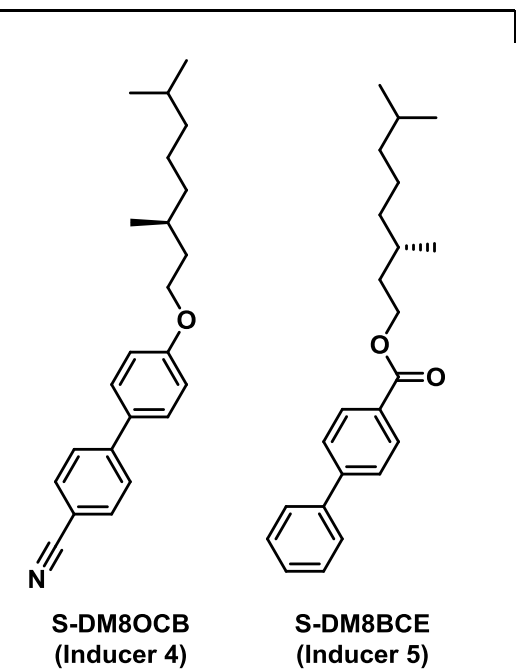

Figure 1. Chemical structures of the compounds.

2,2'-bi(3,4-ethylenedioxythiophene) (bisEDOT) was selected as the monomer because the linear form of bisEDOT allowed the LC to be pre-aligned before electrochemical polymerization, enabling good LC transcription during electrochemical polymerization [33]. Furthermore, polyEDOT is a typical conjugated polymer that is extensively applied in the electron-transporting layer of organic electrodevices [34]. 


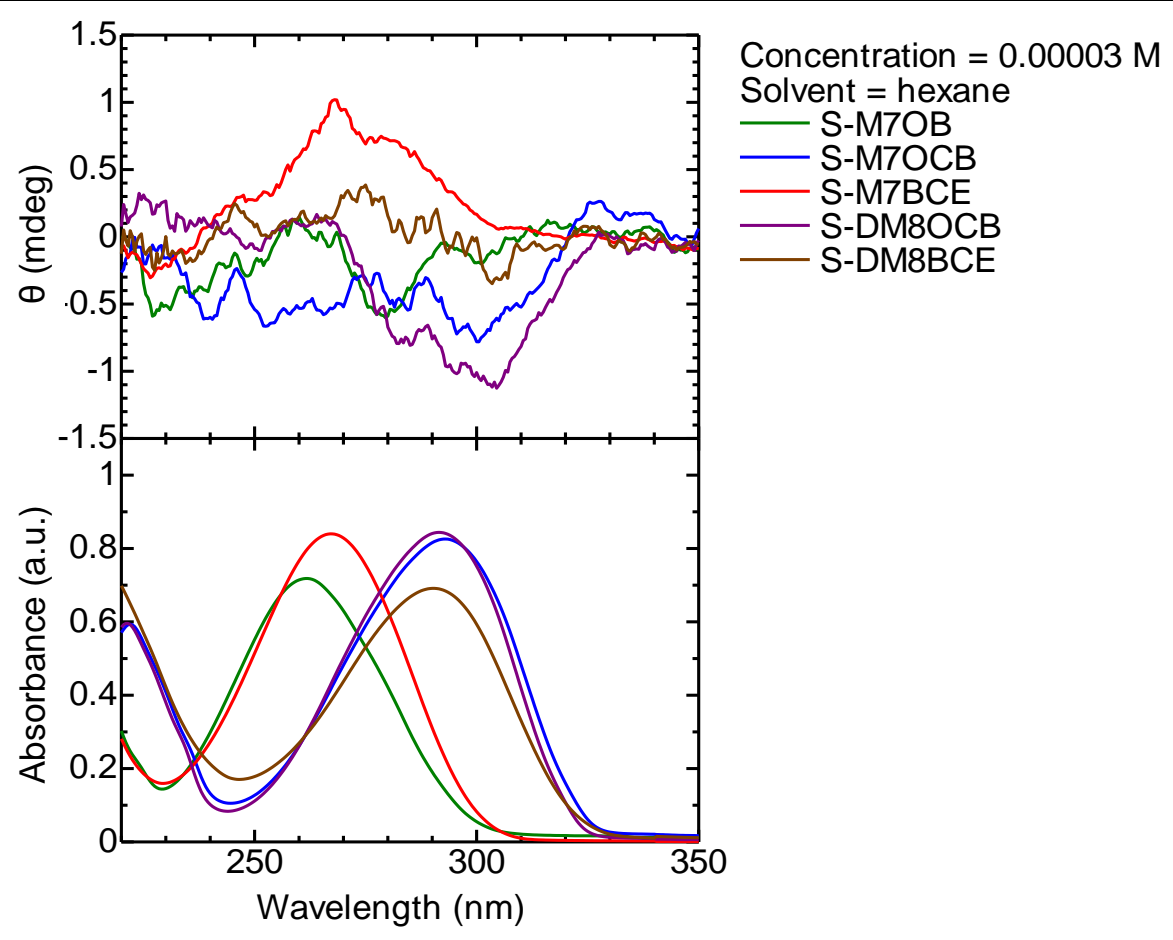

Figure 2. Circular dichroism (CD, $\theta=$ ellipticity) and ultraviolet-visible (UV-vis) optical absorption spectra of five inducers in a hexane solution with a concentration of $3 \times 10^{-5} \mathrm{M}$.

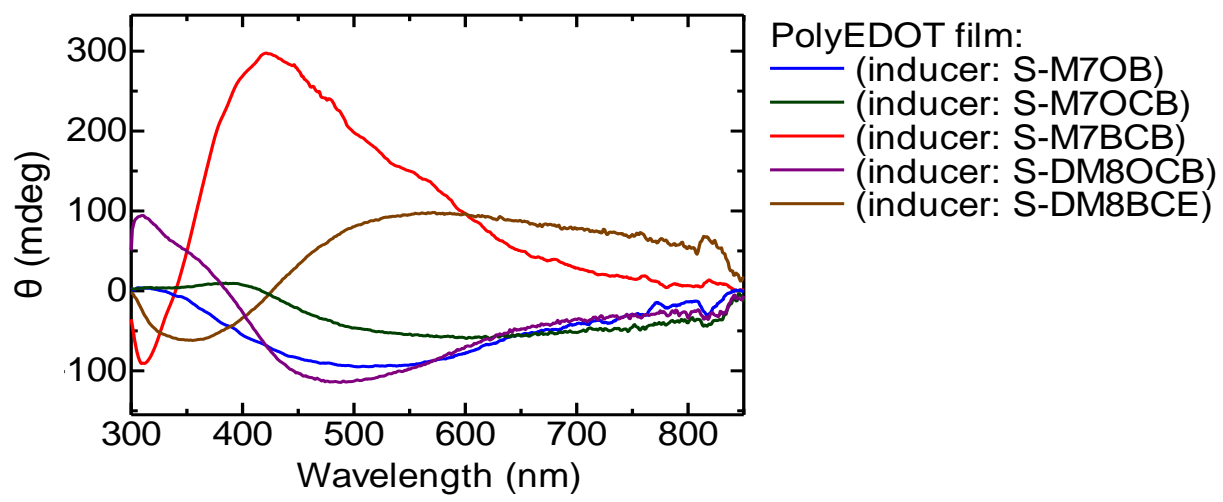

Figure 3. $\mathrm{CD}$ spectra $(\theta=$ ellipticity) of polyEDOT (PEDOT) prepared in a cholesteric liquid crystal solution. S-M7OB, S-M7OCB, S-DM8OCB, and S-DM8CE are the chiral inducers used to prepare the cholesteric liquid crystal electrolyte solutions. 


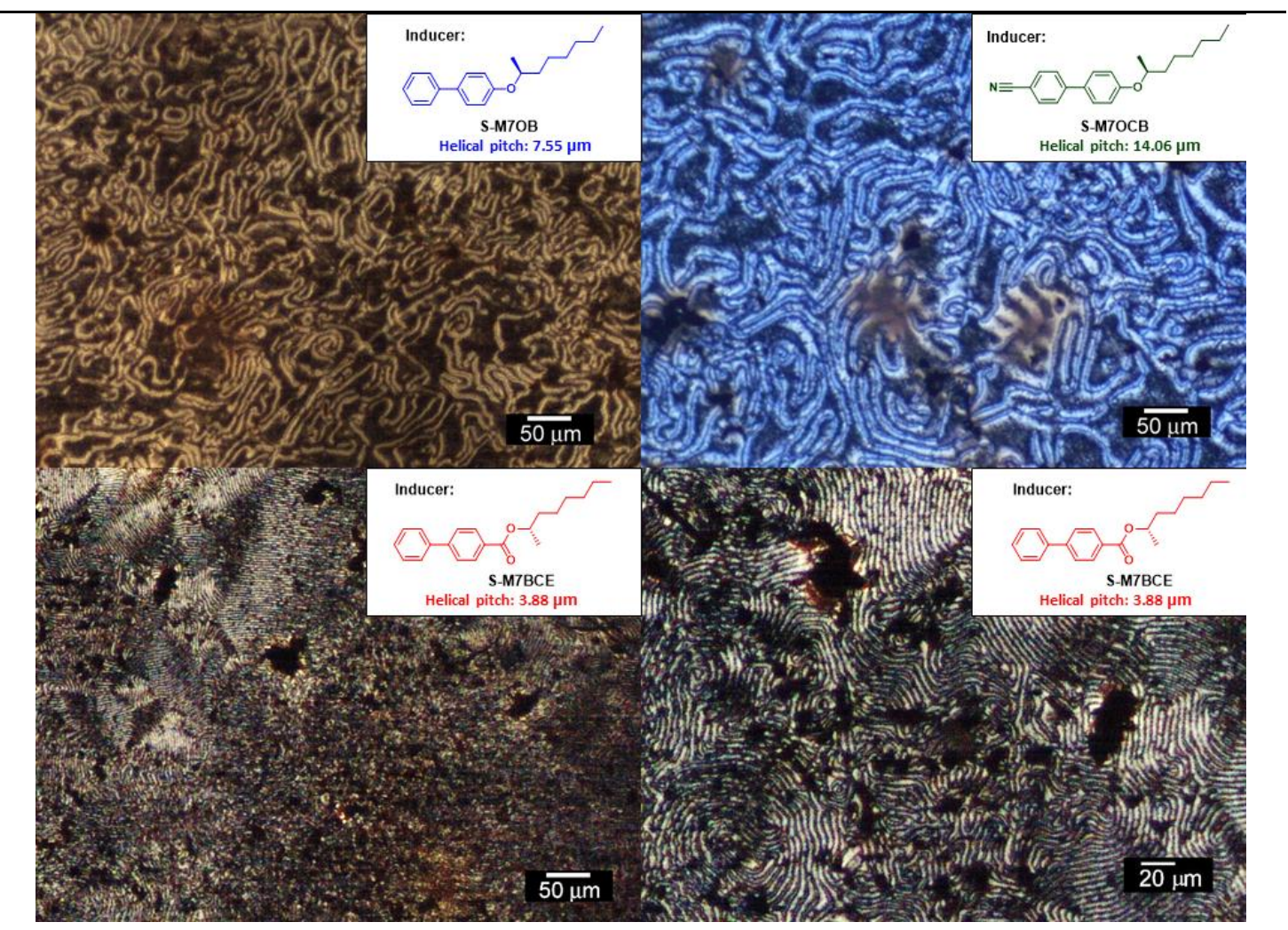

Figure 4. Polarizing optical microscopy (POM) images of polymer films and the helical pitch length (averaged value over five random places) prepared in a cholesteric liquid crystal electrolyte solution using S-M7OB, S-M7OCB, and S-M7BCE as chiral inducers.

The LC electrolyte solution containing monomer (ca. $5 \mathrm{wt} \%$ ), chiral inducer (5 $\mathrm{wt} \%)$, supporting salt (0.5 wt\%, providing ionic conductivity), and host LC (remaining percentage) was prepared [26]. The components of the LC electrolyte solution that are required for ensuring precise preparation to avoid separation or destruction of the LC phase are presented in Table S3.2 (Supplementary Information, SI). The DSC measurement result of the representative LC electrolyte solution is presented in Figure S3.2. The LC solution exhibits phase transitions at a lower temperature range as compared to that of pure 8OCB (e.g., nematic-smectic, $52.92{ }^{\circ} \mathrm{C}$ for the mixture and $67.84{ }^{\circ} \mathrm{C}$ for 8OCB) [35], as depicted in Table S3.1 (Supplementary Information, SI). Visual observations using the POM can be used to verify that the LC electrolyte solution exhibits no phase separation in mesophase. The POM images of the smectic and cholesteric phases of this sample are presented in Figures S3.3 and S3.4 (Supplementary Information, SI), respectively. 


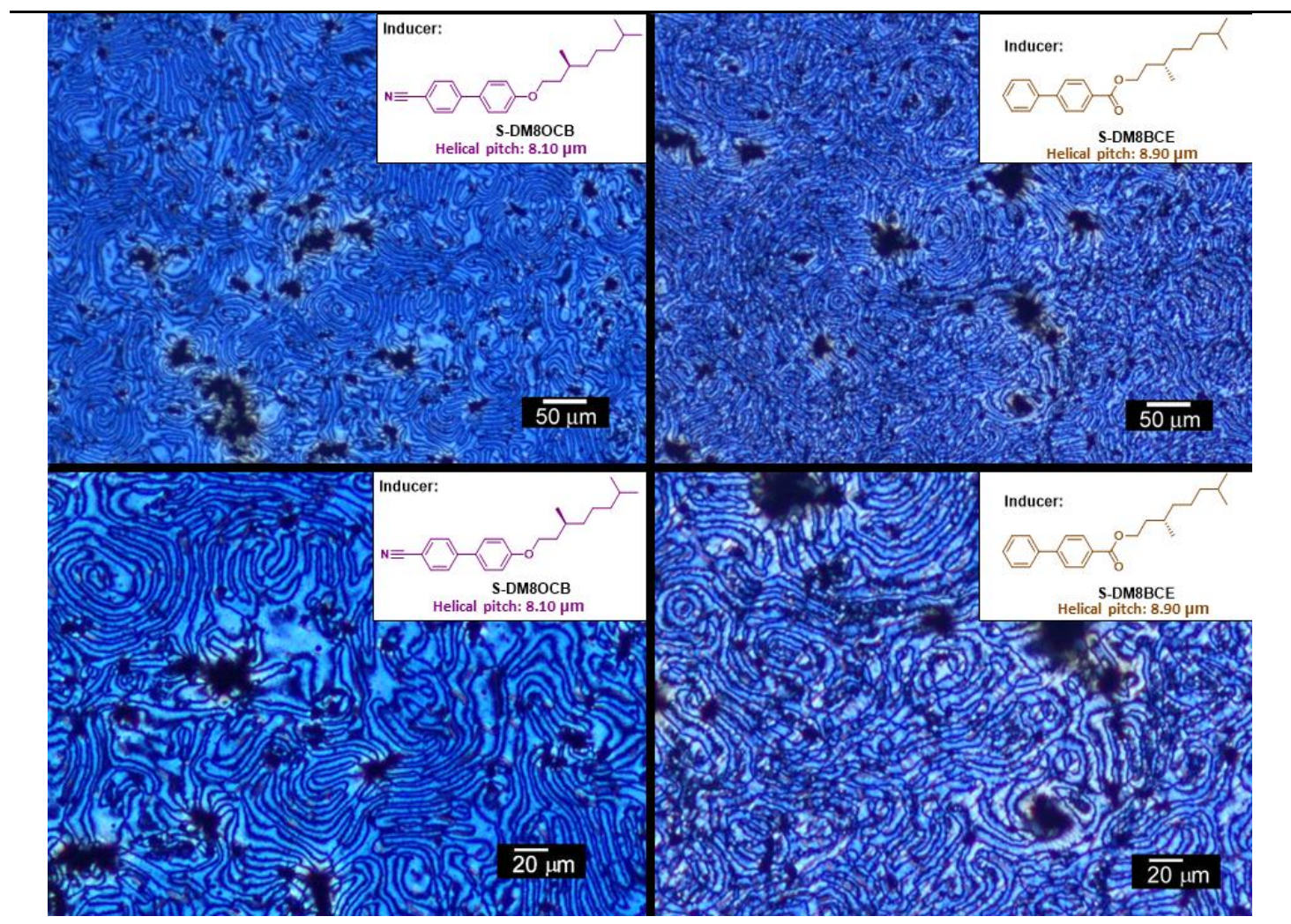

Figure 5. POM images of polymer films and helical pitch length (averaged value over five random places) prepared in the cholesteric liquid crystal electrolyte solutions using S-DM8OCB and S-DM8BCE as chiral inducers.

Further, electrochemical polymerization was conducted in a custom-made cell comprising tetrafluoroethylene film as a spacer $(0.2 \mathrm{~mm}$ thickness $)$ sandwiched between two indium-tin oxide (ITO)-coated glass electrodes. The LC electrolyte solution was heated to $120{ }^{\circ} \mathrm{C}$, and the LC electrolyte solution containing the monomer was injected into the polymerization cell using a pipette. The cell was further cooled to $65^{\circ} \mathrm{C}$. Subsequently, the cell containing the LC electrolyte solution was heated to $120{ }^{\circ} \mathrm{C}$ and again cooled to $65^{\circ} \mathrm{C}$. This annealing process is repeatedly performed to obtain a good fingerprint texture with no phase separation, as depicted in Figure S3.4 (Supplementary Information, SI). Further, direct current (DC) was applied across the cell to initiate electrochemical polymerization. A polymer film was observed at the anode side after 5 min. After completing the polymerization, the cell was disassembled and the anode was washed using acetone to eliminate the residual LC, supporting salt, and oligomer on the surface. The POM images of these polymer films are presented in Figures 4 and 5. The magnified POM images of the polymer films are presented in Figures S3.5 and S3.6 (Supplementary Information, SI). All these polymer films exhibit a fingerprint texture as well as a Schlieren texture [43]. This is attributed to the cholesteric LC-like alignment of polyEDOT in the thin film state. The helical pitch length of the polymers is determined by measuring the distance between the stripes in the fingerprint texture [26]. The helical pitch of the polymer is the same as that of the matrix cholesteric LC in the polymerization, as demonstrated in Figures S3.4 and 5 (Supplementary Information, SI). This indicates that the macroscopic LC structure is transferred to the polymer in electrochemical polymerization. 
CD and UV-vis absorption spectra of the inducers were obtained along with the $\mathrm{CD}$ spectra of the polymer films. The experimental details of the measurements are described in the supplementary information (SI). The experimentally obtained optical spectra are presented in Figures 2 and 3. Further, the optical spectra of the inducers were measured in a hexane solution at a concentration of $3 \times 10^{-5} \mathrm{M}$, which was suitable for performing the CD measurements [36]. The spectrophotometer was set to a 'low' sensitivity mode with low scanning speed and five time scans for integrated measurement by a J-720 CD spectrophotometer from JASCO. The CD spectra of the polymers were measured in the film state on the ITO glass electrodes.

The time-dependent density functional theory (TD-DFT) calculation in this study is conducted using the Gaussian 09 software. Here, one molecule having minimum energy is used to represent the real-time statics of the inducer molecule in the solvent.

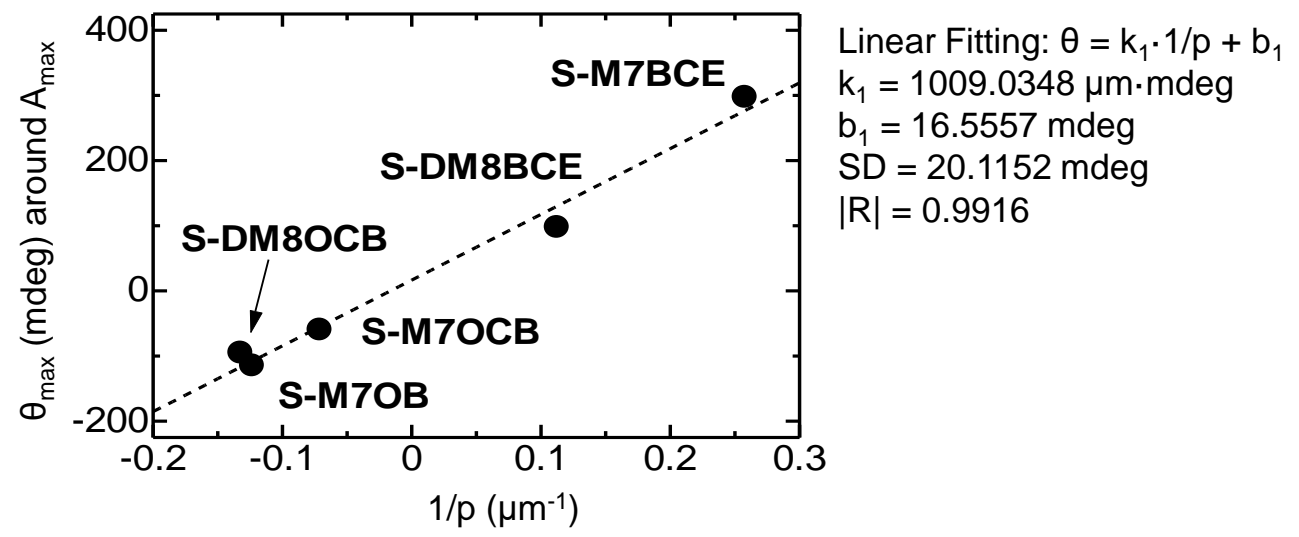

Figure 6. Linear fitting of reciprocal helical pitch length (1/p) and experimental $\theta_{\max }$ (ellipticity maximum, $\mathrm{A}_{\max }=$ absorption maximum) of five polymer films. $\mathrm{SD}=$ standard deviation, $|\mathrm{R}|=$ correlation coefficient.

Table 1. Ellipticity maximum near the absorption maximum and reciprocal helical pitch length $(1 / p)$ of the five polymer films.

\begin{tabular}{cccc}
\hline Inducer & $\begin{array}{c}\text { Ellipticity max. of } \\
\text { polymer } \\
(\text { mdeg, at around 500 } \\
\text { nm) }\end{array}$ & $\begin{array}{c}\text { helical pitch } \\
\text { length } \\
(\mu \mathrm{m})\end{array}$ & $\begin{array}{c}\text { 1/helical pitch } \\
\text { length } \\
\left(\mu \mathrm{m}^{-1}\right)\end{array}$ \\
\hline S-M7OB & -94.94 & -7.55 & -0.1324 \\
S-M7OCB & -59.58 & -14.06 & -0.0711 \\
S-M7BCE & 297.58 & 3.88 & 0.2577 \\
S-DM8OCB & -114.54 & -8.1 & -0.1234 \\
S-DM8BCE & 97.86 & 8.9 & 0.1124 \\
\hline
\end{tabular}

The solvent effect was rectified using the solvent function in Gaussian 09 by considering the default model where heptane is considered to be the solvent. Because our version of Gaussian 09 software did not provide a possibility for selecting hexane as the solvent, heptane was selected instead of hexane in the calculations. All the calculations were conducted using the time-dependent self-consistent field (TD-SCF) treatment on Becke's three-parameter Lee-Yang-Parr hybrid fiction (B3LYP) in 6-311++g(d,p) level. A Core i5-2500K CPU with four threads was used, and the average time required to obtain one molecular model was less than nine days. The 
details of the calculation are provided in the supplementary information (SI). The molecular models and evaluations of the calculated data are described as follows. The conformation with the lowest energy of five inducers, S-M7OB, S-M7OCB, S-M7BCE, S-DM8OCB, and S-DM8BCE, was obtained by optimization using density functional theory (DFT) calculation. Here, two kinds of conformations were obtained due to the steric hindrance of $\alpha$-methyl in the $(S)$-octan-2-yloxy group, $\mathrm{S}-\mathrm{M} 7 \mathrm{OB}, \mathrm{S}-\mathrm{M} 7 \mathrm{OCB}$, and S-M7BCE. This is because the lowest energy conformation (conformation 1) and the second lowest energy conformation (conformation 2) exhibit similar energy levels, and their difference is observed to be only 0.001 atomic units. These two conformations and their energy information are illustrated in Figure 8 using the Newman projection. Here, the carbons in $\mathrm{CH}_{3}-\mathrm{C}^{*} \mathrm{H}-\mathrm{CH}_{2}-\mathrm{CH}_{2}-$ are mostly observed to remain in the same plane for conformation 1. Meanwhile, the carbons and oxygen of $\mathrm{C}-\mathrm{O}-\mathrm{C}^{*} \mathrm{H}-\mathrm{CH}_{2}-\mathrm{CH}_{2}-$ are mostly observed to remain in the same plane for conformation 2. The final atomic axis, calculation time, total energy, and dipole moment of the optimized conformation of each inducer are provided in the supplementary material. Here, a checkpoint file of S-M7OCB was generated to obtain the axis data required for representing conformation 1, which was subsequently renamed as conformation 0 . Conformation 0 of S-M7OCB was considered to be the most completely optimized state with respect to S-M7OB and S-DM8OCB, as depicted in Figures S4.1, S4.2, and S4.4 (Supplementary Information, SI).

The UV-vis and the ECD spectra of S-M7OB, S-M7OCB, S-M7BCE, S-DM8OCB, and S-DM8BCE obtained using the TD-DFT calculation are obtained by estimating the electron transfer between the occupied and unoccupied molecular orbitals. We calculated twenty-four kinds of electron transfers from the lowest to highest energies. The spectra are distributed from 200 to $500 \mathrm{~nm}$. The UV-vis and CD spectra of five inducers were obtained from 300 to $450 \mathrm{~nm}$, as depicted in Figure 9.

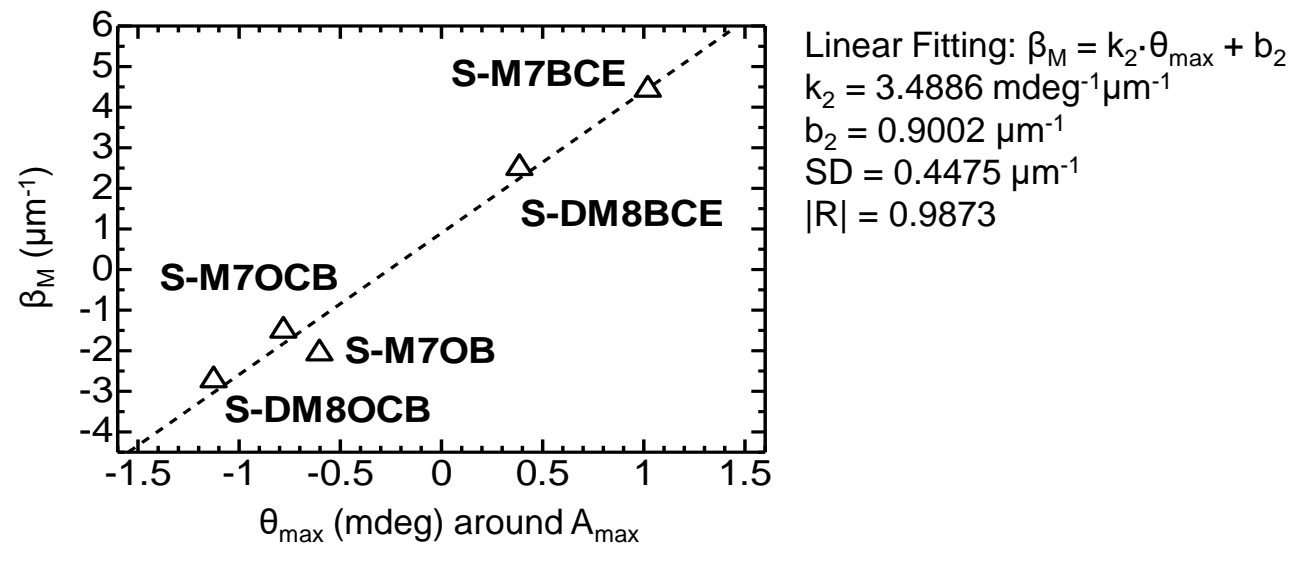

Figure 7. Linear fitting of experimental $\theta_{\max }$ (ellipticity maximum, $\mathrm{A}_{\max }=$ absorption maximum) and experimental $\beta_{\mathrm{M}}$ (macroscopic helical twisting powers) of inducers. $\mathrm{SD}=$ standard deviation, $|\mathrm{R}|=$ correlation coefficient. 


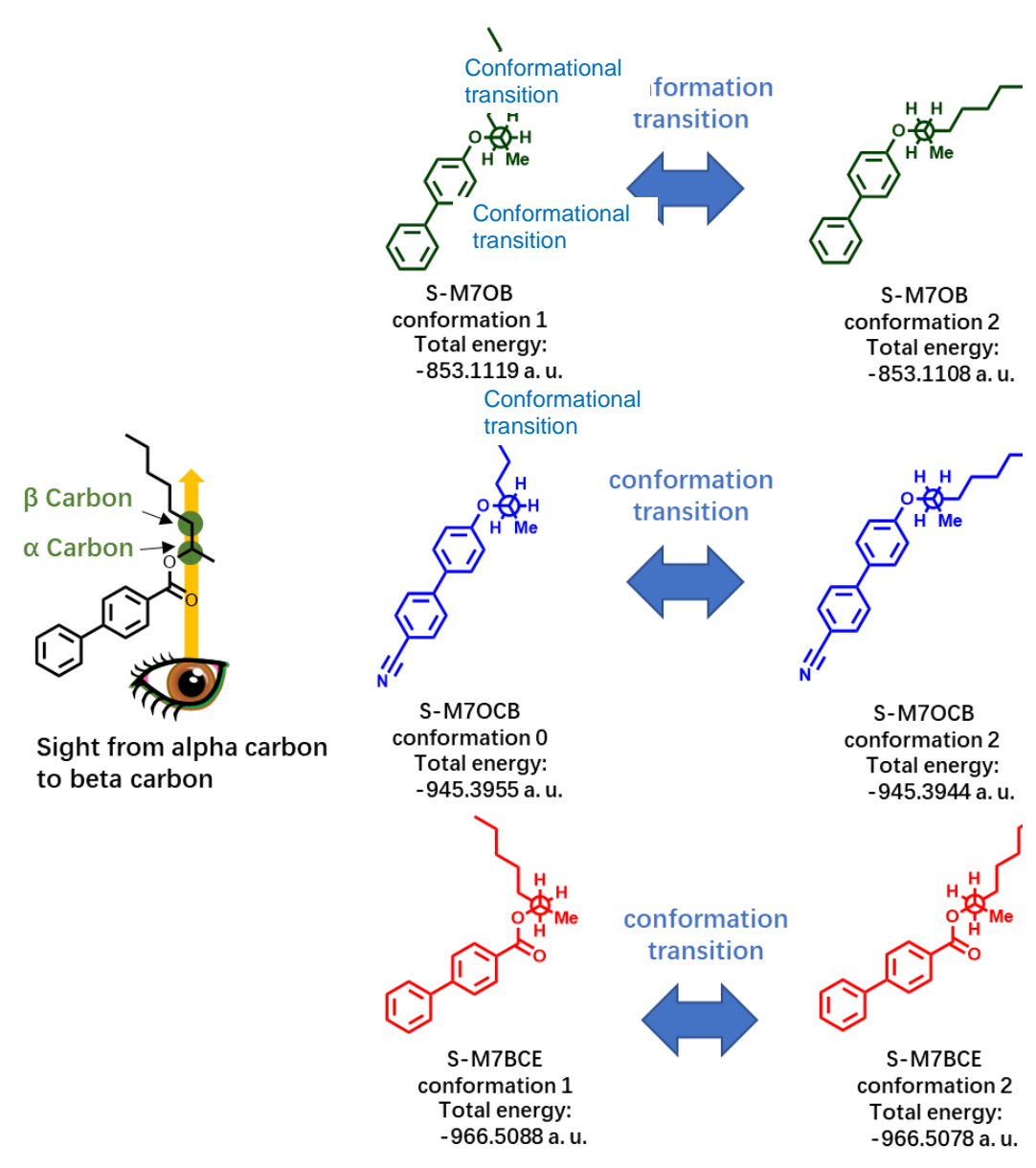

Figure 8. Conformations 1 and 2 of S-M7OB and S-M7BCE expressed by the Newman projection and the calculated total energy by DFT.

\section{RESULTS AND DISCUSSION}

In the UV-vis spectra of the inducers (Figure 2), the absorption peaks around 275 $\mathrm{nm}$ can be attributed to the $\pi-\pi^{*}$ transition in the aromatic structure. S-M7OCB and S-DM8OCB exhibit absorption at long wavelengths. Compounds containing the cyano- and carboxylate groups have an electron-withdrawing group, resulting in an absorption band at long wavelengths compared to S-M7OB. S-DM8BCE contains a weak torsion plane between the alkyl chain and the aromatic plane compared to S-M7BCE due to no $\alpha$-methyl (the molecular models are presented in Figures S4.3 and S4.5, Supplementary Information, SI). The UV-vis spectrum of S-DM8BCE follows the Lambert-Beer law at low concentrations, indicating that the optical absorption of S-DM8BCE is not caused by multimolecular aggregation [37]. 


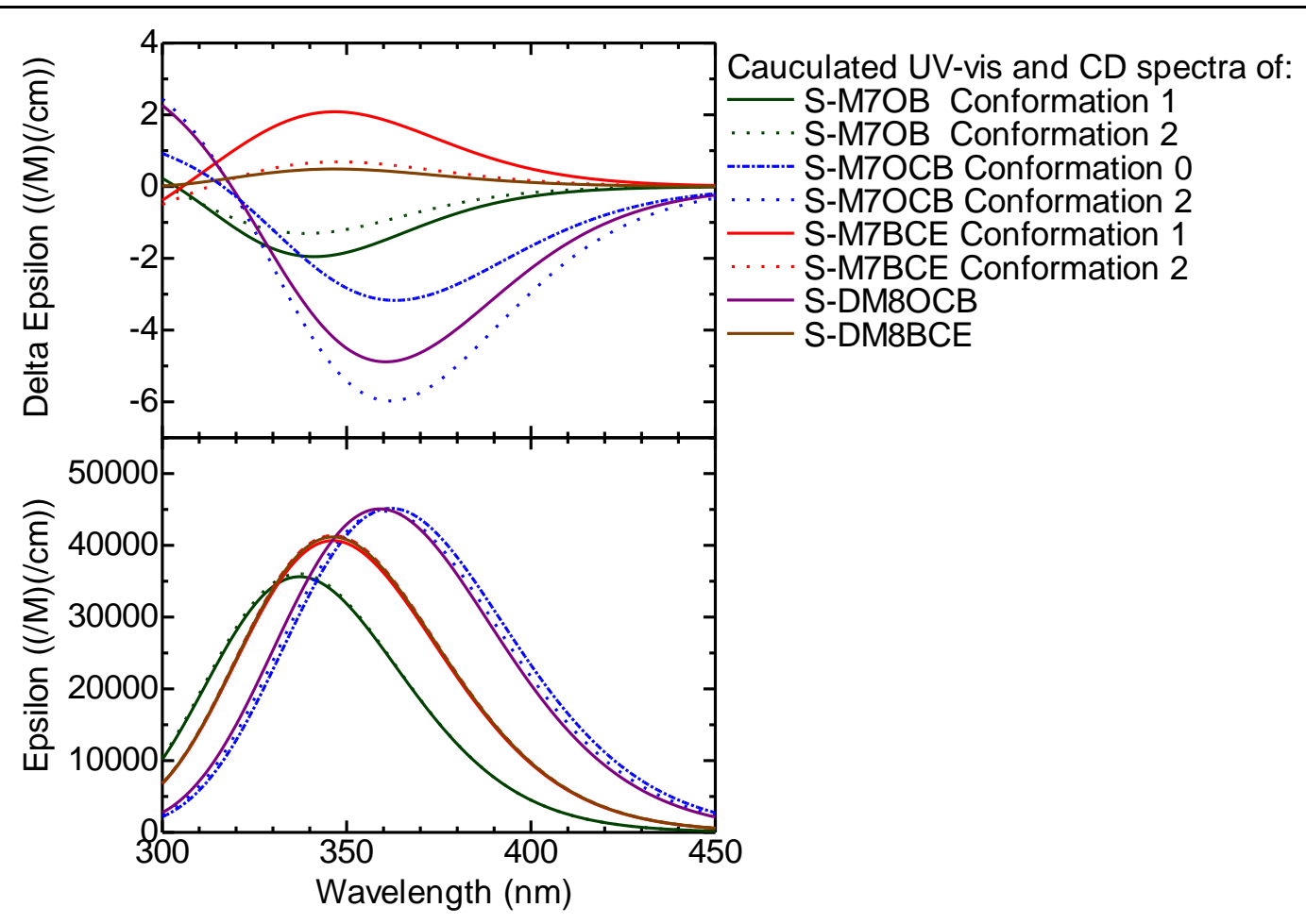

Figure 9. The calculated UV-vis and CD spectra of five inducers by DFT.

All the inducers exhibit either a positive or negative signal in case of the CD around their optical absorption maximum, as depicted in Figure 2. The esters (S-M7BCE and S-DM8BCE) exhibit a positive signal near their optical absorption peaks. This can be attributed to the positive Cotton effect [26]. Furthermore, the ethers (S-M7OB, S-M7OCB, and S-DM8OCB) exhibit negative signals near their absorption maxima, which can be attributed to the negative Cotton effect.

The polyEDOT films that are prepared by LC electrochemical polymerization using a chiral inducer with esters (S-M7BCE and S-DM8BCE) show a positive signal near their optical absorption maxima. Further, the polyEDOT films that are prepared by LC electrochemical polymerization using ethers (S-M7OB, S-M7OCB, and S-DM8OCB) exhibit negative signals near their absorption maxima, as illustrated in Figure 3 [26]. These results indicate that the optical activity and macroscopic morphology of the LC matrix is transferred to the resultant polymer film during the LC electrochemical polymerization.

In a previous study, the CD signals of the optically active polymers are linearly related with the HTP of the inducer at the same concentration [26]. The HTP and relevant parameters can be defined as follows:

$$
\begin{aligned}
& \mathrm{HTP}=1 / c \times 1 / p \\
& \mathrm{MHTP}=\mathrm{HTP} \times \mathrm{M}_{\mathrm{d}} \times 10^{-3} \\
& \beta_{\mathrm{M}}=\mathrm{M}_{\mathrm{d}} / \mathrm{M}_{\mathrm{h}} \times 1 / c \times 1 / p
\end{aligned}
$$

Here, MHTP denotes the molar HTP, $\beta_{\mathrm{M}}$ denotes the microscopic HTP, $c$ denotes the weight concentration of the inducer, $p$ denotes the length of the helical pitch, and $\mathrm{M}_{\mathrm{d}}$ and $\mathrm{M}_{\mathrm{h}}$ denote the molecular weights of the inducer and solvent, respectively.

In this study, $\beta_{M}$ and $1 / p$ were used because $\beta_{M}$ can be used to ignore the 
contributing effect of molecular weight and $1 / p$ was linearly correlated with HTP, both of which were convenient for performing calculations. In accordance with a previous study, the linear relation between the optical activity and reciprocal helical pitch length (proportional to HTP, MHTP, and $\beta_{\mathrm{M}}$ ) of the polymers were verified and presented in Figure 6 and Table 1.

Ellipticity maximum $\left(\theta_{\max }\right)$ is a $\mathrm{CD}$ signal at the lowest energy range in the spectrum, which can be attributed to the asymmetric electron transition that commonly occurred between two energy levels [38]. The ellipticity maximum $\left(\theta_{\max }\right)$ and reciprocal helical pitch length $(1 / p)$ of the polymer films are summarized in Table 1. The preceding sign ( + or - ) of the helical pitch length is defined by the sign of the ellipticity maximum. In a previous research, optically active polyEDOT with a first positive Cotton effect is observed to form a right-handed helix [26]. Thus, the sign of positive helical pitch length represents a right-handed helix, and the sign of negative helical pitch length represents a left-handed helix. Linear fitting between $1 / p$ and $\theta_{\max }$ (polymer) was performed using the least square method with the formula $\theta_{\max }=\mathrm{k}_{1} \cdot 1 / p$ $+b_{1}\left(k_{1}\right.$ : coefficient), as presented in Figure 6. In this fitting, a linear relation could be observed with a satisfied correlation coefficient $R(0.9916)$ between the standard deviation ( $\mathrm{SD}, \pm 20.1152 \mathrm{mdeg}$ ), which was larger than the intercept $\left(b_{1}=16.5557\right.$ mdeg). This indicates that the optical activity of the polymer film with a fingerprint texture is inversely proportional to the helical pitch length. The $\mathrm{k}_{1}$ is determined to be $1009.0348 \mu \mathrm{m} \cdot \mathrm{mdeg}$. Other research groups reported $\mathrm{k}_{1}$ to have a value of ca. $1733.3526 \mu \mathrm{m} \cdot \mathrm{mdeg}$ via calculations [26]. The $\mathrm{k}_{1}$ value depends on the polymerization condition such as the type of LC and monomer.

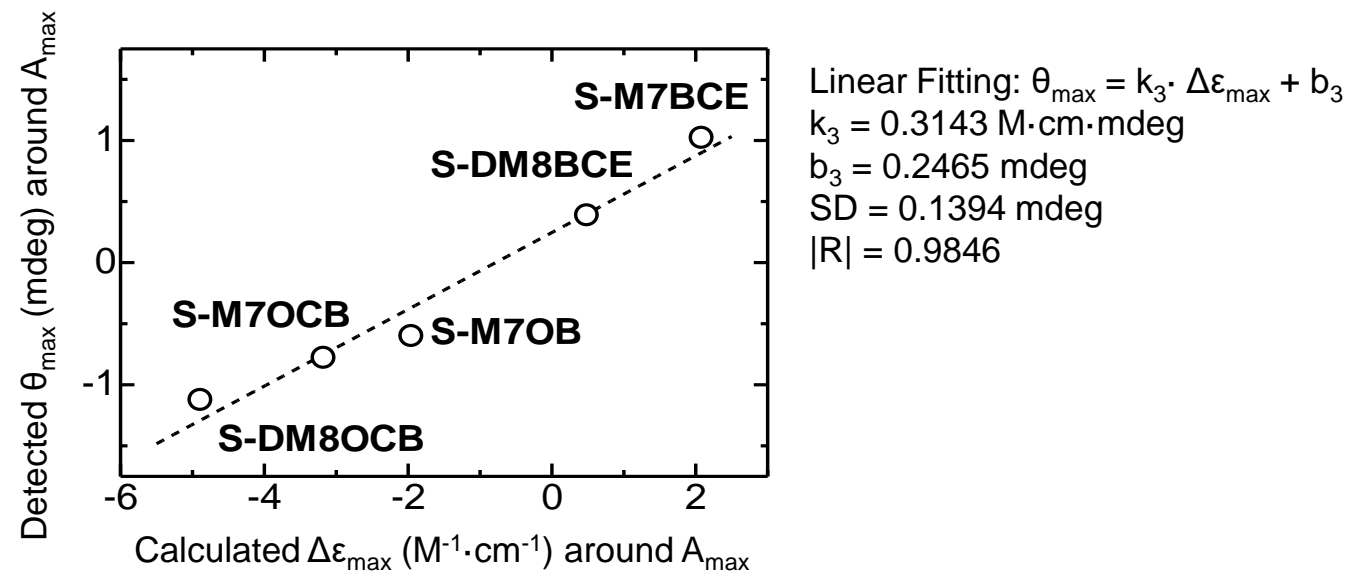

Figure 10. Linear fitting of the calculated $\Delta \varepsilon_{\max }$ and the experimental $\theta_{\max }$ (ellipticity maximum, $\mathrm{A}_{\max }=$ absorption maximum) of inducers. $\mathrm{SD}=$ standard deviation, $|\mathrm{R}|=$ correlation coefficient. 


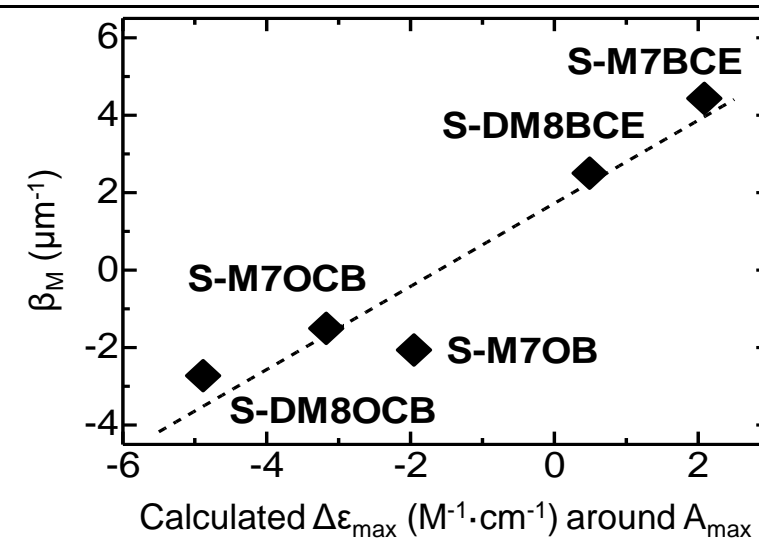

$$
\begin{aligned}
& \text { Linear Fitting: } \beta_{\mathrm{M}}=\mathrm{k}_{4} \cdot \Delta \varepsilon_{\max }+\mathrm{b}_{4} \\
& \mathrm{k}_{4}=0.1073 \mathrm{M} \cdot \mathrm{cm} \cdot \mu \mathrm{m}^{-1} \\
& \mathrm{~b}_{4}=1.7244 \mu \mathrm{m}^{-1} \\
& \mathrm{SD}=0.8727 \mu \mathrm{m}^{-1} \\
& |\mathrm{R}|=0.9509
\end{aligned}
$$

Figure 11. Linear fitting of the calculated $\Delta \varepsilon_{\max }$ and the experimental $\beta_{M}$ (macroscopic helical twisting powers) of inducers. $\mathrm{SD}=$ standard deviation, $|\mathrm{R}|=$ correlation coefficient.

A linear relation can be observed between the ellipticity maximum $\left(\theta_{\max }\right.$, inducer) in the CD and the macroscopic HTP $\left(\beta_{\mathrm{M}}\right)$ of inducer, as depicted in Figure 7. In this research, the experimental data of the helical pitch length estimated from the POM image is employed to calculate $\beta_{M}$ because the direct observation of fingerprint is observed to be convenient for the polymer film. The Cano wedge method can be generally used for estimating the helical pitch of LCs [39]; however, this method cannot be applied for a polymer film with a fingerprint texture. The components of the LC electrolyte solutions are presented in Table S3.2 (Supplementary Information, SI).

Table 2 shows the experimental $\theta_{\max }$ and $\beta_{\mathrm{M}}$ of the chiral inducers. The linear fitting of the experimental ellipticity maxima of inducers and their macroscopic HTP $\left(\beta_{\mathrm{M}}\right)$ exhibits a good correlation coefficient $(R=0.9873)$. However, the intercept $\left(\mathrm{b}_{2}=\right.$ $\left.0.9002 \mu \mathrm{m}^{-1}\right)$ is larger than the standard deviation $\left(0.4475 \mu \mathrm{m}^{-1}\right)$. Thus, in a case where $\theta_{\max }$ (inducer) is zero, $\beta_{M}$ maintains some value, which can be attributed to the

\begin{tabular}{|c|c|c|c|c|}
\hline Inducer & $\begin{array}{c}\text { Ellipticity max. of } \\
\text { inducer } \\
\text { (mdeg, at around } \\
\lambda_{\max } \text { in absorption, } \\
\mathrm{A}_{\max } \text { ) }\end{array}$ & $\begin{array}{l}\text { Concentration } \\
\text { (mol. } \% \text { in LC) }\end{array}$ & $\begin{array}{c}\text { 1/helical pitch } \\
\text { length } \\
\left(\mu \mathrm{m}^{-1}, \text { Polymer }\right)\end{array}$ & $\begin{array}{c}\beta_{\mathrm{M}} \\
\left(\mu \mathrm{m}^{-1}\right)\end{array}$ \\
\hline S-M7OB & -0.6031 & $6.42 \%$ & -0.1324 & -2.06 \\
\hline S-M7OCB & -0.7813 & $4.73 \%$ & -0.0711 & -1.50 \\
\hline S-M7BCE & 1.0199 & $5.81 \%$ & 0.2577 & 4.43 \\
\hline S-DM8OCB & -1.1262 & $4.53 \%$ & -0.1234 & -2.72 \\
\hline S-DM8BCE & 0.3855 & $4.49 \%$ & 0.1124 & 2.50 \\
\hline
\end{tabular}
experimental error [41]. Regardless, this significant linear correlation can be used for estimating HTP from the optical activity of inducers.

Table 2. Ellipticity maximum and experimental macroscopic helical twisting power $\left(\beta_{M}\right)$ of five inducers.

The calculated UV-vis spectra of the five inducers show three types of bands. This is because of their different conjugated lengths and different effects from 
auxochrome group. The peak at the absorption maximum was mostly attributed to the electron transfer with the lowest energy. This electron transfer occurs mostly due to the HOMO (highest occupied molecular orbital)-LUMO (lowest unoccupied molecular orbital) electron transfer.

The ECD spectra obtained by the calculation of five inducers using DFT are presented in Figure 9. Here, delta epsilon $(\Delta \varepsilon)$ of the CD is used instead of the ellipticity. The conversion between $\Delta \varepsilon$ and ellipticity does not affect the correlation coefficient in linear fitting [40]. Linear fitting between the experimental $\theta_{\max }$ value (ellipticity maximum around absorption maximum) and calculated $\Delta \varepsilon_{\max }$ (CD) of the five inducers (Table 3) was obtained, as presented in Figure 10. Conformation 1 with the lowest energy is employed because $\Delta \varepsilon_{\max }$ from conformation 1 is well matched with the experimental results. The correlation coefficient $R$ is 0.9864 , as obtained from the fitting. This result demonstrates that TD-DFT is capable of predicting the optical activity $\left(\theta_{\max }\right.$ and $\left.\Delta \varepsilon_{\max }\right)$ of monomers. Although the prediction accuracy of the CD spectrum is dependent on the calculation method, the TD-DFT calculation is considered to be appropriate for the estimation of optical activity in this system.

Table 3. Experimental ellipticity maximum and calculated delta epsilon $(\Delta \varepsilon)$ of five inducers.

\begin{tabular}{ccc}
\hline Inducer & $\begin{array}{c}\text { Ellipticity Max. at around } \lambda_{\max } \\
\left(\text { mdeg, } \mathrm{A}_{\max } \text { experimental) }\right.\end{array}$ & $\begin{array}{c}\text { Delta Epsilon }(\Delta \varepsilon) \text { Max around } \\
\lambda_{\max }\end{array}$ \\
\hline S-M7OB & -0.6031 & -1.9528 \\
S-M7OCB & -0.7813 & -3.1725 \\
S-M7BCE & 1.0199 & 2.0846 \\
S-DM8OCB & -1.1262 & -4.8846 \\
S-DM8BCE & 0.3855 & 0.4896 \\
\hline
\end{tabular}

Finally, the calculated $\Delta \varepsilon_{\max }$ and the microscopic $\beta_{\mathrm{M}}$ of the inducers are linearly fitted, as depicted in Figure 11. The linear correlation coefficient $R$ is observed to be 0.9509. This method can be used for the prediction of helical direction and HTP. The five inducers containing ester groups exhibited the first positive Cotton effect at long wavelengths and a right-handed HTP. All the ethers exhibited the first negative Cotton effect at long wavelengths and a left-handed HTP. S-M7BCE has the largest HTP in the right-hand direction, while S-DM8OCB has the largest HTP in the left-hand direction. This result indicates that a reliable coefficient between the calculated $\Delta \varepsilon_{\max }$ and $\beta_{\mathrm{M}}$ in a one-process system enables the calculation of the HTP of inducers.

\section{CONCLUSIONS}

Chiral inducers were experimentally synthesized using the Mitsunobu reaction for obtaining the cholesteric LC electrolyte solution. Further, a TD-DFT calculation was demonstrated to predict the HTP of inducers. The electrochemical polymerization of chiral cholesteric LCs can be used to generate the chiral polymer film from the achiral monomers. This chirality generation is based on the chirality transcription of monomers from a LC chiral environment with the addition of a small amount of chiral inducer. This introduction of a theoretical method represents a novel approach for development of the effective chiral inducer in a host nematic LC for achieving cholesteric LC field polymerization. 
Acknowledgment

This research was supported by KAKENHI (No. 17K05985).

\section{REFERENCES}

[1] Wang, S., Wang, A., Liu, X., Xu, H., Chen, J., \& Zhang, L. (2018). Electrochim. Acta, 259, 213.

[2] Tang, C., Hackenberg, K., Fu, Q., Ajayan, P.M., \& Ardebili, H. (2012). Nano Lett., 12,1152 .

[3] Wang, Z., Liang, C., Tang, H., Grosjean, S., Shahnas, A., Lahann, J., Brase, S., \& Woll, C. (2018). Macromol. Rapid Commun., 39, 1700676.

[4] Shen, Z., Shi, L., You, B., Wu, L., \& Zhao, D. (2012). J. Mater. Chem., 22, 8069.

[5] Wach, R.A., Wolszczak, P., \& Wlodarczyk, A.A. (2018). Macromol. Mater. Eng., 303, 1800169.

[6] Egiziano, L., Lamberti, P., Spinelli, G., Tucci, V., Kotsilkova, R., Tabakova, S., Ivanov, E., Silvestre, C., \& Maio, R.D. (1981). AIP Conf. Proc., 020152.

[7] Kaitsuka, Y., \& Goto, H. (2016). Fiber. Polym., 17-6, 815.

[8] Karg, S., Riess, W., Meier, M., \& Schwoerer, M. (1993). Synthetic met., 55-57, 4186.

[9] Yang, S., Yang, C., Zhang, X., Zheng, Z., Bi, S., Zhang, Y., \& Zhou, H. (2018). J. Mater. Chem. C, 6, 9044.

[10] Gustafsson, G., Cao, Y., Treacy, G.M., Klavetter, F., Colaneri, N., \& Heeger, A.J. (1992). Nature, 357, 477.

[11] Tsai, K., Wu, Y., Jen, T., \& Chen, S. (2018). Appl. Mater. Interfaces, 10, 26422.

[12] Savagian, L.R., Osterholm, A.M., Shen, D.E., Christiansen, D.T., Kuepfert, M., \& Reynolds, J.R. (2018). Adv. Opt. Mater., DOI: 10.1002/adom.201800594.

[13] Schraff, S., Sun, Y., \& Pammer, F. (2018). Macromolecules, 51, 5323.

[14] Chae, S., Yi, A., Lee, H., Choi, J., \& Kim, H. (2018). J. Mater. Chem. C, 6, 9374.

[15] Kajiya, D., Koganezawa, T., \& Saitow, K. (2016). J. Phys. Chem. C, 120, 23351.

[16] Leysen, P., Teyssandier, J., Feyter, S.D., \& Koeckelberghs, G. (2018). Macromolecules, 51, 3504.

[17] Wang, P., Jeon, I., Lin, Z., Peeks, M.D., Savagatrup, S., Kooi, S.E., Voorhis, T.V., \& Swager, T.M. (2018). J. Am. Chem. Soc., 140, 6501.

[18] Goto, H. (2007). J. Polym. Sci. Pol. Chem., 45, 1377.

[19] Kawashima, H., Kawabata, K., \& Goto, H. (2015). J. Mater. Chem. C, 3, 1126.

[20] Dong, J., Kawabata, K., \& Goto, H. (2015). J. Mater. Chem. C, 3, 2024.

[21] Zhang, X., Di, Q., Zhu, F., Sun, G., \& Zhang, H. (2011). Micro. Nano. Lett., 6, 947.

[22] Narazaki, Y., Nishikawa, H., Higuchi, H., Okumura, Y., \& Kikuchi, H. (2018). RSC Adv., 8, 971.

[23] Hayashi, H., Wang, A., Kawabata, K., \& Goto, H. (2013). Mater. Chem. Phys., $137,816$.

[24] Hayashi, H., \& Goto, H. (2015). International Letters of Chemistry, Physics and Astronomy, 46, 42.

[25] Iseki, T., Kawabata, K., Shigeki, N., \& Goto, H. (2014). Synthetic met., 187, 217.

[26] Matsumura, A., Fan, Y., \& Goto, H. (2015). Synthetic Met., 202, 157.

[27] Fernandez, B., Rodriguez, R., Rizzo, A., Quinoa, E., Riguera, R., \& Freire, F. (2018). Angew. Chem. Int., 57, 3666. 
[28] Ishido, Y., Kanbayashi, N., Okamura, T., \& Onitsuka, K. (2017). Macromolecules, $50,5301$.

[29] Yamamura, Y., Murakoshi, T., Hishida, M., \& Saito, K. (2017). Phys. Chem. Chem. Phys., 19, 25518.

[30] Sleczkowski, M.L., Meijer, E.W., \& Palmans, A.R.A. (2017). Macromol. Rapid Commun., 38, 1700566.

[31] Alsters, P.L., Jary, W., Nardello-Rataj, V., \& Aubry, J. (2010). Org. Process Res. Dev., 14, 259.

[32] Heravi, M.M., Ghalavand, N., Ghanbarian, M., \& Mohammadkhani, L. (2018). DOI: $10.1002 /$ aoc. 4464 .

[33] Kawabata, K., Takeguchi, M., \& Goto, H. (2013). Macromolecules, 46, 2078.

[34] Nazim, M., Ameen, S., Akhtar, M.S., \& Shin, H. (2018). Sol. Energy., 171, 366.

[35] Novo, M., Reija, B., \& Al-Soufi, W. (2007). J. Chem. Educ., 84, 1673.

[36] Saakov, V.S., Drapkin, V.Z., Krivchenko, A.I., Rozengart, E.V., Bogachev, Y.V., \& Knyazev, M.N. (2013). Derivative Spectrophotometry and Electron Spin Resonance (ESR) Spectroscopy for Ecological and Biological Questions, p13, DOI: 10.1007/978-3-7091-1007-2_2.

[37] Wurthner, F., Kaiser, T.E., \& Saha-Moller, C.R. (2011). Angew. Chem. Int. Ed., $50,3376$.

[38] Miyahara, T., \& Nakatsuji, H. (2018). J. Phys. Chem. A, 122, 100.

[39] Lin, T., Nemitz, I.R., Pendery, J.S., Schubert, C.P.J., Lemieux, R.P., \& Rosenblatt, C. (2013). Appl. Phys. Lett., 102, 134101.

[40] Janes, R.W. (2005). Bioinformatics, 21, 4230.

[41] Satozono, H. (2015). Opt. Lett., 40, 1161.

[42] Chandrasekhar, S., Nair, G.G., Praefcke, K., \& Singer, D. (1996). Mol. Cryst. Liq. Cryst., 288, 7. 
Supplementary Information for:

Estimation of the helical twisting power of chiral inducers by time-dependent density functional theory (TD-DFT) for electrochemical polymerization in cholesteric liquid crystals

\author{
Haoyue Shen and Hiromasa Goto* \\ Department of Materials Science, Faculty of Pure and Applied Sciences, University of \\ Tsukuba, Tsukuba, Ibaraki, 305-8573, Japan \\ *Correspondence to H. Goto, e-mail:gotoh@ims.tsukuba.ac.jp \\ Content : \\ 1. Synthesis and chemical structure confirmation of models \\ 2. Setting in measurement of UV-vis and circular dichroism (CD) spectra \\ 3. Setting in electrochemical polymerization \\ 4. Models used in time-dependent self-consistent field density functional theory \\ (TD-SCF-DFT) calculation
}




\section{Synthesis and chemical structure confirmation of models}

Chemicals were purchased from Tokyo Chemical Industry Co., Ltd. Tetrahydrofuran (THF, $500 \mathrm{~mL}$ ) was dried by refluxing with sodium strip (2 g). In this treatment, benzophenone $(0.5 \mathrm{~g})$ was used as an indicator. When this mixture became purple, the purified THF was collected by distillation.

(S)-3,7-dimethyloctan-1-ol [a], 4-octoxy-4'-cyanobiphenyl (8OCB) [b], (bisEDOT) [c] were synthesized, according to the references.

References.

[a] Eleftheriadis, N., Thee, S., Biesebeek, J., Wouden, P., Baas, \& B., Dekker, F.J. (2015). Eur. J. Med. Chem., 94, 265.

[b] Schneider, J.M.F.M., Sales, E.S., Livotto, P.R., Schneider, P.H., \& Merlo, A.A. (2014). J. Braz. Chem. Soc., 25, 1493-1503

[c] Kawabata, K., Takeguchi, M., \& Goto, H. (2013). Macromolecules, 46, 2078. Inducers was synthesized as followed:

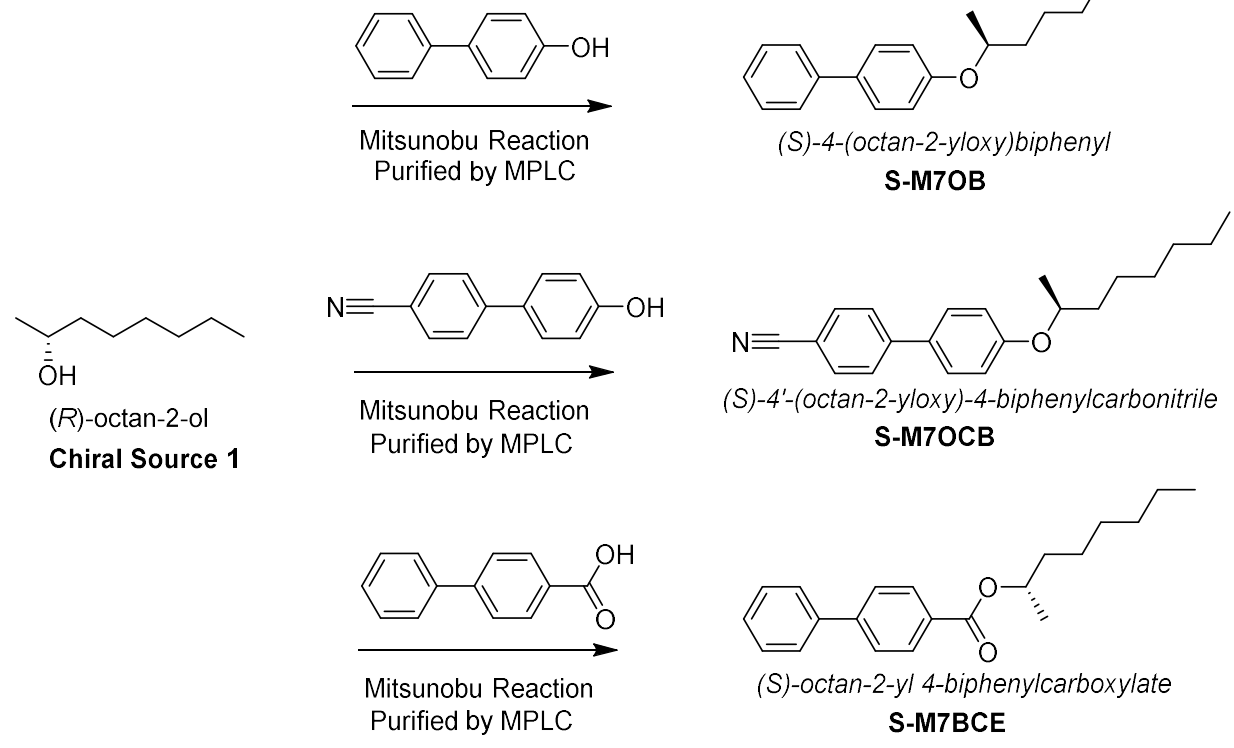

Figure S1.1. Synthetic route for inducers modified by chiral source 1
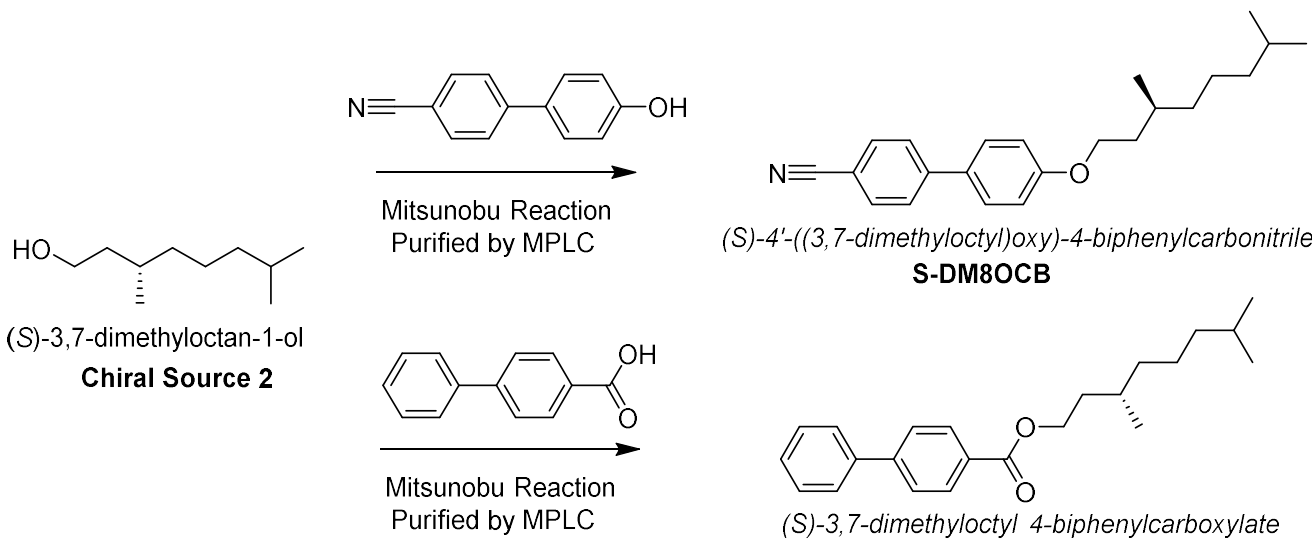

(S)-4'-((3,7-dimethyloctyl)oxy)-4-biphenylcarbonitrile S-DM8OCB

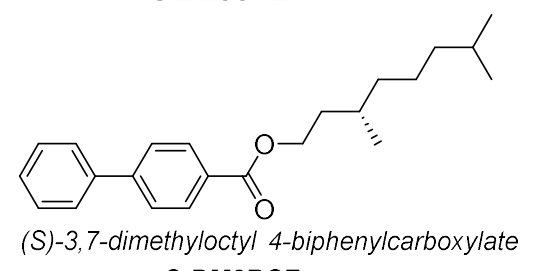

S-DM8BCE

Figure S1.2. Synthetic for inducers modified by chiral source 2 
Under an argon atmosphere, triphenylphosphine $(5 \mathrm{mmol})$ in THF (solvent, 3 $\mathrm{mL}$ ) was stirred and cooled to $0{ }^{\circ} \mathrm{C}$. Alcohol (chiral source, $5 \mathrm{mmol}$ ) was added at this temperature. Then, diethyl azodicarboxylate (DEAD, $5 \mathrm{mmol}, 1.9 \mathrm{M}$ in toluene) diluted by THF ( $3 \mathrm{~mL})$ was added dropwise. The yellow color and the insoluble substance were immediately disappeared after addition of the aromatic acid ( $5 \mathrm{mmol}$ ). The solution was warmed up to room temperature and stirred overnight. The solution was concentrated by rotary evaporator at $50{ }^{\circ} \mathrm{C}$. The product was purified by medium pressure liquid chromatography with silica gel column. S-M7OB (colorless liquid): Y $=45 \%, \mathrm{~S}-\mathrm{M} 7 \mathrm{OCB}$ (colorless liquid): $\mathrm{Y}=43 \%, \mathrm{~S}-\mathrm{M} 7 \mathrm{BCE}$ (colorless liquid): $\mathrm{Y}=63 \%$, $\mathrm{S}-\mathrm{DM} 8 \mathrm{OCB}$ (white crystal, recrystallized from methanol, melting point is ca. $36{ }^{\circ} \mathrm{C}$ ): $\mathrm{Y}=55 \%$, S-DM8BCE (colorless liquid): $\mathrm{Y}=65 \%$.

${ }^{1} \mathrm{H},{ }^{13} \mathrm{C}$ or $\mathrm{HMBC}\left({ }^{1} \mathrm{H}\right.$ detected heteronuclear multiple bond correlation) NMR (nuclear magnetic resonance) spectra of each synthesized compound are shown as follow. 


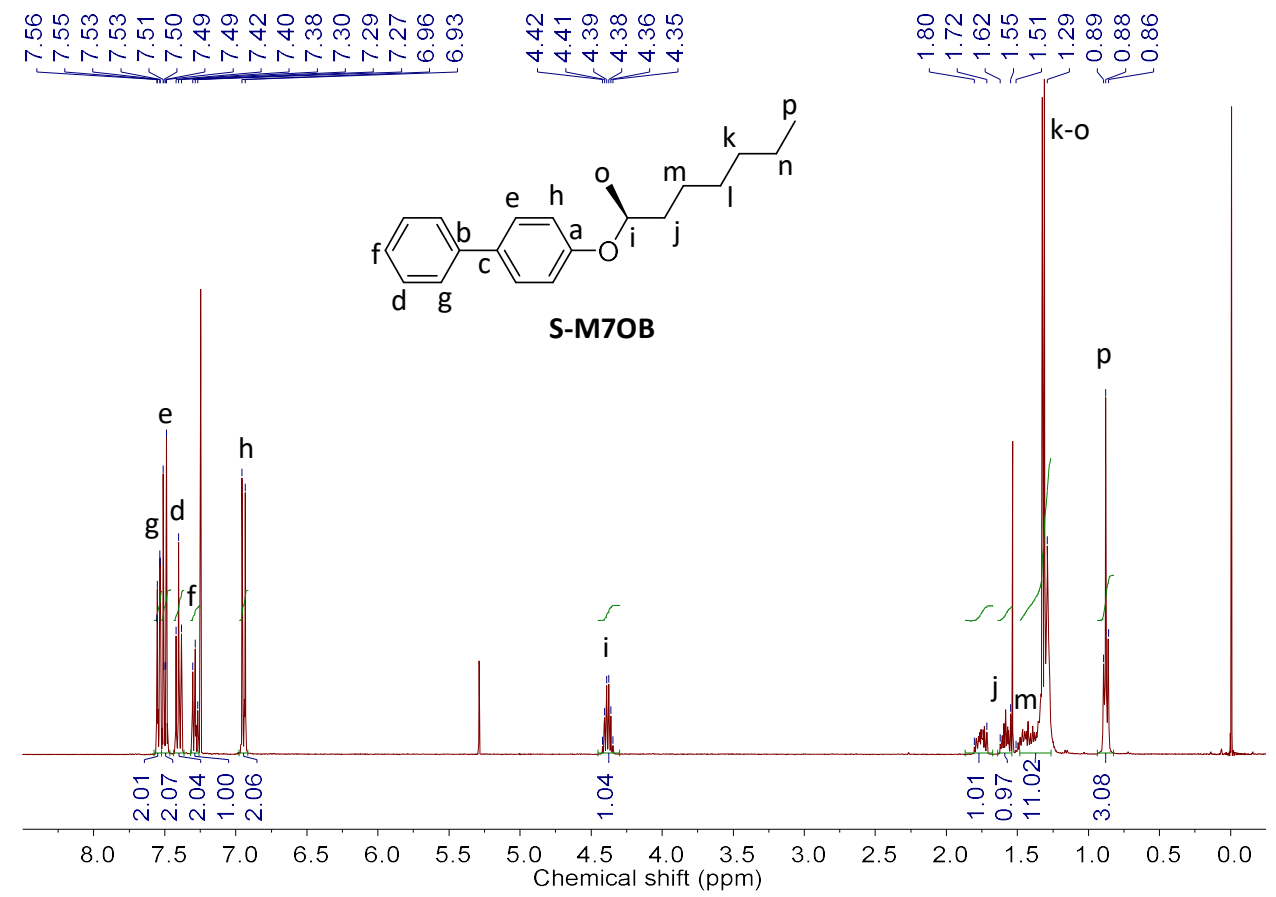

Figure S1.3. ${ }^{1} \mathrm{H}$ NMR spectrum of S-M7OB.

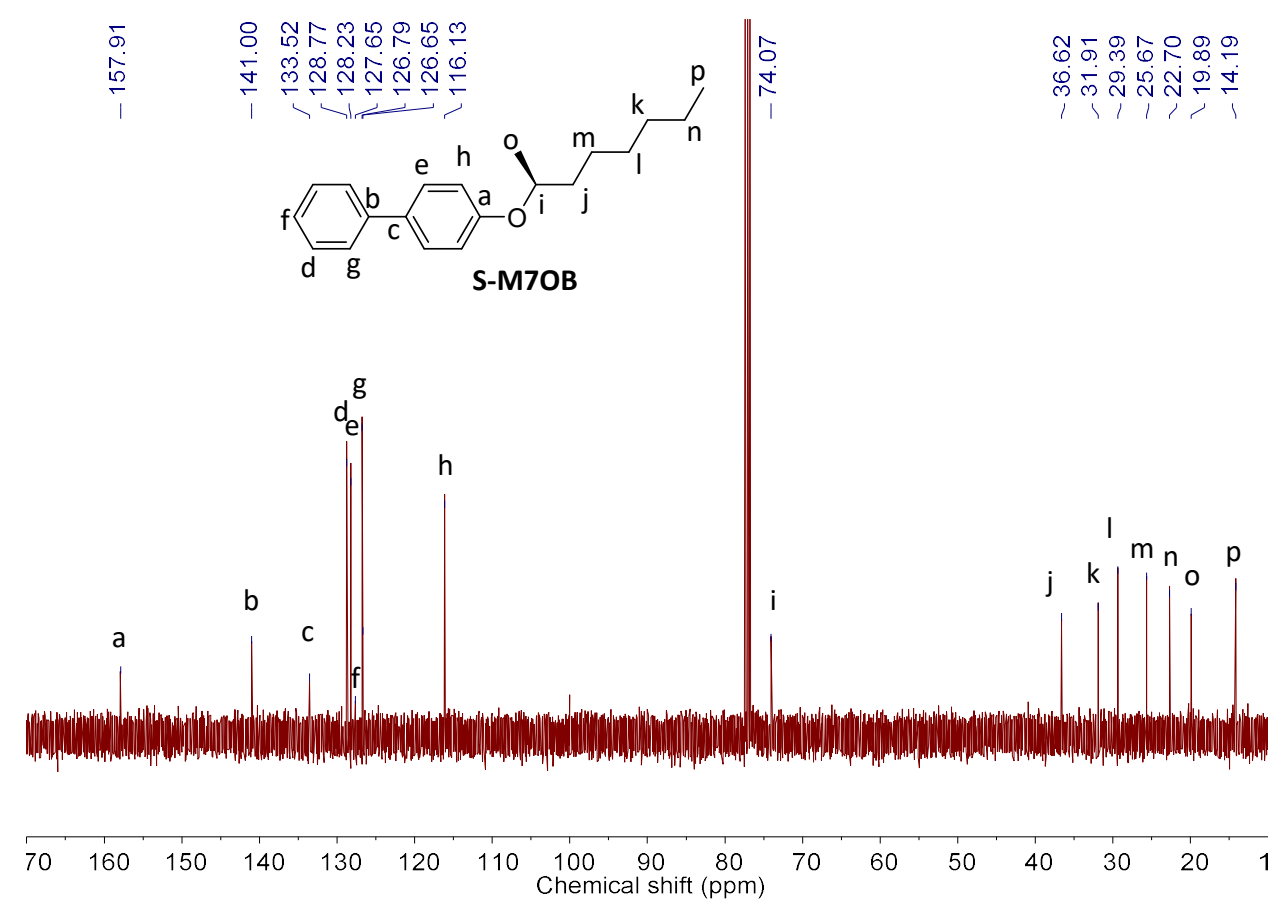

Figure S1.4. ${ }^{13} \mathrm{C}$ NMR spectrum of S-M7OB. 


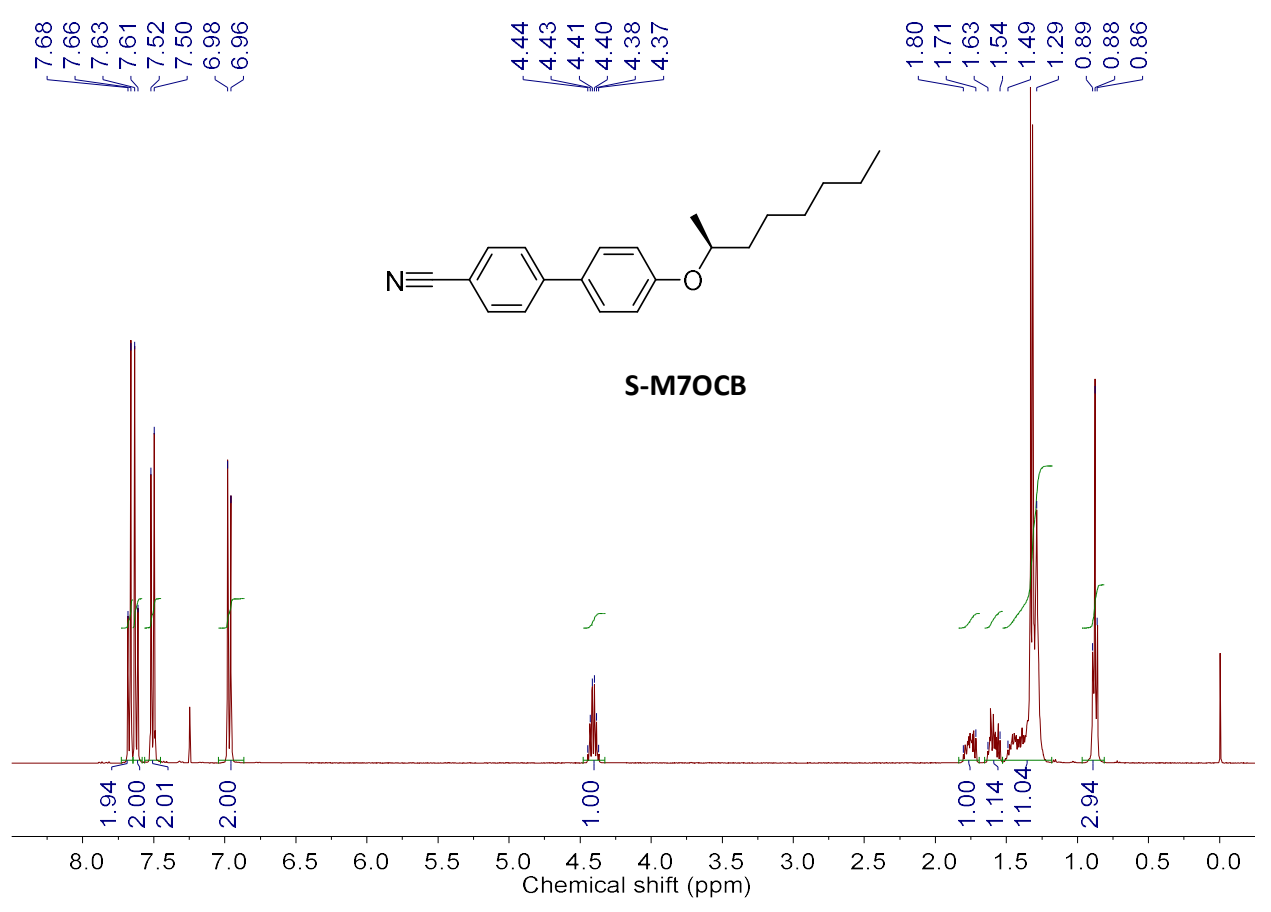

Figure S1.5. ${ }^{1} \mathrm{H}$ NMR spectrum of S-M7OB.

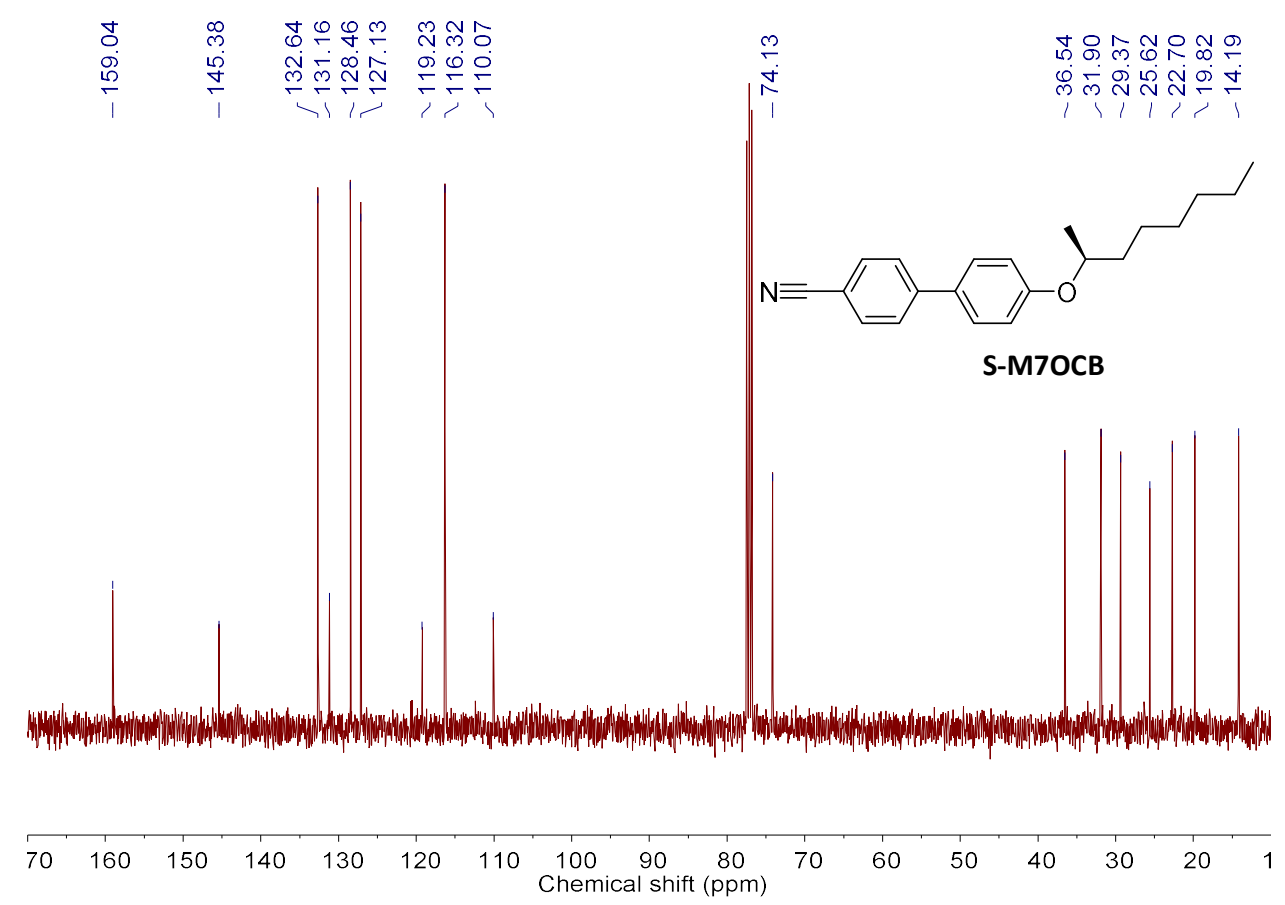

Figure S1.6. ${ }^{13} \mathrm{C}$ NMR spectrum of S-M7OB. 


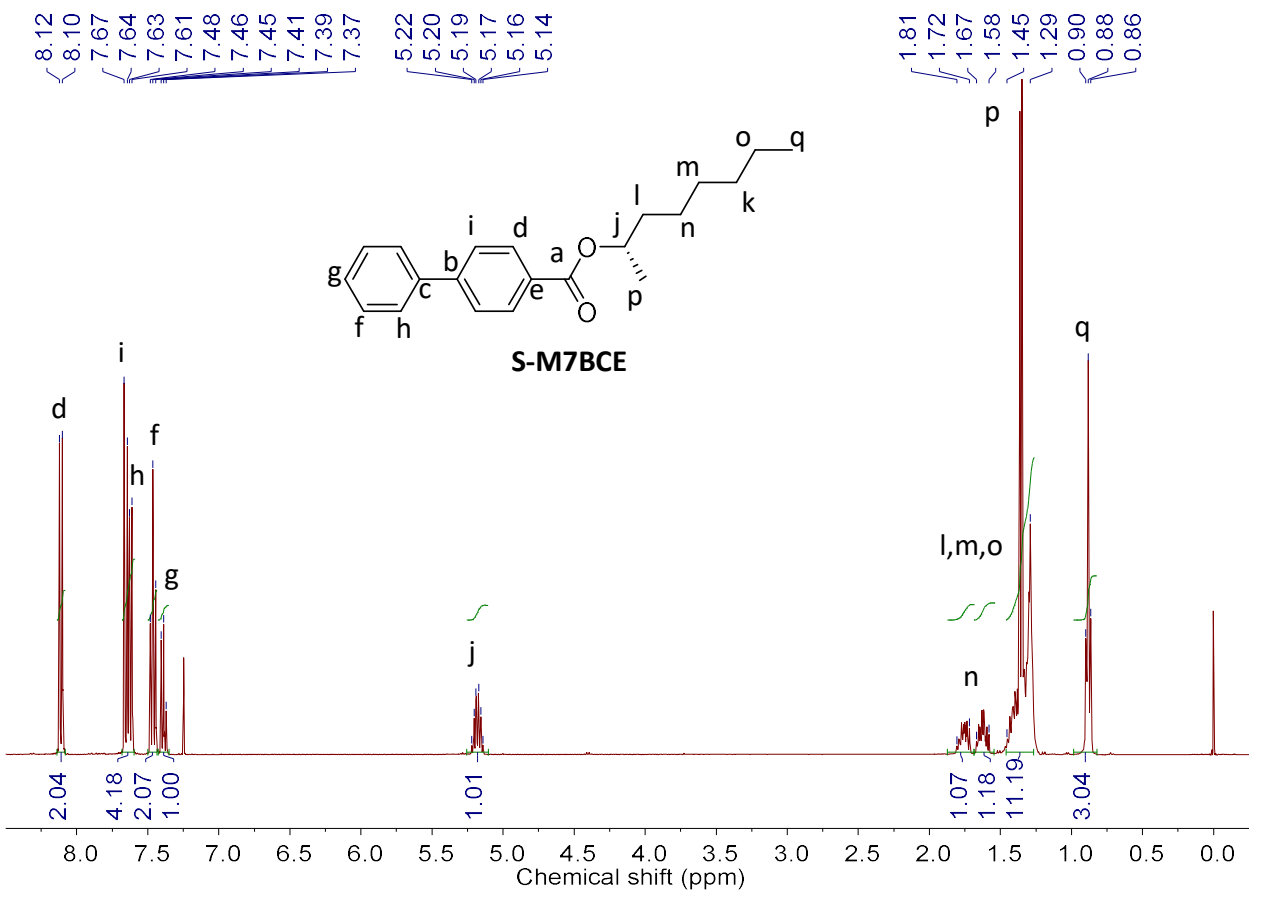

Figure S1.7. ${ }^{1} \mathrm{H}$ NMR spectrum of S-M7BCE.

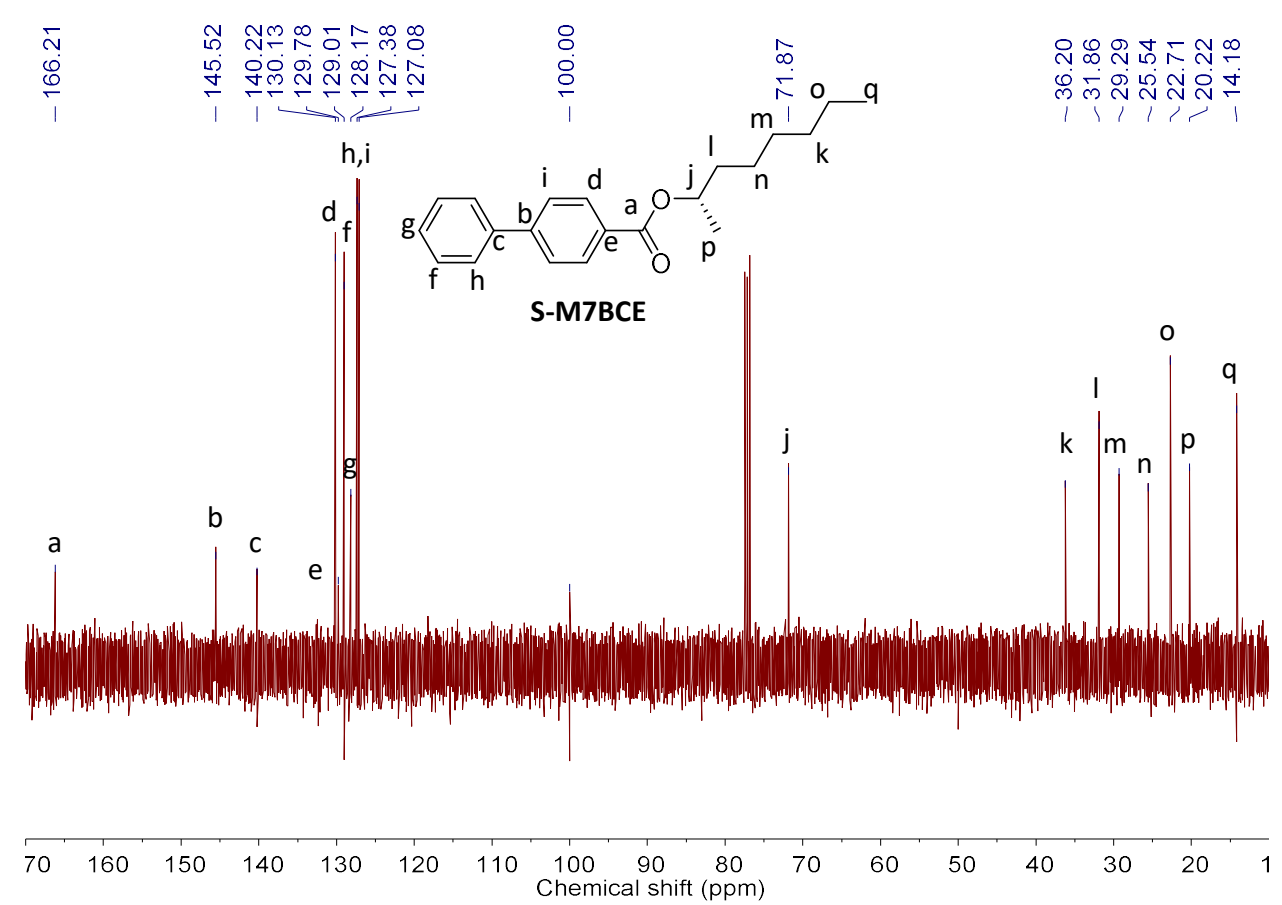

Figure S1.8. ${ }^{13} \mathrm{C}$ NMR spectrum of S-M7BCE. 


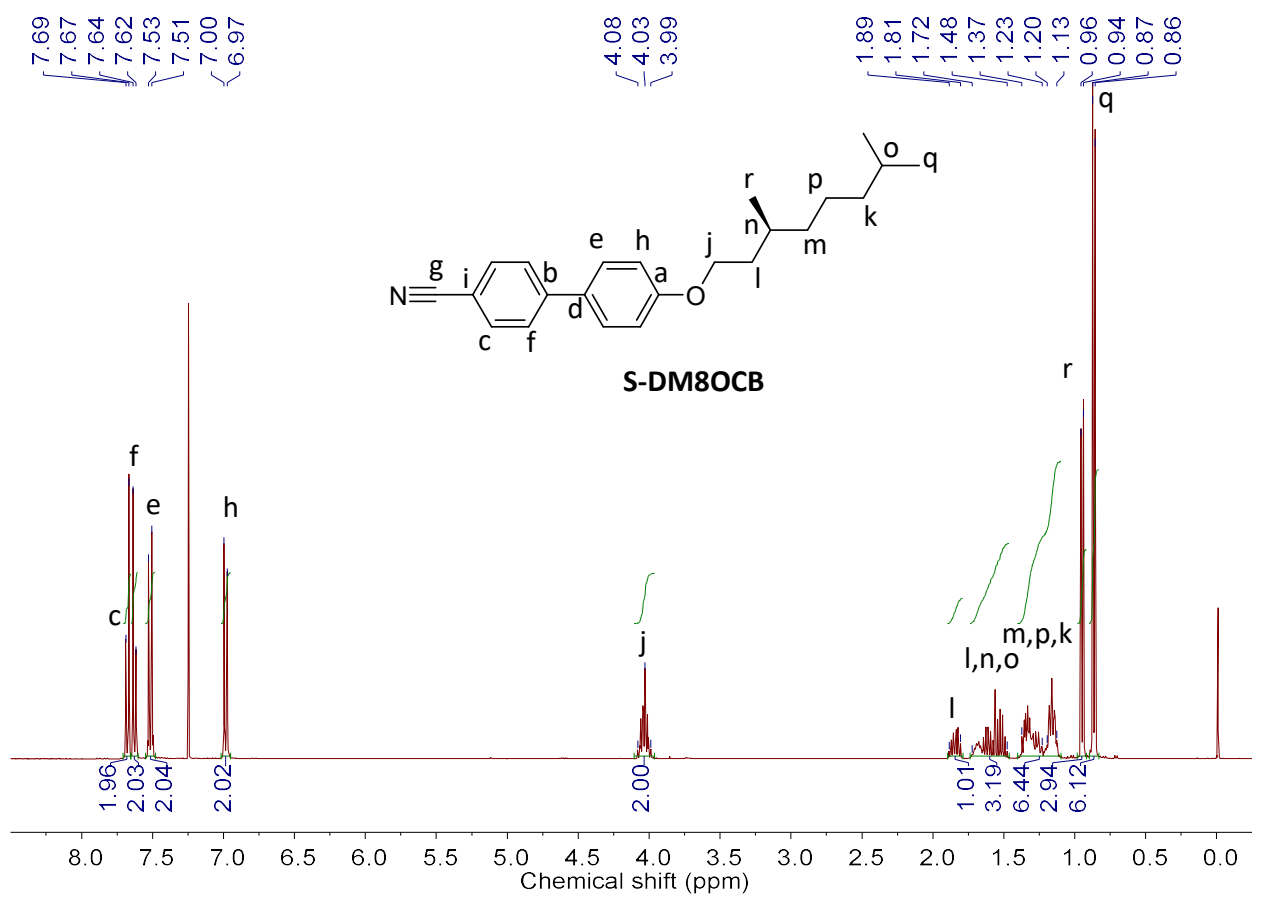

Figure S1.9. ${ }^{1} \mathrm{H}$ NMR spectrum of S-DM8OCB.

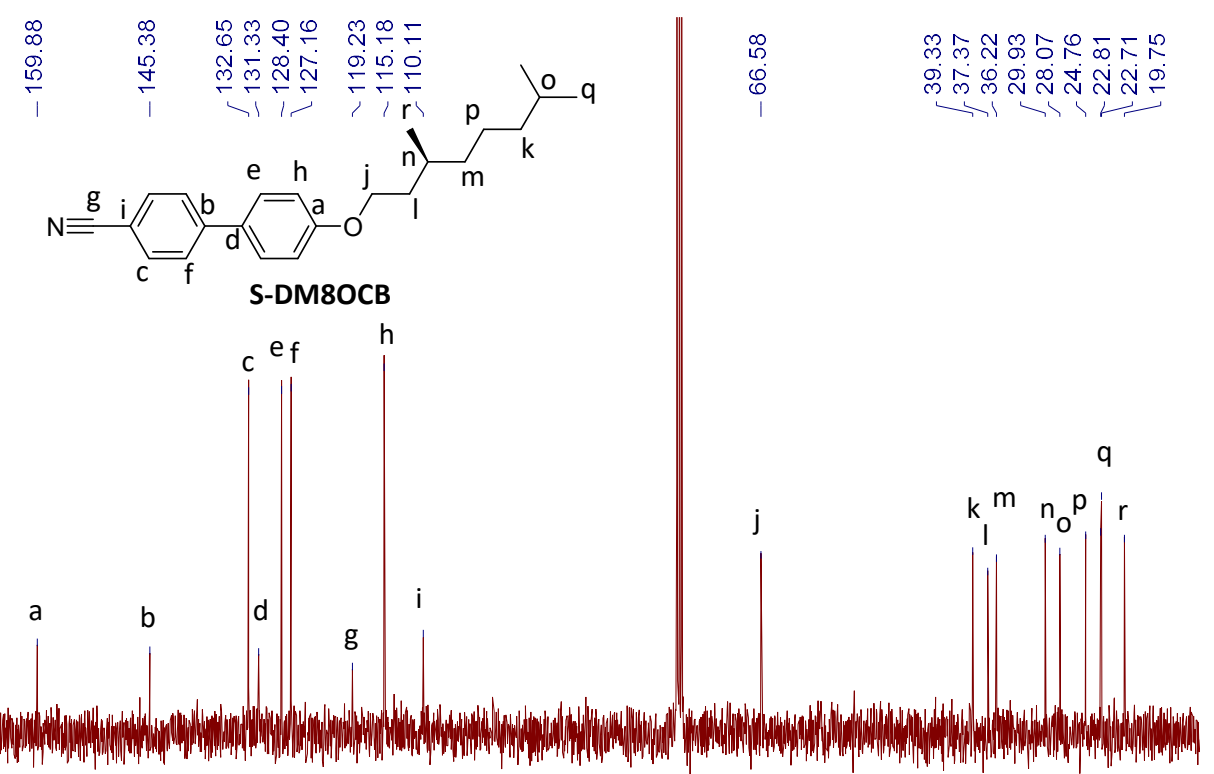

$\begin{array}{llllllllllllllll}70 & 160 & 150 & 140 & 130 & 120 & 110 & \begin{array}{c}100 \\ \text { Chemical shift }(\mathrm{ppm})\end{array} & 70 & 60 & 50 & 40 & 30 & 20 & 1\end{array}$

Figure S1.10. ${ }^{13} \mathrm{C}$ NMR spectrum of S-DM8OCB. 


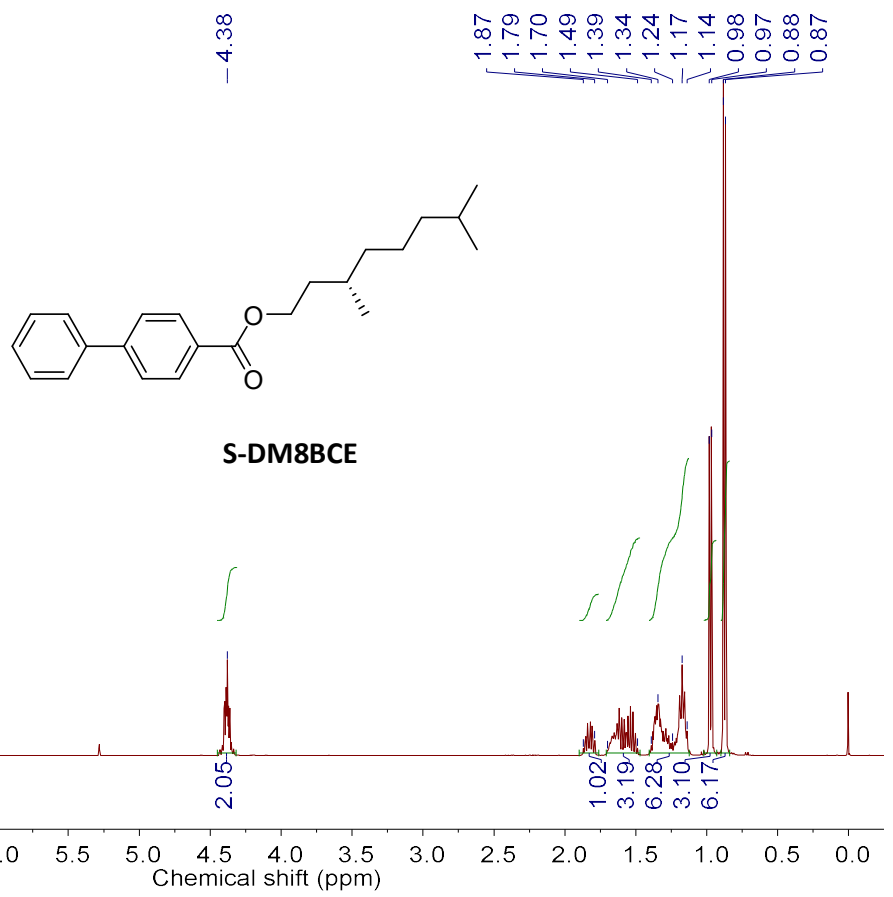

Figure S1.11. ${ }^{13} \mathrm{C}$ NMR spectrum of S-DM8BCE.

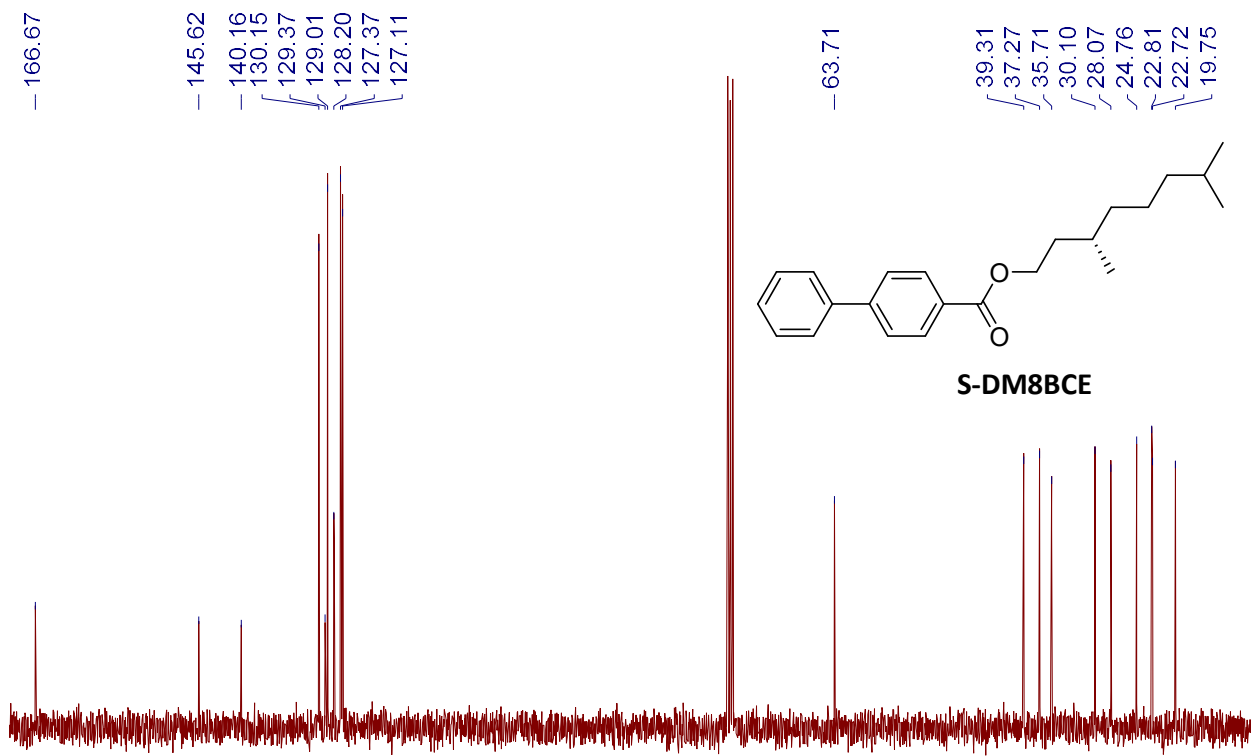

\begin{tabular}{lllllllllllllll}
\hline 70 & 160 & 150 & 140 & 130 & 120 & 110 & $\begin{array}{c}100 \\
\text { Chemical shift }\end{array}(\mathrm{ppm})$ & 70 & 60 & 50 & 40 & 30 & 20
\end{tabular}

Figure S1.12. ${ }^{13} \mathrm{C}$ NMR spectrum of S-DM8BCE. 


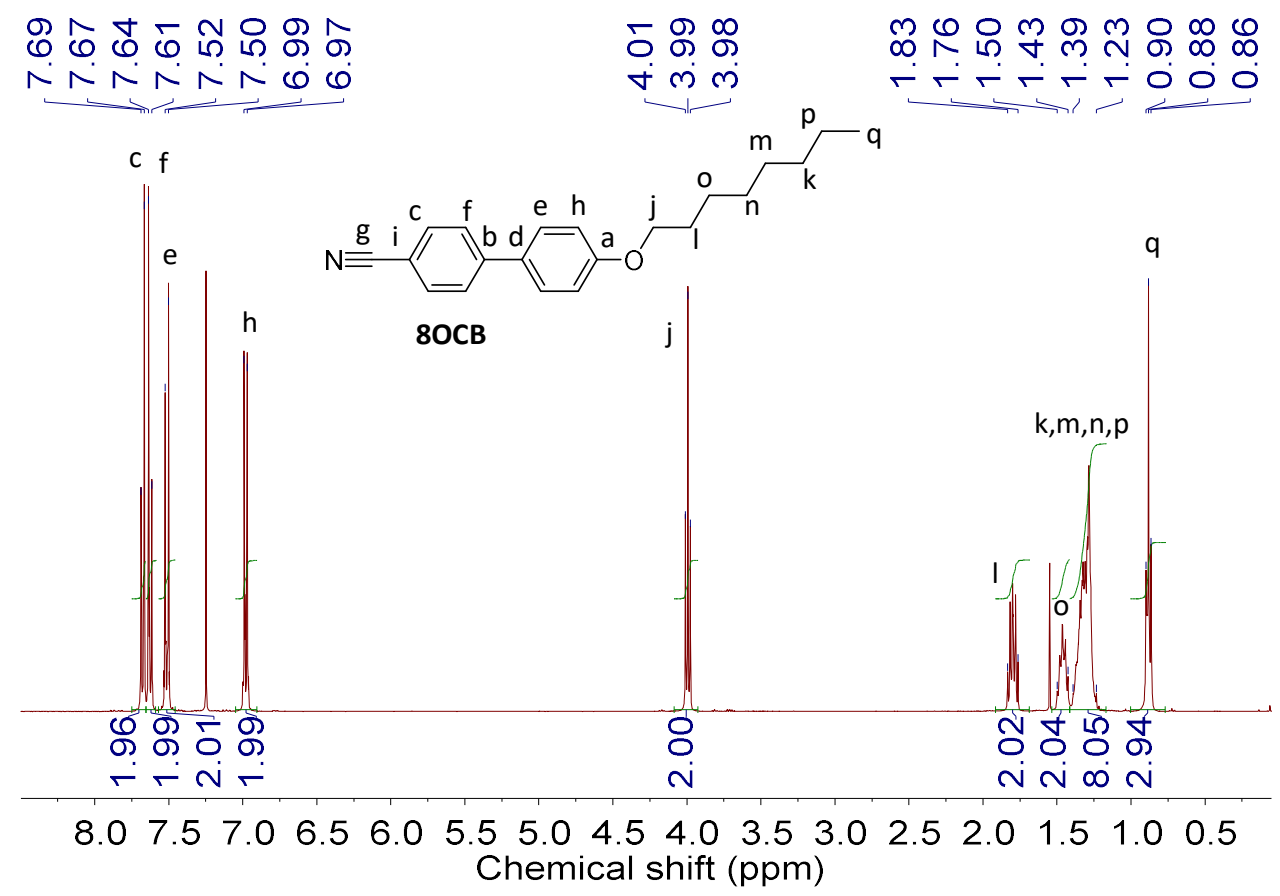

Figure S1.13. ${ }^{1} \mathrm{H}$ NMR spectrum of $8 \mathrm{OCB}$.

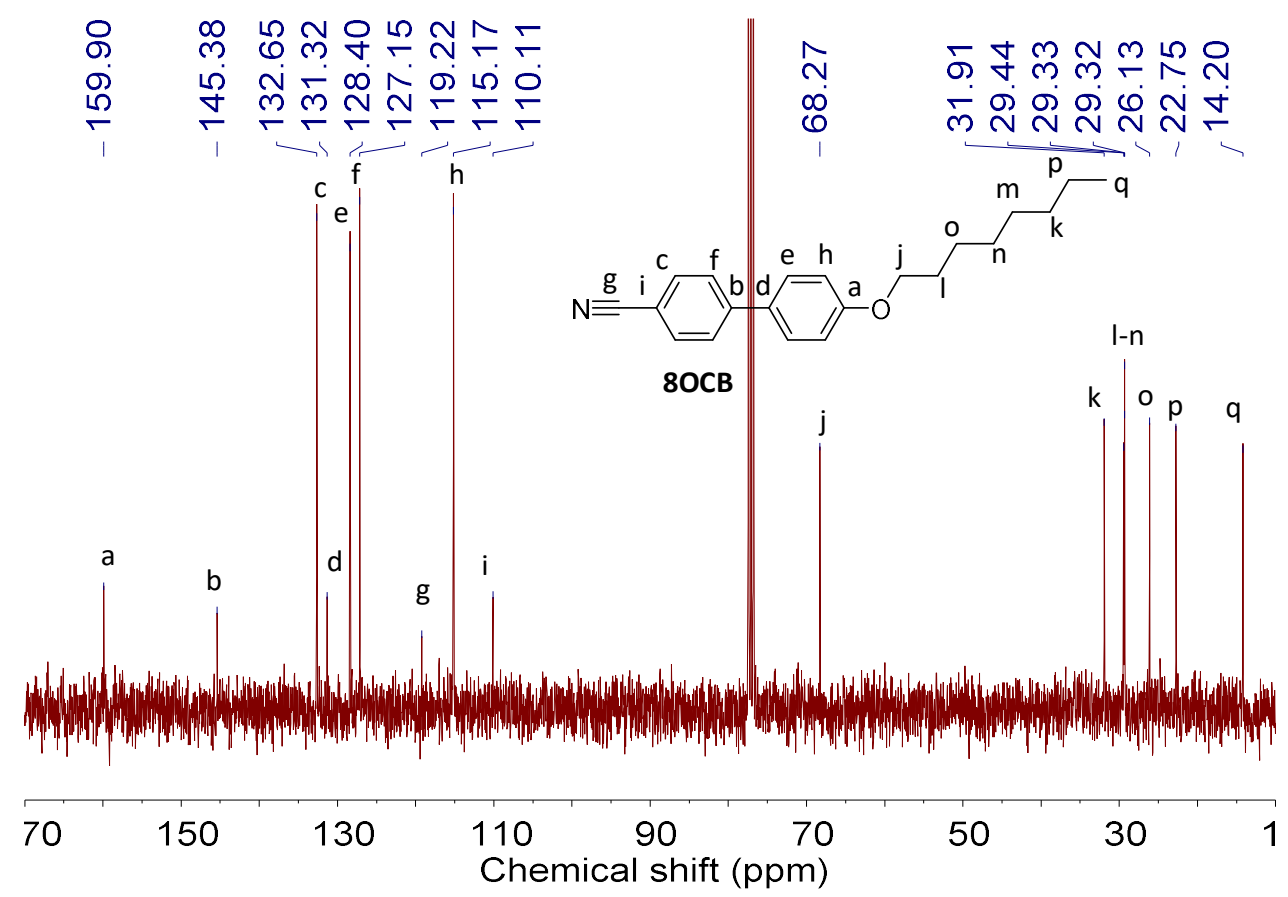

Figure S1.14. ${ }^{13} \mathrm{C}$ NMR spectrum of $8 \mathrm{OCB}$. 


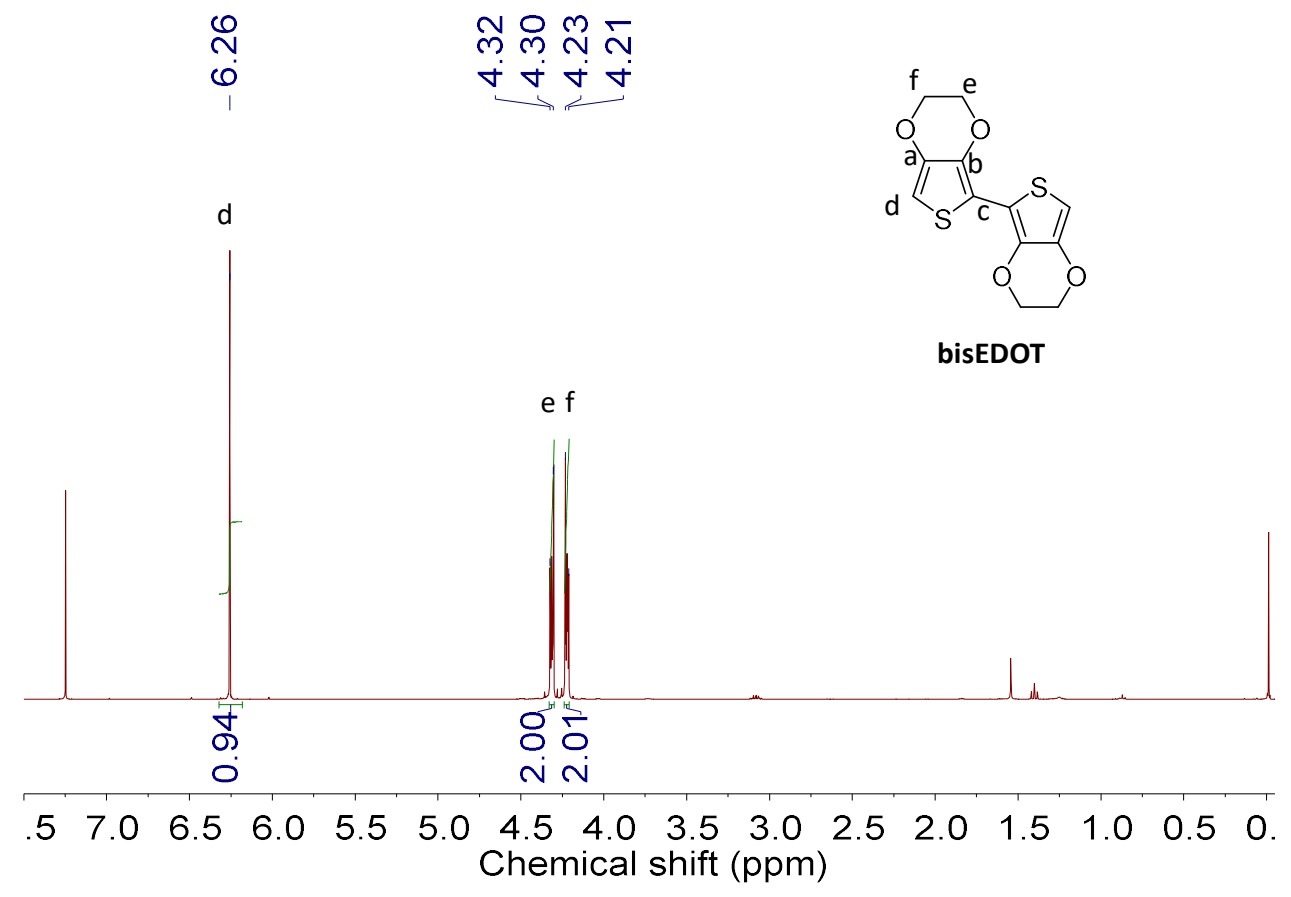

Figure S1.15. ${ }^{1} \mathrm{H}$ NMR spectrum of bisEDOT.

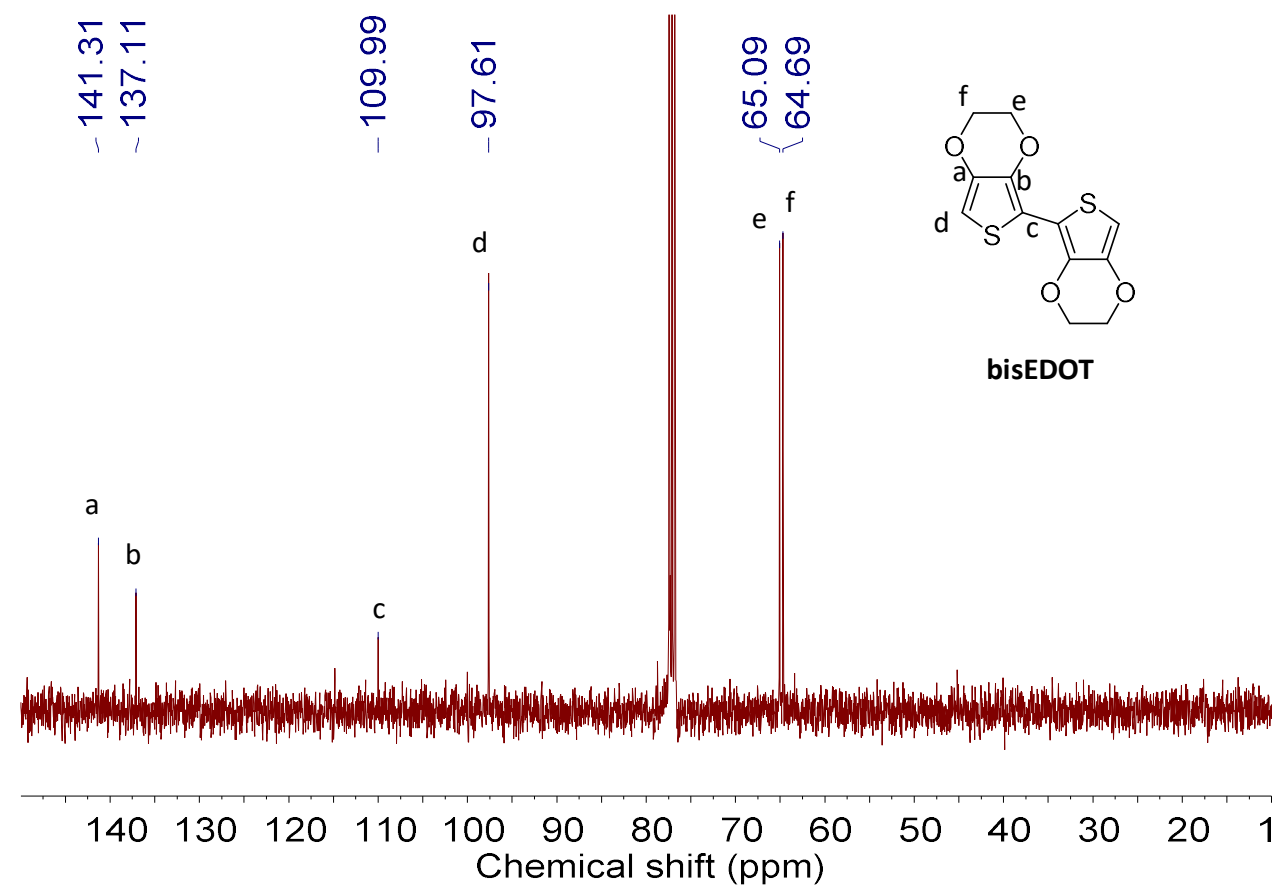

Figure S1.16. ${ }^{13} \mathrm{C}$ NMR spectrum of bisEDOT. 


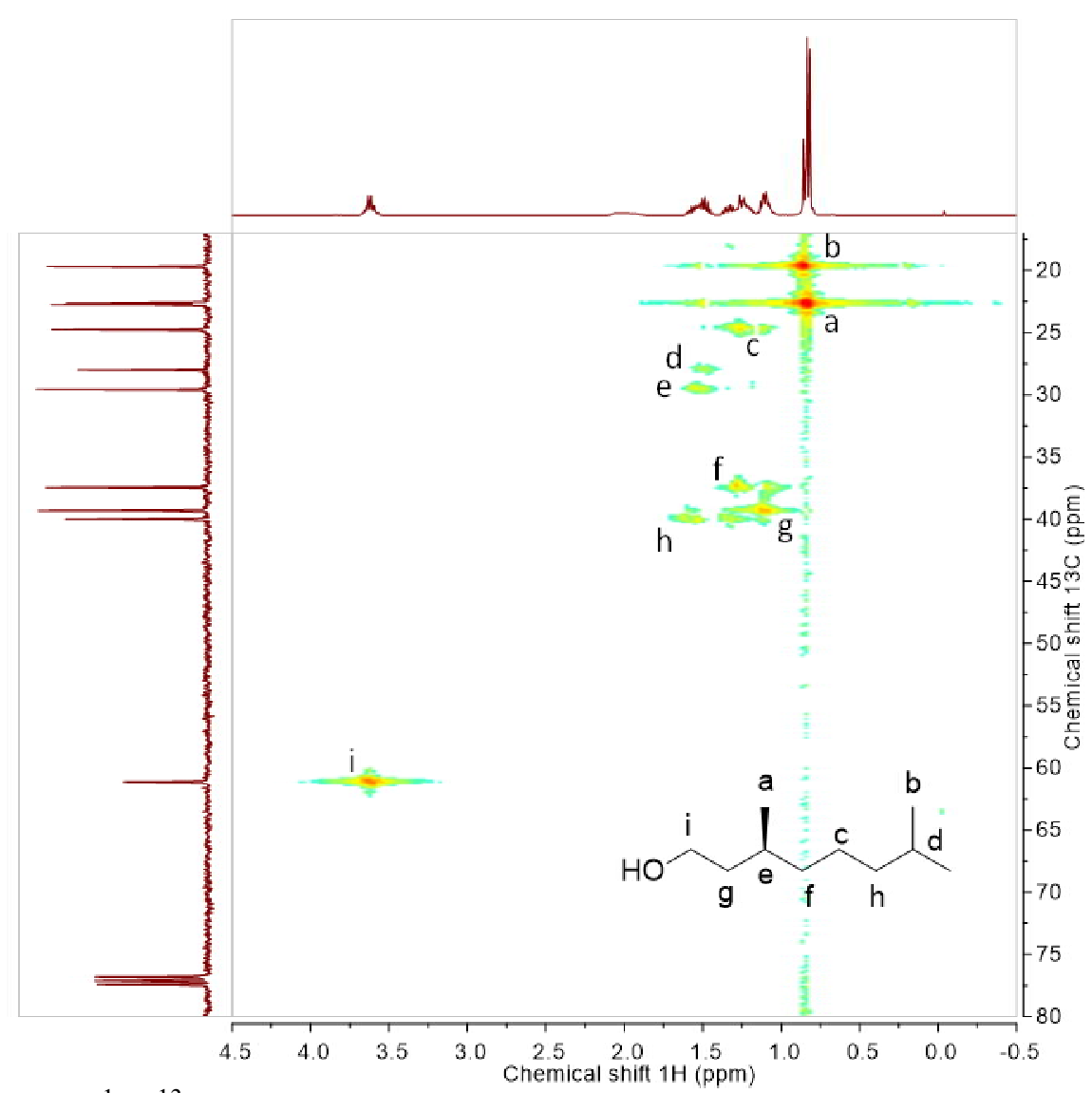

Figure S1.17. ${ }^{1} \mathrm{H}-{ }^{13} \mathrm{C}$ Heteronuclear multiple quantum correlation (HMQC) spectrum of (S)-3,7-dimethyloctan-1-ol. 


\section{S-M7OB}

${ }^{1} \mathrm{H}$ NMR (400 MHz, $\mathrm{CDCl}_{3}, \delta$ from TMS, ppm): 7.56-7.53, 7.42-7.38, 7.30-7.27 $\left(\mathrm{AB}_{2} \mathrm{C}_{2}\right.$ system, 5H; $\left.\mathrm{Ph}-\mathrm{H}\right), 7.51-7.49$, 6.96-6.93 (AA'BB' system, 4H; Ph-H), 4.42-4.35 (sext, $\left.1 \mathrm{H} ; \mathrm{C}^{*}-\mathrm{H}\right), 1.80-1.72,1.62-1.55\left(\mathrm{~m}, 2 \mathrm{H} ; \mathrm{C}^{*}-\mathrm{CH}_{2}\right), 1.51-1.29(\mathrm{~m}, 11 \mathrm{H}$; $\left.-\mathrm{CH}_{2-}, \mathrm{C}^{*}-\mathrm{CH}_{3}\right), 0.89,0.88,0.86\left(\mathrm{t}, 3 \mathrm{H} ;-\mathrm{CH}_{3}\right)$.

${ }^{13} \mathrm{C}$ NMR $\left(400 \mathrm{MHz}, \mathrm{CDCl}_{3}, \delta\right): 157.91,141.00,133.52,128.77,128.23,127.65$, 126.79, 126.65, 116.13 (12C; Ar), 74.07 (1C; C ), 36.62, 31.91, 29.39, 25.67, 22.70, $19.89,14.19\left(7 \mathrm{C} ;-\mathrm{CH}_{2}^{-},-\mathrm{CH}_{3}\right)$.

\section{S-M70CB}

${ }^{1} \mathrm{H}$ NMR (400 MHz, CDCl3, $\delta$ from TMS, ppm): 7.68, 7.66, 7.63, 7.61 (AA'BB' system, 4H; Ph-CN), 7.52, 7.50, 6.98, 6.96 (AA'BB' system, 4H; Ph-O), 4.44-4.37 (sext, $\left.1 \mathrm{H} ; \mathrm{C}^{*}-\mathrm{H}\right), 1.80-1.71,1.63-1.54\left(\mathrm{~m}, 2 \mathrm{H} ; \mathrm{C}^{*}-\mathrm{CH}_{2}\right), 1.49-1.29\left(\mathrm{~m}, 11 \mathrm{H} ;-\mathrm{CH}_{2-}\right.$, $\left.\mathrm{C}^{*}-\mathrm{CH}_{3}\right), 0.89,0.88,0.86\left(\mathrm{t}, 3 \mathrm{H} ;-\mathrm{CH}_{3}\right)$.

${ }^{13} \mathrm{C}$ NMR (400 MHz, $\mathrm{CDCl}_{3}, \delta$ from TMS, ppm): 159.04, 145.38, 132.64, 131.16, 128.46, 127.13, 116.32, 110.07 (12C; Ar), 119.23 (1C; -CN), 74.13 (1C; C*), 36.54, $31.90,29.37,25.62,22.70,19.82,14.19\left(7 \mathrm{C} ;-\mathrm{CH}_{2-},-\mathrm{CH}_{3}\right)$.

\section{S-M7BCE}

${ }^{1} \mathrm{H}$ NMR (400 MHz, $\mathrm{CDCl}_{3}, \delta$ from TMS, ppm): 8.12, 8.10, 7.67, 7.64 (AA'BB' system, 4H; Ph-H), 7.63, 7.61, 7.48, 7.46, 7.45, 7.41, 7.39, 7. $37\left(\mathrm{AB}_{2} \mathrm{C}_{2}\right.$ system, $5 \mathrm{H}$; Ph-H), 5.22-5.14 (sext, $\left.1 \mathrm{H} ; \mathrm{C}^{*}-\mathrm{H}\right), 1.80-1.72,1.67-1.58$ (m, $\left.2 \mathrm{H} ; \mathrm{C}^{*}-\mathrm{CH}_{2}\right), 1.45-1.29$ (m, $\left.11 \mathrm{H} ;-\mathrm{CH}_{2-}, \mathrm{C}^{*}-\mathrm{CH}_{3}\right), 0.90,0.88,0.86\left(\mathrm{t}, 3 \mathrm{H} ;-\mathrm{CH}_{3}\right)$.

${ }^{13} \mathrm{C} \mathrm{NMR}\left(400 \mathrm{MHz}, \mathrm{CDCl}_{3}, \delta\right): 166.21$ (1C; -COO-) 145.52, 140.22, 130.13, 129.78, 129.01, 127.38, 127.08 (12C; Ar), 71.87 (1C; $\left.\mathrm{C}^{*}\right), 36.20,31.86,29.29,25.54,22.71$, $20.22,14.18\left(7 \mathrm{C} ;-\mathrm{CH}_{2}^{-},-\mathrm{CH}_{3}\right)$. 


\section{S-DM80CB}

${ }^{1} \mathrm{H}$ NMR (400 MHz, $\mathrm{CDCl}_{3}, \delta$ from TMS, ppm): 7.69, 7.67, 7.64, 7.62 (AA'BB' system, 4H; Ph-CN), 7.53, 7.51, 7.00, 6.97 (AA'BB' system, 4H; Ph-O), 4.08-3.99 (m, $2 \mathrm{H}$; $\left.-\mathrm{CH}_{2}\right), 1.89-1.81,1.72-1.48$ (m, 4H; O-C-CH, $\left.\mathrm{CH}\right), 1.37-1.13\left(\mathrm{~m}, 6 \mathrm{H}\right.$; $-\mathrm{CH}_{2}-$ ), $0.96,0.94\left(\mathrm{~d}, 3 \mathrm{H} ; \mathrm{C}^{*}-\mathrm{CH}_{3}\right), 0.87,0.86\left(\mathrm{~d}, 6 \mathrm{H} ;-\mathrm{CH}_{3}\right)$.

${ }^{13} \mathrm{C}$ NMR (400 MHz, $\mathrm{CDCl}_{3}, \delta$ from TMS, ppm): 159.88, 145.38, 132.65, 131.33, 128.40, 127.16, 115.18, 110.11 (12C; Ar), $119.23(1 \mathrm{C} ;-\mathrm{CN}), 66.58\left(1 \mathrm{C} ; \mathrm{C}^{*}\right), 39.33$, $37.37,36.22,29.93,28.07,24.76,22.81,22.71,19.75$ (7C; $\left.-\mathrm{CH}(-)-,-\mathrm{CH}_{2-},-\mathrm{CH}_{3}\right)$.

\section{S-DM8BCE}

${ }^{1} \mathrm{H}$ NMR (400 MHz, $\mathrm{CDCl}_{3}$, $\delta$ from TMS, ppm): 8.12, 8.10, 7.67, 7.65 (AA'BB' system, $4 \mathrm{H}$; $\mathrm{Ph}-\mathrm{H}), 7.63,7.61,7.48,7.46,7.44,7.41,7.39,7.37\left(\mathrm{AB}_{2} \mathrm{C}_{2}\right.$ system, $5 \mathrm{H}$; Ph-H), 4.38 (m, 2H; - $\mathrm{CH}_{2}$ ), 1.87-1.79, 1.70-1.49 (m, 4H; O-C-CH $\left.\mathrm{CH}_{2}, \mathrm{CH}\right), 1.49-1.14$ $\left(\mathrm{m}, 6 \mathrm{H} ;-\mathrm{CH}_{2}-\right), 0.98,0.97\left(\mathrm{~d}, 3 \mathrm{H} ; \mathrm{C}^{*}-\mathrm{CH}_{3}\right), 0.88,0.87\left(\mathrm{~d}, 6 \mathrm{H} ;-\mathrm{CH}_{3}\right)$.

${ }^{13} \mathrm{C}$ NMR (400 MHz, $\mathrm{CDCl}_{3}, \delta$ from TMS, ppm): 166.67 (1C; -COO-) 145.62, 140.16, 130.15, 129.37, 129.01, 128.20, 127.37, 127.11 (12C; Ar), 63.71 (1C; C $\left.{ }^{*}\right), 39.31$, $37.27,35.71,30.10,28.07,24.76,22.81,22.72,19.75$ (7C; $\left.-\mathrm{CH}(-)-,-\mathrm{CH}_{2-},-\mathrm{CH}_{3}\right)$.

\section{OCB}

${ }^{1} \mathrm{H}$ NMR (400 MHz, $\mathrm{CDCl}_{3}, \delta$ from TMS, ppm): 7.69, 7.67, 7.64, 7.61 (AA'BB' system, 4H; Ph-CN), 7.52, 7.50, 9.66, 6.97 (AA'BB' system, 4H; Ph-O), 4.01-3.98 (m, $\left.2 \mathrm{H} ;-\mathrm{CH}_{2}\right), 1.83-1.76,1.50-1.43\left(\mathrm{~m}, 2 \mathrm{H} ; \mathrm{O}-\mathrm{C}-\mathrm{CH}_{2}\right), 1.39-1.23\left(\mathrm{~m}, 8 \mathrm{H} ;-\mathrm{CH}_{2}-\right), 0.90$, $0.0 .88,0.86\left(\mathrm{t}, 3 \mathrm{H} ;-\mathrm{CH}_{3}\right)$.

${ }^{13} \mathrm{C}$ NMR (400 MHz, $\mathrm{CDCl}_{3}, \delta$ from TMS, ppm): 159.90, 145.38, 132.65, 131.32, 128.40, 127.15, 115.17, 110.11 (12C; Ar), 119.22 (1C; -CN), 68.27 (1C; -O-C), 31.91, 29.44, 29.33, 29.92, 26.13, 22.75, $14.20\left(7 \mathrm{C} ;-\mathrm{CH}_{2-}^{-},-\mathrm{CH}_{3}\right)$. 


\section{BisEDOT}

${ }^{1} \mathrm{H}$ NMR (400 MHz, $\mathrm{CDCl}_{3}, \delta$ from TMS, ppm): 6.26 (s, 2H; H-Th), 4.32-4.30, 4.23-4.21 ( $\mathrm{A}_{2} \mathrm{~B}_{2}$ system, $\left.8 \mathrm{H} ;-\mathrm{CH}_{2}-\right)$.

${ }^{13} \mathrm{C}$ NMR (400 MHz, CDCl3, $\left.\delta\right): 141.31,137.11,109.99,97.61$ (8C; Ar), 65.09, 64.69 $\left(4 \mathrm{C} ;-\mathrm{CH}_{2}-\right)$.

\section{(S)-3,7-dimethyloctan-1-ol}

${ }^{1} \mathrm{H}$ NMR (400 MHz, $\mathrm{CDCl}_{3}, \delta$ from TMS, ppm): 3.69-3.59 (m, 2H; O-CH $), 1.71$ (s, $1 \mathrm{H},-\mathrm{OH}), 1.61-1.44$ (m, 3H; O-C- $\left.\mathrm{CH}_{2}-\mathrm{C}^{*} \mathrm{H}\right), 1.38-1.18$ (m, $\left.4 \mathrm{H} ; \mathrm{C}^{*}-\mathrm{CH}_{2}-\mathrm{CH}_{2}-\mathrm{C}\right)$,

1.16-1.05 (m, 3H; C-CH $\left.2-\mathrm{CHMe}_{2}\right), 0.86\left(\mathrm{~d}, \mathrm{~J}=6.5 \mathrm{~Hz}, 3 \mathrm{H} ; \mathrm{C}^{*}-\mathrm{CH}_{3}\right), 0.83(\mathrm{~d}, \mathrm{~J}=6.6$ $\left.\mathrm{Hz}, 6 \mathrm{H} ; \mathrm{C}\left(\mathrm{CH}_{3}\right)_{2}\right)$.

${ }^{13} \mathrm{C}$ NMR (400 MHz, $\mathrm{CDCl}_{3}, \delta$ from TMS, ppm): 61.23 (1C; O-C), 40.03 (1C;

$\mathrm{Me}_{2} \mathrm{CH}-\mathrm{C}$ ), 39.32 (1C; O-CH $\mathrm{CH}_{2} \mathrm{C}$ ), 37.44 (1C; O-C $\left.\mathrm{H}_{4}-\mathrm{C}^{*} \mathrm{HMe}-\mathrm{C}\right), 29.57$ (1C; $\mathrm{C}^{*}$ ), $28.03\left(1 \mathrm{C}, \mathrm{Me}_{2} \mathrm{C}\right), 24.75\left(\mathrm{Me}_{2} \mathrm{CHCH}_{2}-\mathrm{C}\right), 22.66-22.76$ (2C; $\left.\mathrm{Me}\right), 19.70$ (1C:

$\left.\mathrm{Me}\left(-\mathrm{C}^{*}\right)\right)$. 
2. Setting for optical measurements of UV-vis and circular dichroism (CD) optical absorption spectra

UV-vis and CD spectra measurements of inducers were set as followed:

Solvent: hexane

Concentration: $3 \times 10^{-5} \mathrm{M}$

Cuvette: quartz, $1 \mathrm{~cm}$

Machine: JASCO V-630 for UV-vis, JASCO J-720 for CD

CD spectra measurements of inducers were set as followed:

Sensitivity: Low (1000 mdeg)

Scanning speed: $100 \mathrm{~nm} / \mathrm{min}$

Response: $4 \mathrm{~s}$

Cumulative number: 5 


\section{Setting for electrochemical polymerization}

All the polymerization was processed between two Indium-Tin Oxide (ITO) glass (10 $\Omega / \mathrm{cm}^{2}$, act as two electrode) in $0.20 \mathrm{~mm}$ thickness. A detected $3.0 \mathrm{~V}$ direct current $(\mathrm{dc})$ was processed on two ITO for $5 \mathrm{~min}$.

Constituents of the LC electrolyte solution.

Matrix liquid crystal: $80 \mathrm{OB}$

Supporting salt: tetrabutylammonium perchlorate (TBAP), ca. $0.5 \mathrm{wt} \%$

Inducer: S-M7OB/S-M7OCB/S-M7BCE/S-DM8OCB/S-DM8BCE, ca. 5 wt\%

Monomer: BisEDOT, ca. $5 \mathrm{wt} \%$

Temperature: cholesteric phase [c], ca. $65{ }^{\circ} \mathrm{C}$

Table S3.2 displays details.

Differential scanning calorimetry (DSC) measurement and polarizing optical microscopy (POM) image of $8 \mathrm{OCB}$ and the LC electrolyte solution (using S-DM8OCB) are shown as follow.

Table S3.1 Phase transition temperatures obtained with DSC measurements.

\begin{tabular}{cccc}
\hline Sample and process & Solid-Smectic & Smectic-Nematic & Nematic-Isotropic \\
\hline 8COB, heating & $47.01{ }^{\circ} \mathrm{C}$ & $66.16{ }^{\circ} \mathrm{C}$ & $79.99{ }^{\circ} \mathrm{C}$ \\
8COB, cooling & $19.93{ }^{\circ} \mathrm{C}$ & $67.84{ }^{\circ} \mathrm{C}$ & $80.43{ }^{\circ} \mathrm{C}$ \\
LC electrolyte*, heating & $38.26{ }^{\circ} \mathrm{C}$ & $58.05{ }^{\circ} \mathrm{C}$ & $68.94{ }^{\circ} \mathrm{C}$ \\
LC electrolyte*, cooling & $9.86{ }^{\circ} \mathrm{C}$ & $52.92^{\circ} \mathrm{C}$ & $69.43{ }^{\circ} \mathrm{C}$ \\
\hline
\end{tabular}

* LC electrolyte solution containing monomer. S-DM8OCB was used for chiral inducer. 


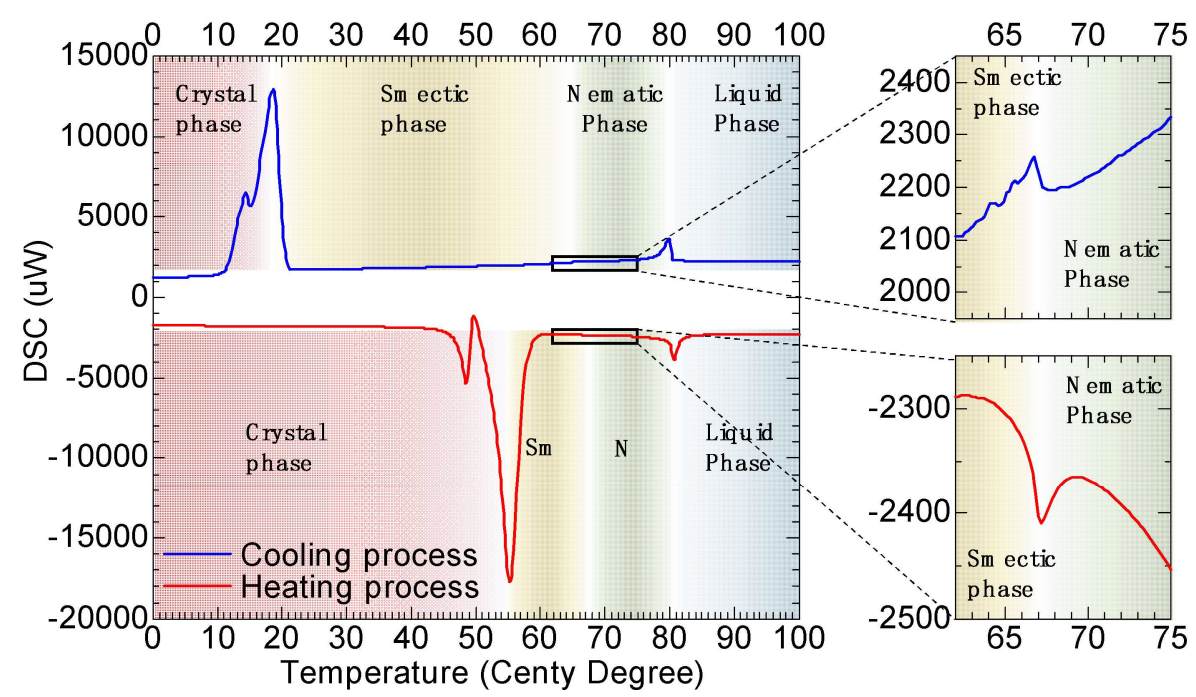

Figure S3.1. DSC result of 8OCB.

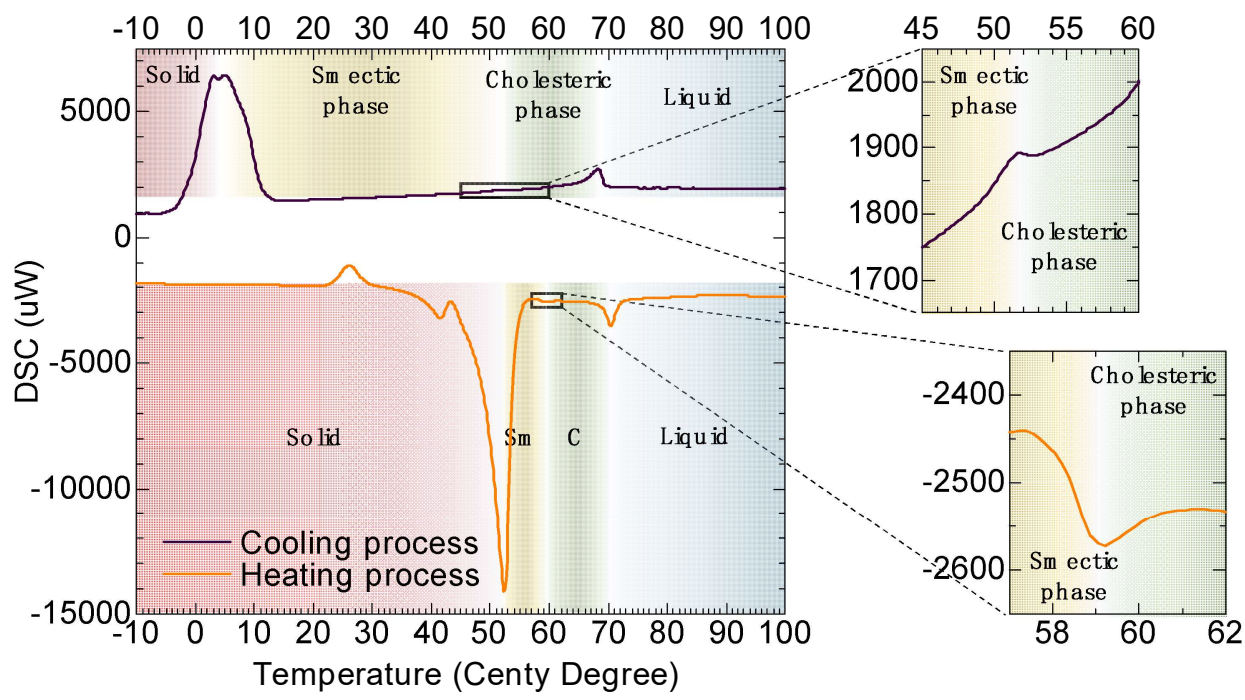

Figure S3.2. DSC result of LC electrolyte solution (using S-DM8OCB). 


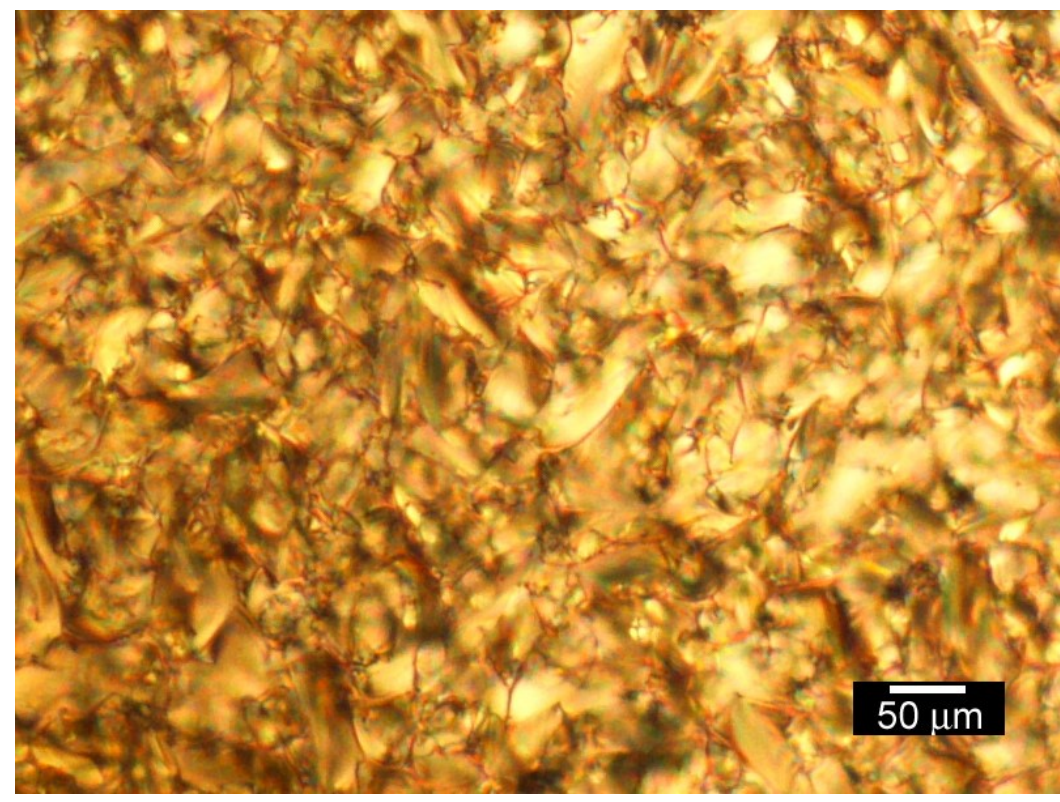

Figure S3.3. POM image of LC electrolyte solution containing monomer, S-DM8OCB in smectic phase.

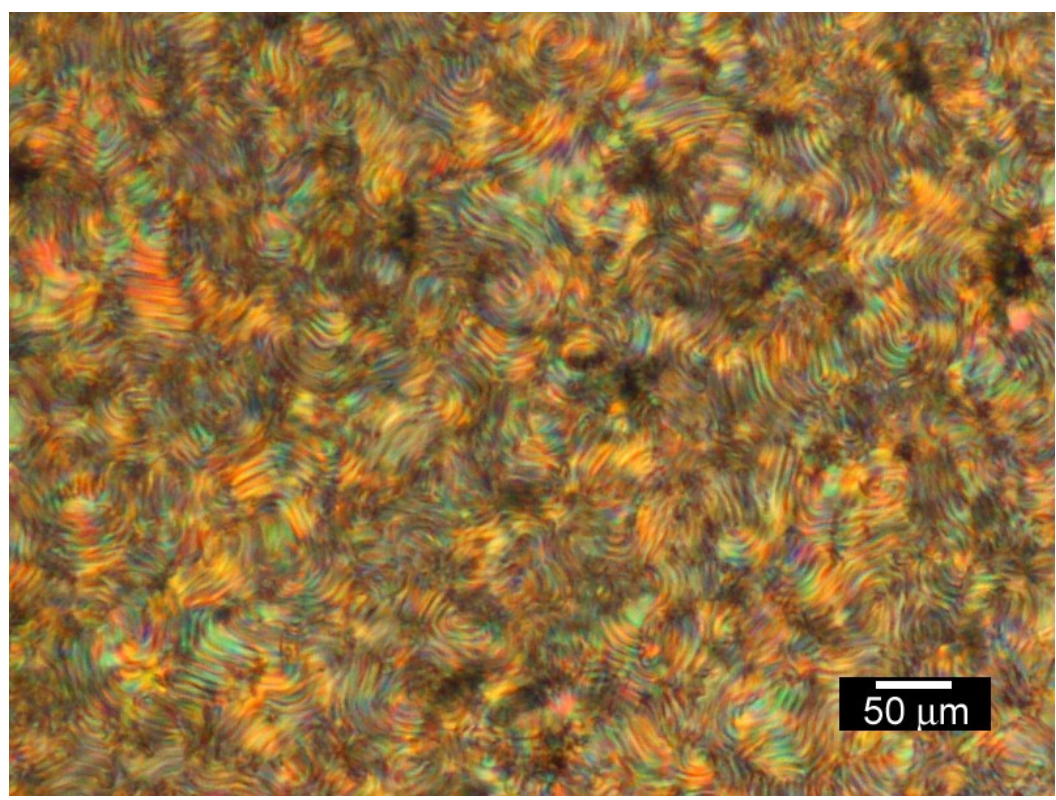

Figure S3.4. POM image of LC electrolyte containing monomer, S-DM8OCB in cholesteric phase 
Table S3.2. Components of liquid crystal electrolyte solutions ${ }^{1}$.

\begin{tabular}{lcccc}
\hline LC electrolyte solution $^{2}$ & Chiral inducer $(\mathrm{mg})$ & $\begin{array}{c}\text { BisEDOT } \\
(\mathrm{mg})\end{array}$ & $\begin{array}{c}\text { TBAP } \\
(\mathrm{mg})\end{array}$ & $\begin{array}{c}8 \mathrm{OCB} \\
(\mathrm{mg})\end{array}$ \\
\hline S-M7OB- based LC & $\begin{array}{c}5.1 \\
(5.96 \mathrm{wt} \%, 6.42 \mathrm{~mol} \%)\end{array}$ & 5.0 & 0.5 & 75.0 \\
S-M7OCB- based LC & $\begin{array}{c}8.3 \\
(4.75 \mathrm{wt} \%, 4.73 \%)\end{array}$ & 8.1 & 0.8 & 157.6 \\
S-M7BC- based LC & $\begin{array}{c}5.0 \\
(5.89 \mathrm{wt} \%, 5.81 \mathrm{~mol} \%)\end{array}$ & 5.0 & 0.5 & 75.0 \\
S-DM8OCB- based LC & $\begin{array}{c}5.5 \mathrm{~g} \\
(4.94 \mathrm{wt} \%, 4.53 \mathrm{~mol} \%)\end{array}$ & 5.3 & 0.5 & 100.0 \\
S-DM8BCE- based LC & $\begin{array}{c}10.1 \\
(4.94 \mathrm{wt} \%, 4.49 \mathrm{~mol} \%)\end{array}$ & 10.0 & 1.0 & 183.0 \\
\hline
\end{tabular}

${ }^{1}$ Chiral inducer: S-M7OB, S-M7OCB, S-M7BCE, S-DM8OCB and S-DM8BCE.

${ }^{2}$ Chiral inducer based LC electrolyte solution containing monomer.

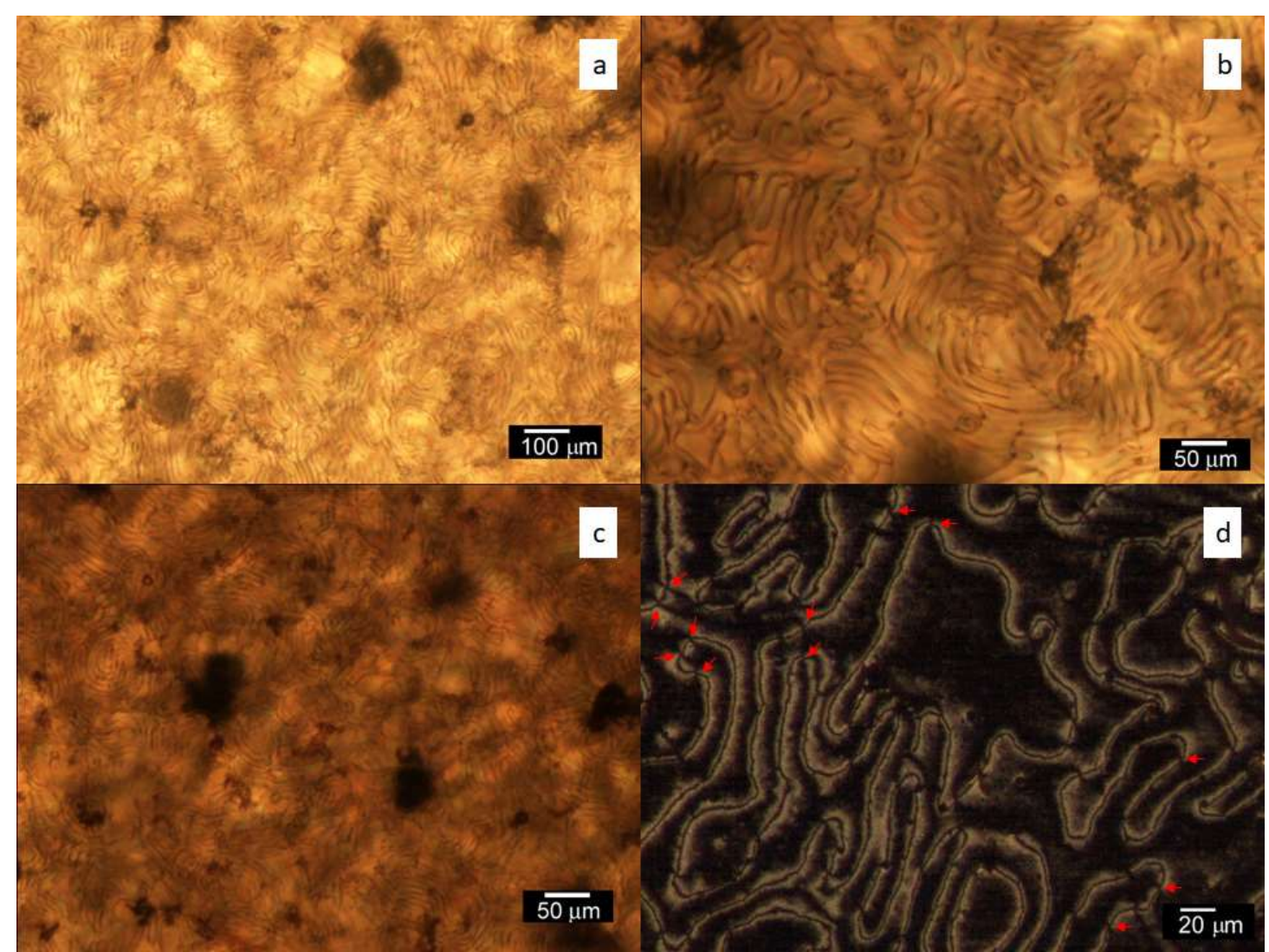

Figure S3.5 POM image of a: LC electrolyte solution containing monomer, S-M7OB; b: Magnification image of LC electrolyte solution containing monomer, S-M7OB); c: LC electrolyte solution containing monomer, S-M7OB at the half-time of the polymerization process; d: Magnification image of polymer film comparing to Figure 4 left top. Red arrows: center of Schlieren brush. 


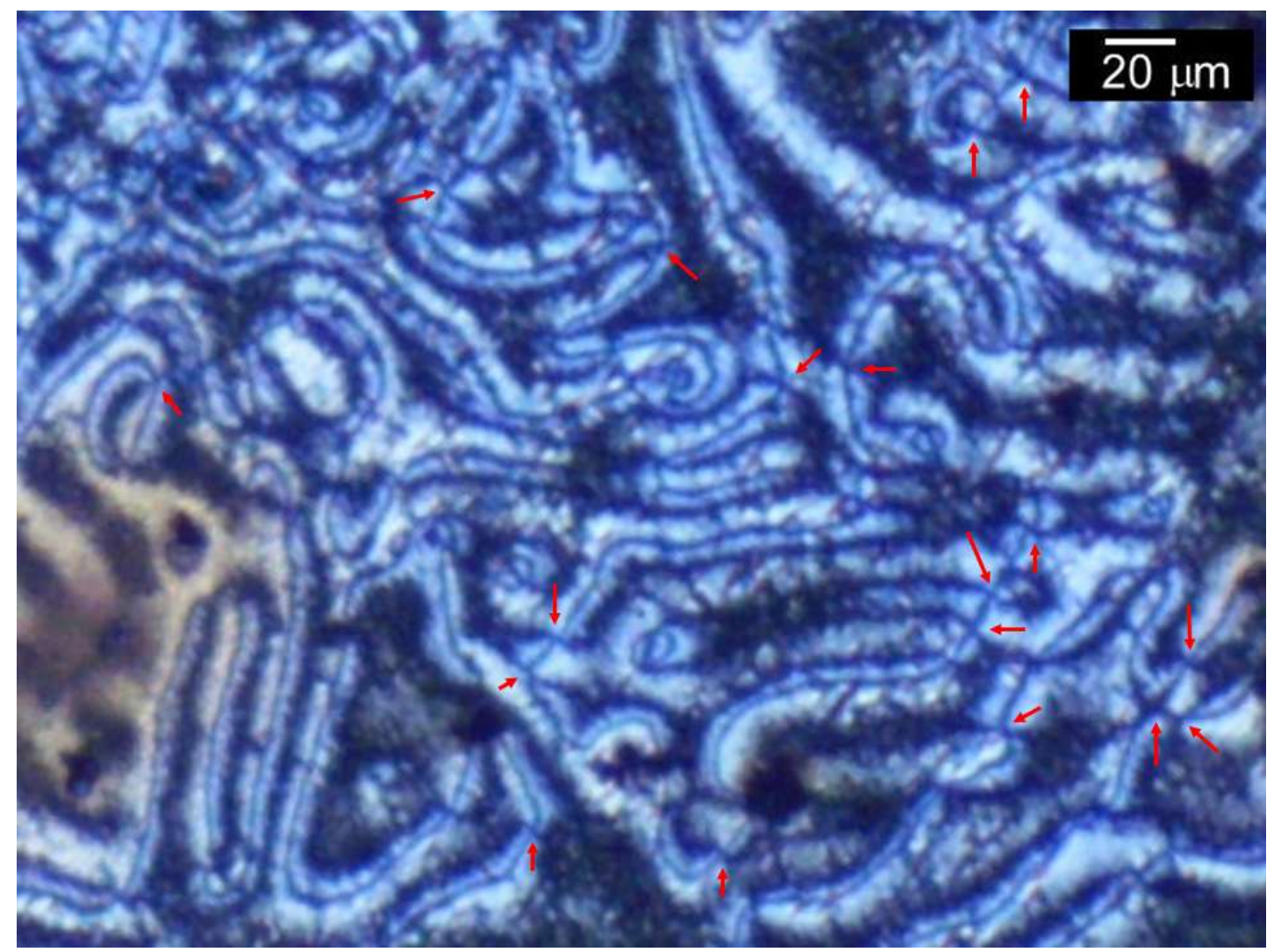

Figure S3.6 Magnification image of Figure 4 right top (polyEDOT film using S-M7OCB). Red arrows: center of Schlieren brush. 
4. Models used in time-dependent self-consistent field density functional theory (TD-SCF-DFT) calculation

These models are optimized to minimum energy by TD-SCF-DFT calculation using the soft or parameters as followed.

Operation system:

Windows 10 professional 64-bit (DirectX 12)

Soft:

Gaussian 09 revision D.01 WIN64 Version 9.5

Hard hardware:

CPU: Intel Core i5-2500K 3.30GHz, RAM: 16 G ADATA DDR3 1600 MHz, SSD: 480 GB CT480BX200SSD1

Keywords example in Gaussian 09:

$\%$ nprocshared $=4$

$\%$ mem $=15000 \mathrm{MB}$

$\%$ chk $=\mathrm{C}: \backslash$

$\#$ opt td $=($ nstates $=24)$ b3lyp $/ 6-311++g(d, p)$ scrf $=($ solvent $=$ heptane $)$

geom $=$ connectivity 
Atomic axis of each model whose energy was minimized:

S-M7OB (conformation 1):

Job cpu time: 3 days 23 hours 24 minutes 4.0 seconds.

Total energy: -853.1119 a. u. (Lower)

Dipole moment: 5.3363 Debye $(4.8371,2.2033,-0.4739)$

\begin{tabular}{|c|c|c|c|}
\hline $\mathrm{C}$ & -2.7494 & -2.39084 & 0.36541 \\
\hline $\mathrm{C}$ & -3.81929 & -1.31867 & 0.55069 \\
\hline $\mathrm{H}$ & -2.84486 & -2.85968 & -0.61683 \\
\hline $\mathrm{H}$ & -4.78282 & -1.83044 & 0.6612 \\
\hline $\mathrm{H}$ & -3.63383 & -0.79814 & 1.49835 \\
\hline $\mathrm{C}$ & -3.90889 & -0.30623 & -0.59628 \\
\hline $\mathrm{H}$ & -4.11413 & -0.84044 & -1.53277 \\
\hline $\mathrm{H}$ & -2.9366 & 0.18081 & -0.72603 \\
\hline $\mathrm{C}$ & -4.98811 & 0.75886 & -0.37287 \\
\hline $\mathrm{H}$ & -4.77374 & 1.30015 & 0.55793 \\
\hline $\mathrm{H}$ & -5.95821 & 0.26728 & -0.22147 \\
\hline $\mathrm{C}$ & -5.10807 & 1.76361 & -1.5244 \\
\hline $\mathrm{H}$ & -5.33054 & 1.22379 & -2.45412 \\
\hline $\mathrm{H}$ & -4.13754 & 2.25189 & -1.68216 \\
\hline $\mathrm{C}$ & -6.17986 & 2.83515 & -1.29583 \\
\hline $\mathrm{H}$ & -5.95456 & 3.37841 & -0.36988 \\
\hline $\mathrm{H}$ & -7.14861 & 2.34687 & -1.13353 \\
\hline $\mathrm{C}$ & -6.299 & 3.83038 & -2.45405 \\
\hline $\mathrm{H}$ & -6.55909 & 3.32122 & -3.38761 \\
\hline $\mathrm{H}$ & -7.07046 & 4.58084 & -2.25937 \\
\hline $\mathrm{H}$ & -5.35494 & 4.35951 & -2.61921 \\
\hline $\mathrm{C}$ & -2.78034 & -3.46406 & 1.44979 \\
\hline $\mathrm{H}$ & -1.98441 & -4.19415 & 1.2937 \\
\hline $\mathrm{H}$ & -2.65957 & -3.01505 & 2.43979 \\
\hline $\mathrm{H}$ & -3.73722 & -3.99305 & 1.42453 \\
\hline $\mathrm{O}$ & -1.48568 & -1.72243 & 0.3993 \\
\hline $\mathrm{C}$ & -0.53584 & -2.45766 & -0.37668 \\
\hline $\mathrm{C}$ & 0.81943 & -2.04762 & -0.53901 \\
\hline $\mathrm{C}$ & -0.95939 & -3.6606 & -1.01304 \\
\hline $\mathrm{C}$ & 1.69425 & -2.78976 & -1.28986 \\
\hline $\mathrm{H}$ & 1.15373 & -1.13844 & -0.05814 \\
\hline $\mathrm{C}$ & -0.09027 & -4.40811 & -1.76268 \\
\hline $\mathrm{H}$ & -1.98936 & -3.96961 & -0.8886 \\
\hline $\mathrm{C}$ & 1.29006 & -4.01479 & -1.94531 \\
\hline $\mathrm{H}$ & 2.71325 & -2.43987 & -1.38152 \\
\hline $\mathrm{H}$ & -0.46044 & -5.3115 & -2.22728 \\
\hline $\mathrm{C}$ & 2.19865 & -4.78864 & -2.72458 \\
\hline $\mathrm{C}$ & 1.80274 & -6.02745 & -3.35799 \\
\hline $\mathrm{C}$ & 3.5721 & -4.3823 & -2.92842 \\
\hline $\mathrm{C}$ & 2.68912 & -6.76764 & -4.10658 \\
\hline $\mathrm{H}$ & 0.79107 & -6.38958 & -3.24333 \\
\hline $\mathrm{C}$ & 4.44119 & -5.13791 & -3.68205 \\
\hline
\end{tabular}




$\begin{array}{llll}\mathrm{H} & 3.93174 & -3.46451 & -2.48575 \\ \mathrm{C} & 4.01885 & -6.33921 & -4.28243 \\ \mathrm{H} & 2.35887 & -7.69232 & -4.56601 \\ \mathrm{H} & 5.46357 & -4.80288 & -3.81541 \\ \mathrm{H} & 4.70988 & -6.92792 & -4.87414\end{array}$

S-M7OB (conformation 2):

Job cpu time: 2 days 11 hours 6 minutes 8.0 seconds.

Total energy: -853.1108 a. u. (Higher)

Dipole moment: 5.5616 Debye (5.4886, 0.2912, 0.8496)

$\begin{array}{lccc}\mathrm{C} & 1.78193 & 2.09723 & -0.16743 \\ \mathrm{C} & 3.24954 & 1.77489 & 0.10415 \\ \mathrm{H} & 1.30392 & 1.22685 & -0.62969 \\ \mathrm{H} & 3.75693 & 2.71782 & 0.33825 \\ \mathrm{H} & 3.30548 & 1.15545 & 1.00684 \\ \mathrm{C} & 3.96237 & 1.07995 & -1.06031 \\ \mathrm{H} & 3.90548 & 1.71964 & -1.95057 \\ \mathrm{H} & 3.43005 & 0.1559 & -1.30898 \\ \mathrm{C} & 5.43139 & 0.75755 & -0.76334 \\ \mathrm{H} & 5.48786 & 0.11094 & 0.12178 \\ \mathrm{H} & 5.96226 & 1.68182 & -0.50007 \\ \mathrm{C} & 6.15145 & 0.0775 & -1.93285 \\ \mathrm{H} & 6.09881 & 0.72671 & -2.81664 \\ \mathrm{H} & 5.61682 & -0.84317 & -2.20024 \\ \mathrm{C} & 7.61864 & -0.25849 & -1.64193 \\ \mathrm{H} & 7.67148 & -0.91129 & -0.76209 \\ \mathrm{H} & 8.1526 & 0.66067 & -1.37121 \\ \mathrm{C} & 8.32881 & -0.93221 & -2.81972 \\ \mathrm{H} & 8.3231 & -0.28846 & -3.7051 \\ \mathrm{H} & 9.37157 & -1.15924 & -2.58085 \\ \mathrm{H} & 7.83786 & -1.872 & -3.09174 \\ \mathrm{C} & 1.58969 & 3.33514 & -1.03997 \\ \mathrm{H} & 0.53203 & 3.57474 & -1.16596 \\ \mathrm{H} & 2.08766 & 4.19815 & -0.59101 \\ \mathrm{H} & 2.02107 & 3.16175 & -2.02942 \\ \mathrm{O} & 1.16962 & 2.31466 & 1.13126 \\ \mathrm{C} & -0.15418 & 2.14476 & 1.33444 \\ \mathrm{C} & -0.60581 & 2.44798 & 2.64977 \\ \mathrm{C} & -1.08862 & 1.70088 & 0.3734 \\ \mathrm{C} & -1.92034 & 2.29299 & 2.99439 \\ \mathrm{H} & 0.12289 & 2.8026 & 3.36913 \\ \mathrm{C} & -2.41589 & 1.54314 & 0.71011 \\ \mathrm{H} & -0.77779 & 1.48245 & -0.63962 \\ \mathrm{C} & -2.90902 & 1.81449 & 2.05211 \\ \mathrm{H} & -2.21681 & 2.53474 & 4.00542 \\ \mathrm{H} & -3.10044 & 1.2119 & -0.05707 \\ \mathrm{C} & -4.27039 & 1.62083 & 2.408 \\ \mathrm{C} & -5.24376 & 1.12636 & 1.44951 \\ \mathrm{C} & & & \\ & -47148 & 1.90677 & 3.73367\end{array}$




$\begin{array}{llll}\mathrm{C} & -6.56504 & 0.94851 & 1.80183 \\ \mathrm{H} & -4.93837 & 0.88342 & 0.44116 \\ \mathrm{C} & -6.09562 & 1.72219 & 4.05899 \\ \mathrm{H} & -4.09972 & 2.27709 & 4.497 \\ \mathrm{C} & -7.01908 & 1.24027 & 3.10149 \\ \mathrm{H} & -7.26602 & 0.57582 & 1.06205 \\ \mathrm{H} & -6.43448 & 1.94923 & 5.06409 \\ \mathrm{H} & -8.06039 & 1.09807 & 3.36556\end{array}$

S-M7OCB (conformation 0, Checkpoint file before error): Error termination in NtrErr: NtrErr Called from FileIO

Total energy: -945.3955 a. u. (Lower)

Dipole moment: 9.1866 Debye $(8.6454,3.0848,-0.3678)$

$\begin{array}{llcr}\mathrm{C} & 1.78193 & 2.09723 & -0.16743 \\ \mathrm{C} & 3.24954 & 1.77489 & 0.10415 \\ \mathrm{H} & 1.53484 & 1.8034 & -1.19327 \\ \mathrm{H} & 3.85542 & 2.48531 & -0.46993 \\ \mathrm{H} & 3.45551 & 1.97011 & 1.16299 \\ \mathrm{C} & 3.65186 & 0.34181 & -0.25842 \\ \mathrm{H} & 3.44892 & 0.16938 & -1.32336 \\ \mathrm{H} & 3.01981 & -0.36091 & 0.29455 \\ \mathrm{C} & 5.12623 & 0.03691 & 0.03039 \\ \mathrm{H} & 5.32722 & 0.20107 & 1.09687 \\ \mathrm{H} & 5.75998 & 0.75028 & -0.51264 \\ \mathrm{C} & 5.5355 & -1.39092 & -0.34715 \\ \mathrm{H} & 5.3387 & -1.55313 & -1.41499 \\ \mathrm{H} & 4.89743 & -2.10395 & 0.19083 \\ \mathrm{C} & 7.00592 & -1.70902 & -0.05245 \\ \mathrm{H} & 7.20184 & -1.55208 & 1.01529 \\ \mathrm{H} & 7.64393 & -0.99456 & -0.58699 \\ \mathrm{C} & 7.40419 & -3.13633 & -0.43921 \\ \mathrm{H} & 7.25245 & -3.31271 & -1.50889 \\ \mathrm{H} & 8.45683 & -3.33187 & -0.21638 \\ \mathrm{H} & 6.80649 & -3.87439 & 0.10507 \\ \mathrm{C} & 1.43647 & 3.56641 & 0.06252 \\ \mathrm{H} & 0.37037 & 3.75322 & -0.08053 \\ \mathrm{H} & 1.70581 & 3.86612 & 1.07836 \\ \mathrm{H} & 1.99066 & 4.19211 & -0.64215 \\ \mathrm{O} & 1.0116 & 1.26602 & 0.74057 \\ \mathrm{C} & -0.26578 & 0.91599 & 0.47905 \\ \mathrm{C} & -0.89813 & 0.14208 & 1.49257 \\ \mathrm{C} & -0.99246 & 1.24643 & -0.68565 \\ \mathrm{C} & -2.1836 & -0.29955 & 1.33994 \\ \mathrm{H} & -0.33011 & -0.08801 & 2.38624 \\ \mathrm{C} & -2.28901 & 0.80781 & -0.84831 \\ \mathrm{H} & -0.54451 & 1.85042 & -1.46353 \\ \mathrm{C} & -2.95819 & -0.01 & 0.15229 \\ \mathrm{H} & -2.62198 & -0.88515 & 2.13583 \\ \mathrm{H} & -2.81383 & 1.09145 & -1.74886\end{array}$




$\begin{array}{lllc}\mathrm{C} & -4.28279 & -0.48938 & -0.02965 \\ \mathrm{C} & -5.03765 & -0.19806 & -1.23628 \\ \mathrm{C} & -4.96097 & -1.28586 & 0.96832 \\ \mathrm{C} & -6.32594 & -0.6614 & -1.40107 \\ \mathrm{H} & -4.5906 & 0.38537 & -2.02927 \\ \mathrm{C} & -6.24801 & -1.73446 & 0.77979 \\ \mathrm{H} & -4.45599 & -1.54073 & 1.89088 \\ \mathrm{C} & -6.9568 & -1.43197 & -0.40679 \\ \mathrm{H} & -6.8613 & -0.42712 & -2.31543 \\ \mathrm{H} & -6.72421 & -2.32862 & 1.55232 \\ \mathrm{C} & -8.39718 & -1.93891 & -0.60656 \\ \mathrm{~N} & -9.48215 & -2.32075 & -0.75704\end{array}$

S-M7OCB (conformation 2):

Job cpu time: 3 days 1 hours 14 minutes 22.0 seconds

Total energy: -945.3944 a. u. (Higher)

Dipole moment: 16.5913 Debye $(-16.4446,1.4262,1.6773)$

$\begin{array}{llcc}\mathrm{C} & -2.44798 & 0.2939 & 0.7393 \\ \mathrm{C} & -3.7271 & 0.6955 & 0.00676 \\ \mathrm{H} & -2.18967 & -0.73523 & 0.47205 \\ \mathrm{H} & -3.9607 & 1.73654 & 0.25562 \\ \mathrm{H} & -3.5206 & 0.66526 & -1.06809 \\ \mathrm{C} & -4.92869 & -0.20477 & 0.31988 \\ \mathrm{H} & -5.18196 & -0.13931 & 1.38386 \\ \mathrm{H} & -4.66076 & -1.25188 & 0.12916 \\ \mathrm{C} & -6.16706 & 0.15709 & -0.50983 \\ \mathrm{H} & -5.92012 & 0.08797 & -1.5766 \\ \mathrm{H} & -6.43183 & 1.20591 & -0.32493 \\ \mathrm{C} & -7.37938 & -0.73159 & -0.21179 \\ \mathrm{H} & -7.62655 & -0.66285 & 0.85562 \\ \mathrm{H} & -7.11341 & -1.78071 & -0.39575 \\ \mathrm{C} & -8.61908 & -0.37449 & -1.03995 \\ \mathrm{H} & -8.37148 & -0.44112 & -2.10627 \\ \mathrm{H} & -8.88662 & 0.6729 & -0.85467 \\ \mathrm{C} & -9.82473 & -1.26965 & -0.73943 \\ \mathrm{H} & -10.11853 & -1.19743 & 0.31258 \\ \mathrm{H} & -10.69055 & -0.98971 & -1.34578 \\ \mathrm{H} & -9.59886 & -2.32022 & -0.94813 \\ \mathrm{C} & -2.5124 & 0.45534 & 2.25507 \\ \mathrm{H} & -1.54978 & 0.23526 & 2.7207 \\ \mathrm{H} & -2.79779 & 1.47744 & 2.51583 \\ \mathrm{H} & -3.25339 & -0.22901 & 2.67413 \\ \mathrm{O} & -1.40941 & 1.17163 & 0.20691 \\ \mathrm{C} & -0.11683 & 0.81698 & 0.18337 \\ \mathrm{C} & 0.76806 & 1.77787 & -0.37277 \\ \mathrm{C} & 0.41056 & -0.4092 & 0.65012 \\ \mathrm{C} & 2.11321 & 1.52517 & -0.46447 \\ \mathrm{H} & 0.34772 & 2.70981 & -0.73118 \\ \mathrm{C} & 1.76331 & -0.65726 & 0.56072\end{array}$




$\begin{array}{llcr}\mathrm{H} & -0.23314 & -1.15798 & 1.09067 \\ \mathrm{C} & 2.68537 & 0.29124 & -0.00374 \\ \mathrm{H} & 2.74819 & 2.27502 & -0.91531 \\ \mathrm{H} & 2.13451 & -1.59501 & 0.94965 \\ \mathrm{C} & 4.10047 & 0.01784 & -0.10098 \\ \mathrm{C} & 4.63332 & -1.29146 & 0.15755 \\ \mathrm{C} & 5.04523 & 1.03898 & -0.45165 \\ \mathrm{C} & 5.97696 & -1.55851 & 0.06434 \\ \mathrm{H} & 3.96966 & -2.1094 & 0.40662 \\ \mathrm{C} & 6.39215 & 0.7858 & -0.53328 \\ \mathrm{H} & 4.70746 & 2.05095 & -0.63501 \\ \mathrm{C} & 6.90194 & -0.5268 & -0.28107 \\ \mathrm{H} & 6.3469 & -2.55967 & 0.24968 \\ \mathrm{H} & 7.08161 & 1.58141 & -0.78771 \\ \mathrm{C} & 8.2799 & -0.79522 & -0.37094 \\ \mathrm{~N} & 9.42307 & -1.01751 & -0.44648\end{array}$

S-M7BCE (conformation 1):

Job cpu time: 3 days 22 hours 16 minutes 48.0 seconds Total energy: -966.5088 a. u. (Lower)

Dipole moment: 5.7819 Debye (3.9548, 3.6777, 2.0651)

$\begin{array}{llrl}\mathrm{C} & 4.44563 & 3.78927 & 4.95825 \\ \mathrm{C} & 3.94764 & 3.18405 & 3.83343 \\ \mathrm{C} & 2.6046 & 3.41155 & 3.41381 \\ \mathrm{C} & 1.79234 & 4.28812 & 4.19053 \\ \mathrm{C} & 2.28326 & 4.89585 & 5.31564 \\ \mathrm{C} & 3.64104 & 4.67989 & 5.76646 \\ \mathrm{H} & 5.46992 & 3.58485 & 5.23776 \\ \mathrm{H} & 4.57398 & 2.52212 & 3.25107 \\ \mathrm{H} & 0.7735 & 4.46144 & 3.86843 \\ \mathrm{H} & 1.6282 & 5.55237 & 5.87134 \\ \mathrm{C} & 2.02561 & 2.78822 & 2.22507 \\ \mathrm{O} & 0.87517 & 2.96844 & 1.83671 \\ \mathrm{O} & 2.9082 & 1.96748 & 1.58582 \\ \mathrm{C} & 2.45379 & 1.28599 & 0.38225 \\ \mathrm{C} & 3.3571 & 0.06245 & 0.23396 \\ \mathrm{H} & 1.42085 & 0.97421 & 0.55361 \\ \mathrm{H} & 3.09602 & -0.46328 & -0.69243 \\ \mathrm{H} & 4.38521 & 0.42058 & 0.1127 \\ \mathrm{C} & 4.15567 & 5.30562 & 6.93907 \\ \mathrm{C} & 3.35101 & 6.19269 & 7.7505 \\ \mathrm{C} & 5.51382 & 5.09099 & 7.38887 \\ \mathrm{C} & 3.85846 & 6.79138 & 8.88094 \\ \mathrm{H} & 2.32713 & 6.39528 & 7.47054 \\ \mathrm{C} & 6.00048 & 5.70071 & 8.52267 \\ \mathrm{H} & 6.16786 & 4.43845 & 6.82851 \\ \mathrm{C} & 5.18644 & 6.55832 & 9.28684 \\ \mathrm{H} & 3.22745 & 7.45084 & 9.46582 \\ \mathrm{H} & 7.02352 & 5.51746 & 8.83102\end{array}$




$\begin{array}{llll}\mathrm{H} & 5.57788 & 7.034 & 10.17831 \\ \mathrm{C} & 3.29743 & -0.90912 & 1.41964 \\ \mathrm{H} & 2.29145 & -1.33461 & 1.50711 \\ \mathrm{H} & 3.4813 & -0.35925 & 2.3516 \\ \mathrm{C} & 4.31342 & -2.05177 & 1.30059 \\ \mathrm{H} & 5.32409 & -1.62953 & 1.23243 \\ \mathrm{H} & 4.14399 & -2.58938 & 0.35864 \\ \mathrm{C} & 4.258 & -3.04525 & 2.46623 \\ \mathrm{H} & 3.25011 & -3.47605 & 2.52845 \\ \mathrm{H} & 4.41704 & -2.50672 & 3.40966 \\ \mathrm{C} & 5.28399 & -4.17901 & 2.35536 \\ \mathrm{H} & 6.29089 & -3.74831 & 2.29557 \\ \mathrm{H} & 5.1267 & -4.71641 & 1.41215 \\ \mathrm{C} & 5.22112 & -5.16854 & 3.52262 \\ \mathrm{H} & 4.2355 & -5.6405 & 3.5878 \\ \mathrm{H} & 5.96362 & -5.96407 & 3.41341 \\ \mathrm{H} & 5.41004 & -4.66625 & 4.4768 \\ \mathrm{C} & 2.50579 & 2.25864 & -0.79175 \\ \mathrm{H} & 1.83835 & 3.10391 & -0.61653 \\ \mathrm{H} & 3.52346 & 2.63387 & -0.93455 \\ \mathrm{H} & 2.1866 & 1.76422 & -1.71262\end{array}$

S-M7BCE (conformation 2):

Job cpu time: 8 days 12 hours 36 minutes 19.0 seconds

Total energy: -966.5078 a. u. (Higher)

Dipole moment: 5.6875 Debye $(-4.1204,-3.7971,0.9760)$

$\begin{array}{lccl}\mathrm{C} & -1.16247 & -0.12605 & 0 . \\ \mathrm{C} & 0.2327 & -0.12605 & 0 . \\ \mathrm{C} & 0.93023 & 1.0817 & 0 . \\ \mathrm{C} & 0.23258 & 2.29021 & -0.0012 \\ \mathrm{C} & -1.16225 & 2.29013 & -0.00168 \\ \mathrm{C} & -1.85985 & 1.08193 & -0.00068 \\ \mathrm{H} & -1.71222 & -1.07837 & 0.00045 \\ \mathrm{H} & 0.7822 & -1.07856 & 0.00132 \\ \mathrm{H} & 0.78278 & 3.24235 & -0.00126 \\ \mathrm{H} & -1.71237 & 3.24241 & -0.00263 \\ \mathrm{C} & 2.47023 & 1.08181 & 0.00089 \\ \mathrm{O} & 3.26217 & 2.0233 & 0.00103 \\ \mathrm{O} & 2.98512 & -0.17369 & 0.00153 \\ \mathrm{C} & 4.4145 & -0.1315 & 0.00234 \\ \mathrm{C} & 4.98629 & -1.5185 & 0.00592 \\ \mathrm{H} & 4.74733 & 0.43105 & -0.90363 \\ \mathrm{H} & 4.65318 & -2.08077 & 0.91199 \\ \mathrm{H} & 4.65425 & -2.08502 & -0.8979 \\ \mathrm{C} & -3.39985 & 1.08218 & -0.00093 \\ \mathrm{C} & -4.09717 & 2.29058 & -0.00162 \\ \mathrm{C} & -4.09755 & -0.12561 & -0.00059 \\ \mathrm{C} & -5.49188 & 2.29109 & -0.00127 \\ \mathrm{H} & -3.54682 & 3.2426 & -0.00111\end{array}$




$\begin{array}{lccc}\mathrm{C} & -5.49269 & -0.12527 & -0.00125 \\ \mathrm{H} & -3.54811 & -1.0781 & -0.00023 \\ \mathrm{C} & -6.18991 & 1.08279 & -0.00145 \\ \mathrm{H} & -6.04158 & 3.24352 & -0.00118 \\ \mathrm{H} & -6.04253 & -1.07771 & -0.00139 \\ \mathrm{H} & -7.28959 & 1.08345 & -0.00124 \\ \mathrm{C} & 6.52564 & -1.47368 & 0.0067 \\ \mathrm{H} & 6.86698 & -0.95736 & 0.87951 \\ \mathrm{H} & 6.86797 & -0.96087 & -0.86779 \\ \mathrm{C} & 7.08101 & -2.91005 & 0.0099 \\ \mathrm{H} & 6.73971 & -3.42636 & -0.86293 \\ \mathrm{H} & 6.73865 & -3.42288 & 0.88437 \\ \mathrm{C} & 8.62036 & -2.86523 & 0.01074 \\ \mathrm{H} & 8.96167 & -2.34895 & 0.8836 \\ \mathrm{H} & 8.96272 & -2.35236 & -0.8637 \\ \mathrm{C} & 9.17573 & -4.30159 & 0.01389 \\ \mathrm{H} & 8.83443 & -4.81787 & -0.85896 \\ \mathrm{H} & 8.83337 & -4.81445 & 0.88834 \\ \mathrm{C} & 10.71508 & -4.25677 & 0.01473 \\ \mathrm{H} & 11.05639 & -3.7405 & 0.88759 \\ \mathrm{H} & 11.10096 & -5.25477 & 0.01691 \\ \mathrm{H} & 11.05744 & -3.7439 & -0.85971 \\ \mathrm{C} & 4.87172 & 0.64967 & 1.24826 \\ \mathrm{H} & 5.29517 & 1.58507 & 0.94724 \\ \mathrm{H} & 4.0312 & 0.82745 & 1.88609 \\ \mathrm{H} & 5.60645 & 0.07926 & 1.77713\end{array}$

\section{S-DM8OCB:}

Job cpu time: 6 days 2 hours 2 minutes 30.0 seconds

Total energy: -1024.0378 a. u.

Dipole moment: 15.9858 Debye $(-15.9408,0.7552,0.9311)$

$\begin{array}{lccc}\mathrm{C} & 0.64655 & -0.10051 & -0.01744 \\ \mathrm{C} & 1.45942 & 0.63037 & -0.92349 \\ \mathrm{C} & 1.23954 & -1.11621 & 0.76785 \\ \mathrm{C} & 2.79805 & 0.35718 & -1.04482 \\ \mathrm{H} & 0.98835 & 1.40096 & -1.52179 \\ \mathrm{C} & 2.58567 & -1.38495 & 0.64594 \\ \mathrm{H} & 0.65224 & -1.6829 & 1.47722 \\ \mathrm{C} & 3.43516 & -0.66813 & -0.26695 \\ \mathrm{H} & 3.37589 & 0.91991 & -1.7647 \\ \mathrm{H} & 3.01217 & -2.1486 & 1.28113 \\ \mathrm{C} & 4.84322 & -0.96349 & -0.39277 \\ \mathrm{C} & 5.41588 & -2.15117 & 0.17877 \\ \mathrm{C} & 5.74064 & -0.08485 & -1.08629 \\ \mathrm{C} & 6.75281 & -2.44112 & 0.05774 \\ \mathrm{H} & 4.78524 & -2.86442 & 0.69391 \\ \mathrm{C} & 7.08213 & -0.35671 & -1.19698 \\ \mathrm{H} & 5.37229 & 0.83933 & -1.5131\end{array}$




$\begin{array}{llll}\mathrm{C} & 7.6306 & -1.55047 & -0.63131 \\ \mathrm{H} & 7.15212 & -3.3536 & 0.48336 \\ \mathrm{H} & 7.73721 & 0.33472 & -1.71239 \\ \mathrm{C} & 9.00256 & -1.84031 & -0.7499 \\ \mathrm{~N} & 10.14018 & -2.08085 & -0.84908 \\ \mathrm{O} & -0.61018 & 0.23673 & -0.00051 \\ \mathrm{C} & -1.31713 & -0.58885 & 0.94927 \\ \mathrm{C} & -2.70373 & 0.00889 & 1.1316 \\ \mathrm{H} & -1.36808 & -1.61114 & 0.56205 \\ \mathrm{H} & -0.7451 & -0.61487 & 1.87919 \\ \mathrm{H} & -2.60704 & 1.02589 & 1.53068 \\ \mathrm{H} & -3.1657 & 0.10076 & 0.14283 \\ \mathrm{C} & -3.63074 & -0.81769 & 2.04556 \\ \mathrm{H} & -3.66907 & -1.84054 & 1.64418 \\ \mathrm{C} & -5.06102 & -0.24434 & 1.98744 \\ \mathrm{C} & -3.0994 & -0.8908 & 3.4861 \\ \mathrm{H} & -5.33843 & -0.11227 & 0.93418 \\ \mathrm{H} & -5.0592 & 0.76182 & 2.42866 \\ \mathrm{C} & -6.14049 & -1.09626 & 2.66854 \\ \mathrm{H} & -3.02668 & 0.1127 & 3.92082 \\ \mathrm{H} & -3.75532 & -1.4846 & 4.12646 \\ \mathrm{H} & -2.10769 & -1.34692 & 3.53362 \\ \mathrm{H} & -5.92999 & -1.18616 & 3.74034 \\ \mathrm{H} & -6.09913 & -2.11236 & 2.25955 \\ \mathrm{C} & -7.54974 & -0.5154 & 2.49097 \\ \mathrm{H} & -7.7962 & -0.47559 & 1.42079 \\ \mathrm{H} & -7.54397 & 0.5255 & 2.83872 \\ \mathrm{C} & -8.67127 & -1.26822 & 3.23163 \\ \mathrm{H} & -8.38505 & -1.33017 & 4.29079 \\ \mathrm{C} & -8.8629 & -2.70013 & 2.71066 \\ \mathrm{C} & -9.99051 & -0.48708 & 3.14949 \\ \mathrm{H} & -7.96185 & -3.30699 & 2.82857 \\ \mathrm{H} & -9.67166 & -3.20569 & 3.24692 \\ \mathrm{H} & -9.12476 & -2.6929 & 1.6463 \\ \mathrm{H} & -10.78569 & -0.99127 & 3.70683 \\ \mathrm{H} & -9.88235 & 0.52234 & 3.55766 \\ \mathrm{H} & -0.3923 & 2.1097\end{array}$

\section{S-DM8BCE:}

Job cpu time: 6 days 2 hours 16 minutes 49.0 seconds Total energy: -1045.15080845 a. u.

Dipole moment: 2.8911 Debye (0.7862, 2.7346, 0.5122)

$\begin{array}{llcc}\mathrm{C} & 0.96155 & 0.71885 & 0.07758 \\ \mathrm{C} & 1.85217 & 1.80339 & -0.1321 \\ \mathrm{C} & 1.48481 & -0.58555 & 0.22085 \\ \mathrm{C} & 3.20597 & 1.59442 & -0.19291 \\ \mathrm{H} & 1.43197 & 2.79522 & -0.24769 \\ \mathrm{C} & 2.84611 & -0.79224 & 0.1606 \\ \mathrm{H} & 0.82648 & -1.42838 & 0.38293\end{array}$




\begin{tabular}{|c|c|c|c|}
\hline $\mathrm{C}$ & 3.77921 & 0.28447 & -0.04775 \\
\hline $\mathrm{H}$ & 3.85001 & 2.44346 & -0.37405 \\
\hline $\mathrm{H}$ & 3.2151 & -1.79915 & 0.29551 \\
\hline $\mathrm{C}$ & 5.20256 & 0.06021 & -0.10897 \\
\hline $\mathrm{C}$ & 5.75254 & -1.26634 & -0.19315 \\
\hline $\mathrm{C}$ & 6.14224 & 1.14544 & -0.0842 \\
\hline $\mathrm{C}$ & 7.10631 & -1.48654 & -0.25611 \\
\hline $\mathrm{H}$ & 5.0957 & -2.1251 & -0.23967 \\
\hline $\mathrm{C}$ & 7.49786 & 0.93394 & -0.13082 \\
\hline $\mathrm{H}$ & 5.79054 & 2.16548 & 0.00176 \\
\hline $\mathrm{C}$ & 8.02339 & -0.39331 & -0.22214 \\
\hline $\mathrm{H}$ & 7.48975 & -2.4965 & -0.33487 \\
\hline $\mathrm{H}$ & 8.1817 & 1.77294 & -0.09522 \\
\hline $\mathrm{C}$ & -0.53413 & 1.08239 & 0.12657 \\
\hline $\mathrm{O}$ & -1.51888 & 0.36368 & 0.29175 \\
\hline $\mathrm{O}$ & -0.75809 & 2.48328 & -0.05298 \\
\hline $\mathrm{C}$ & -2.15208 & 2.76647 & 0.09361 \\
\hline $\mathrm{C}$ & -2.33313 & 4.26543 & -0.08022 \\
\hline $\mathrm{H}$ & -2.7069 & 2.21014 & -0.67047 \\
\hline $\mathrm{H}$ & -2.47108 & 2.42216 & 1.08131 \\
\hline $\mathrm{H}$ & -1.77742 & 4.7854 & 0.70822 \\
\hline $\mathrm{H}$ & -1.8758 & 4.55008 & -1.03301 \\
\hline $\mathrm{C}$ & -3.80606 & 4.72315 & -0.06677 \\
\hline $\mathrm{H}$ & -4.34124 & 4.15125 & -0.8383 \\
\hline $\mathrm{C}$ & -3.8812 & 6.21214 & -0.46106 \\
\hline $\mathrm{C}$ & -4.48128 & 4.44902 & 1.28651 \\
\hline $\mathrm{H}$ & -3.30094 & 6.355 & -1.38097 \\
\hline $\mathrm{H}$ & -3.37814 & 6.8102 & 0.3108 \\
\hline $\mathrm{C}$ & -5.29491 & 6.76278 & -0.68982 \\
\hline $\mathrm{H}$ & -3.96817 & 4.98778 & 2.09085 \\
\hline $\mathrm{H}$ & -5.52489 & 4.76956 & 1.28387 \\
\hline $\mathrm{H}$ & -4.47675 & 3.386 & 1.54168 \\
\hline $\mathrm{H}$ & -5.87282 & 6.71774 & 0.2402 \\
\hline $\mathrm{H}$ & -5.81491 & 6.11914 & -1.40876 \\
\hline $\mathrm{C}$ & -5.28414 & 8.21223 & -1.19391 \\
\hline $\mathrm{H}$ & -4.76651 & 8.25728 & -2.16207 \\
\hline $\mathrm{H}$ & -4.6848 & 8.81726 & -0.50182 \\
\hline $\mathrm{C}$ & -6.6689 & 8.8711 & -1.33959 \\
\hline $\mathrm{H}$ & -7.17951 & 8.78716 & -0.37014 \\
\hline $\mathrm{C}$ & -7.54342 & 8.17742 & -2.39439 \\
\hline $\mathrm{C}$ & -6.52192 & 10.36484 & -1.66217 \\
\hline $\mathrm{H}$ & -7.73391 & 7.1295 & -2.14958 \\
\hline $\mathrm{H}$ & -8.51368 & 8.67483 & -2.48445 \\
\hline $\mathrm{H}$ & -7.06237 & 8.2094 & -3.37877 \\
\hline $\mathrm{H}$ & -7.49806 & 10.8546 & -1.72689 \\
\hline $\mathrm{H}$ & -5.9368 & 10.88253 & -0.89618 \\
\hline $\mathrm{H}$ & -6.01461 & 10.50818 & -2.62277 \\
\hline $\mathrm{H}$ & 9.07902 & -0.56327 & -0.26285 \\
\hline
\end{tabular}


For red ball = oxygen, gray ball $=$ carbon, white ball $=$ hydrogen, blue ball $=$ nitrogen

\section{S-M70B (Conformation 1)}
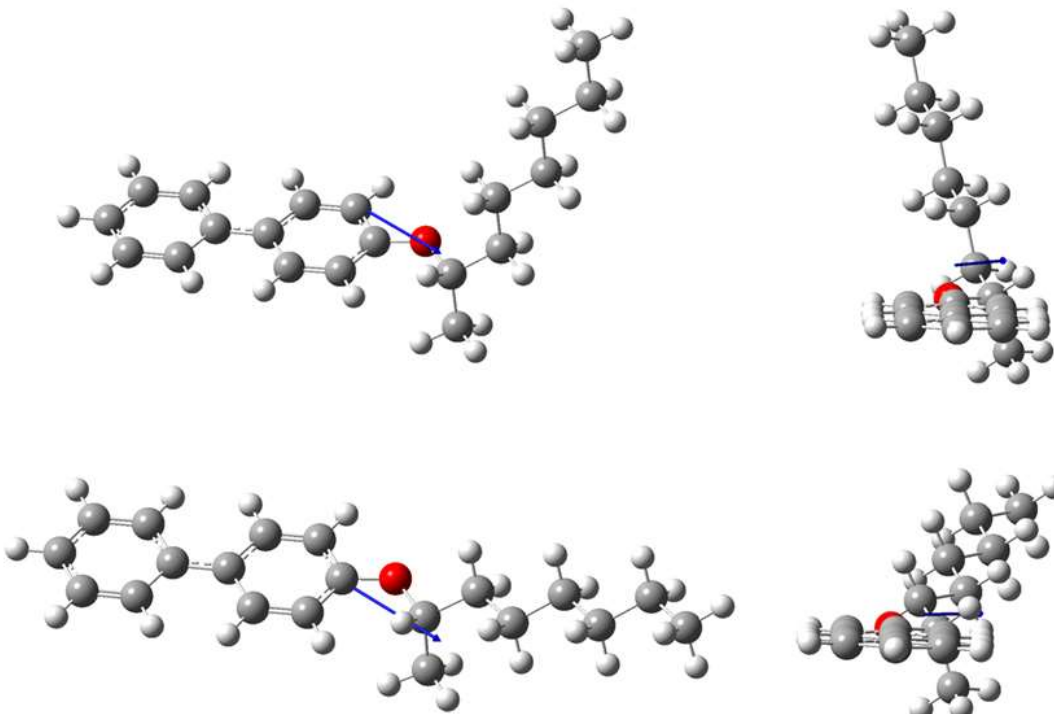

S-M7OB (Conformation 2)

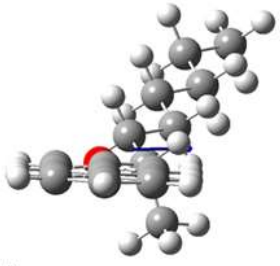

Figure S4.1. Molecular model of S-M7OB. Blue arrow: dipole moment.

\section{S-M70CB (Conformation 0)}
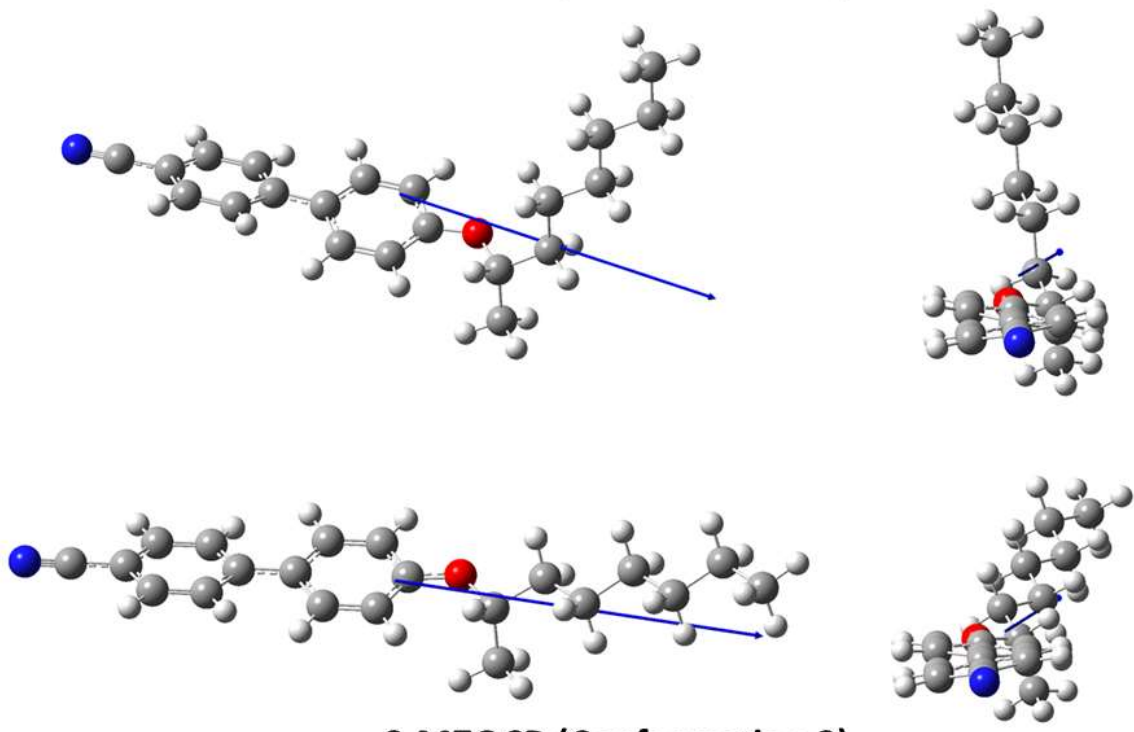

S-M70CB (Conformation 2)

Figure S4.2. Molecular model of S-M7OCB. Blue arrow: dipole moment. 


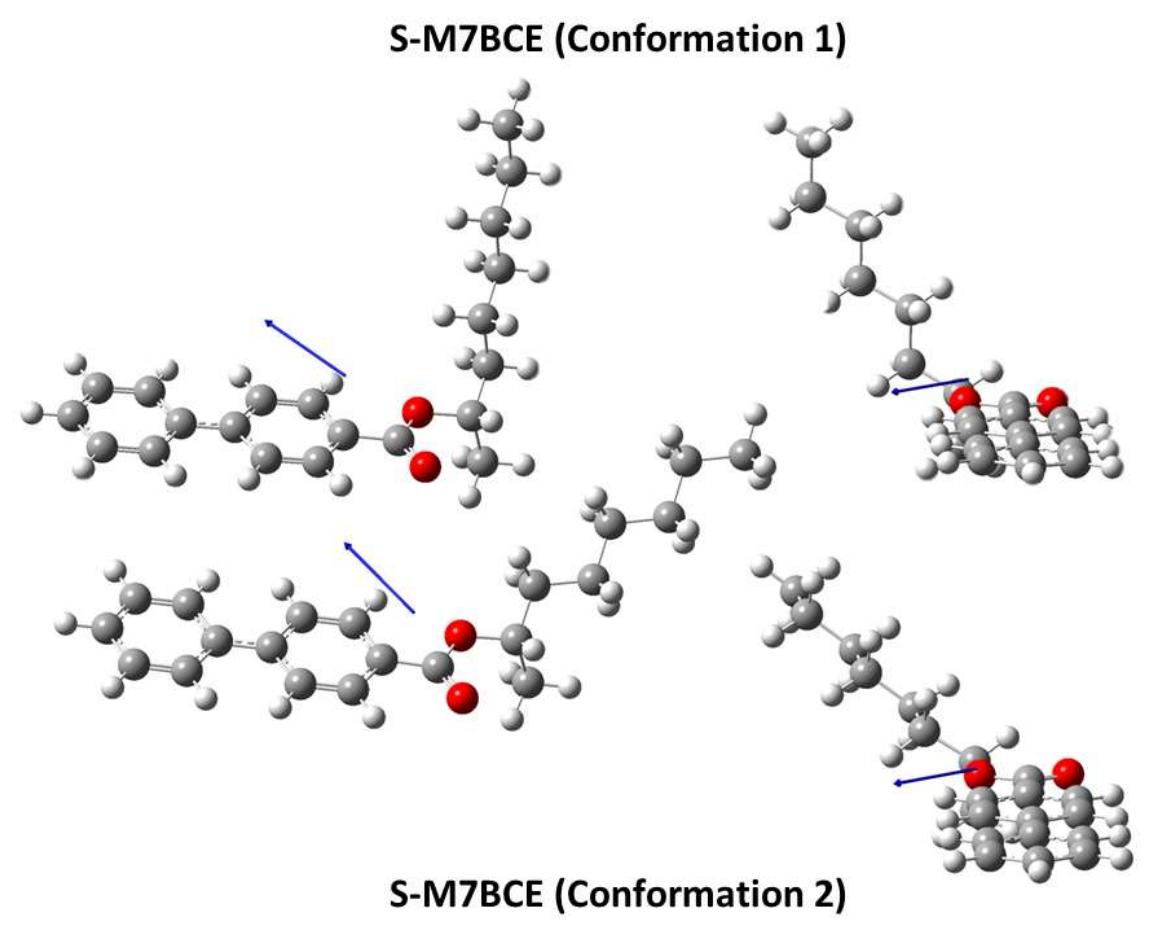

Figure S4.3. Molecular model of S-M7BCE.Blue arrow: dipole moment.

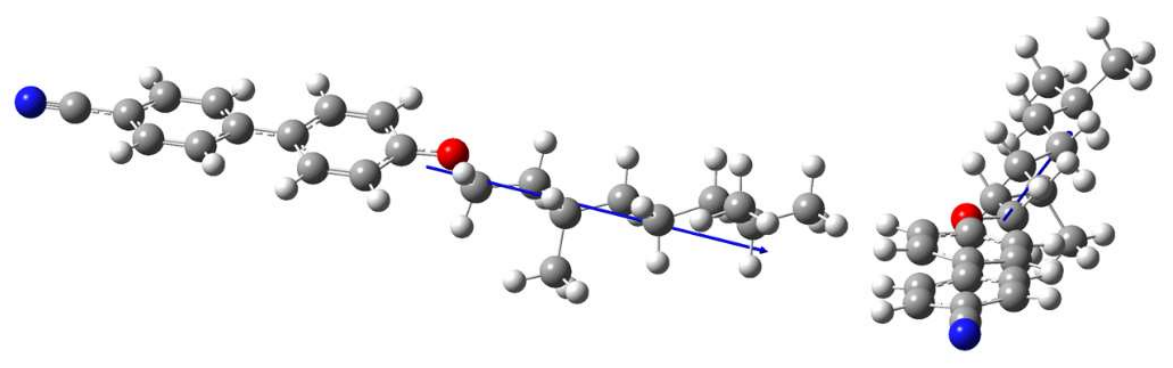

Figure S4.4. Molecular model of S-DM8OCB. Blue arrow: dipole moment. 


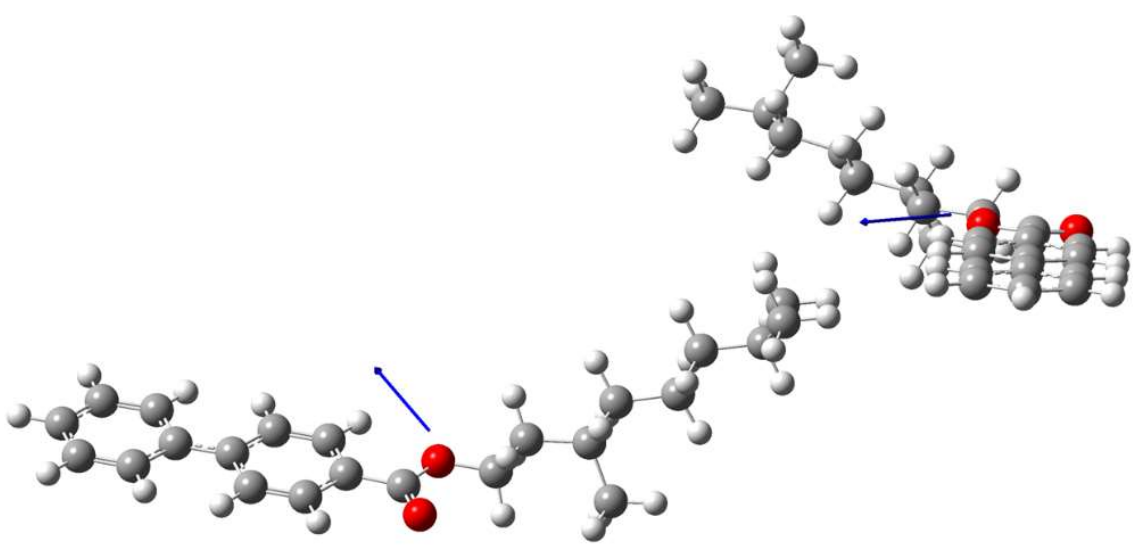

Figure S4.5. Molecular model of S-DM8BCE. Blue arrow: dipole moment. 